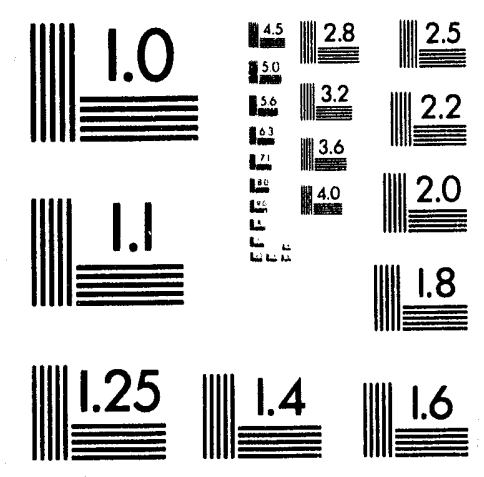



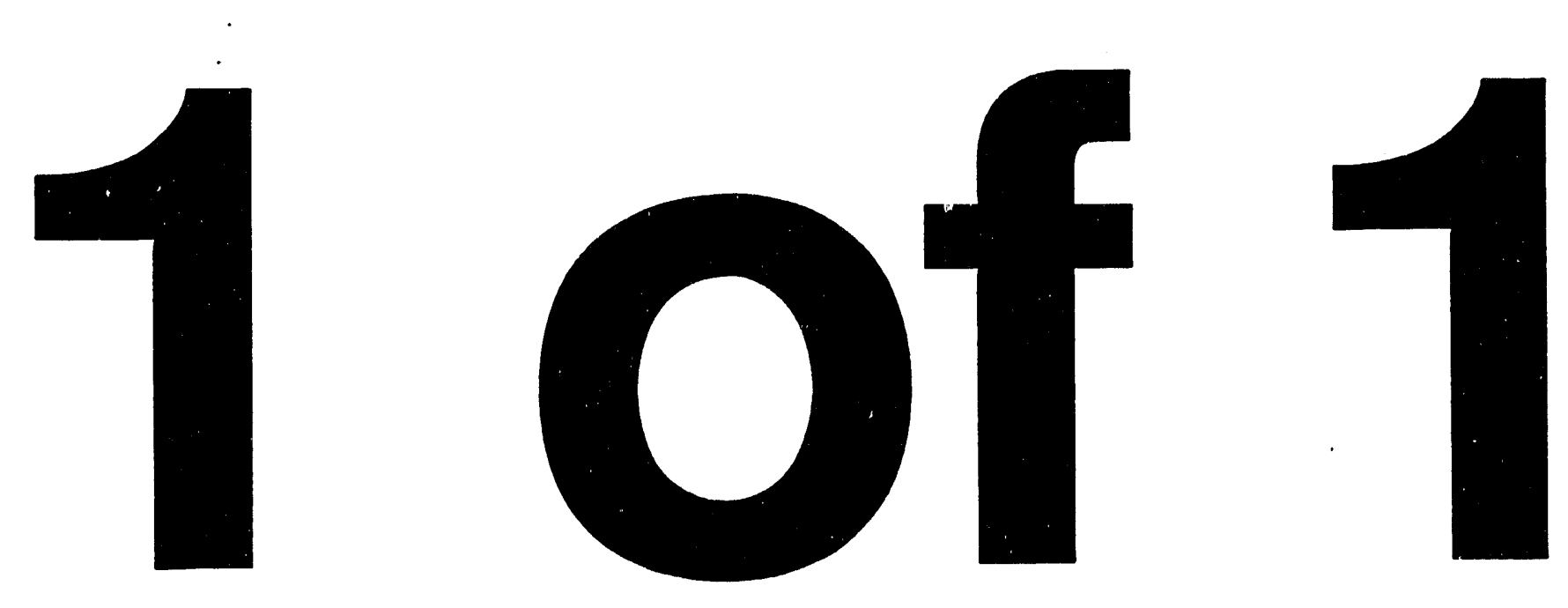


\title{
THERMAL PROCESSES FOR HEAVY OIL RECOVERY
}

\author{
By
}

A.K. Sarkar

P.S. Sarathi

November 1993

Work Performed Under Cooperative Agreement No. DE-FC22-83FE60149

\author{
Prepared for \\ U.S. Department of Energy \\ Assistant Secretary for Fossil Energy \\ Jerry Casteel, Project Manager \\ Bartlesville Project Office \\ P.O. Box 1398 \\ Bartlesville, OK 74005
}

Prepared by

IIT Research Institute

National Institute for Petroleum and Energy Research

P.O. Box 2128

Bartlesville, OK 74005

\section{MASTER}




\section{TABLE OF CONTENTS}

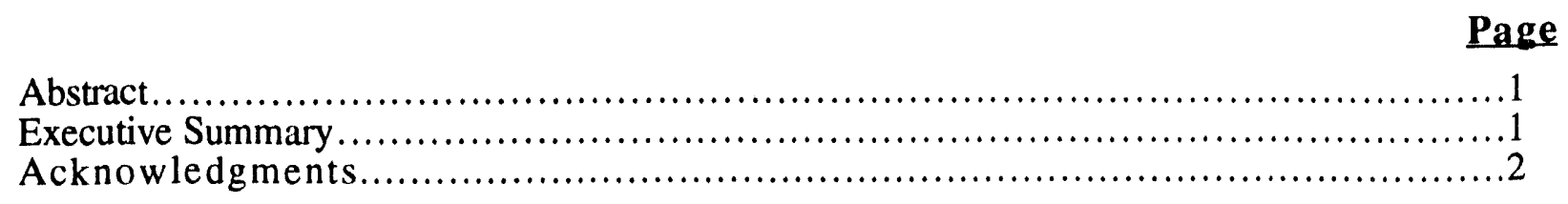

PART I-EVALUATION OF STEAMFLOOD POTENTIAL OF TEXAS GULF COAST HEAVY OIL RESERVOIRS-A SIMULATION

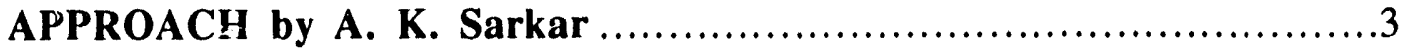

CHAPTER 1. INTRODUCTION ............................................

\section{CHAPTER 2. SELECTION OF POTENTIAL RESERVOIRS USING SCREENING GUIDES}

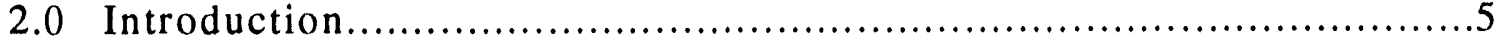

2.1 Reservoir Data...............................................................

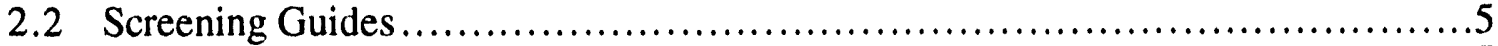

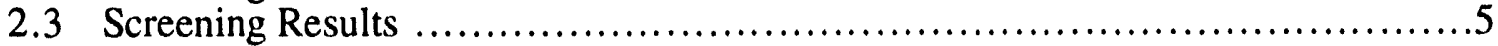

2.4 Discussion and Conclusions...............................................

TABLE

2.1 Reservoir data and results of screening studies 6

\section{CHAPTER 3. RESERVOIR DESCRIPTION OF TAYLOR-INA FIELD}

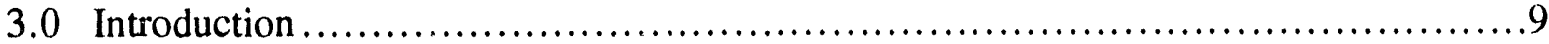

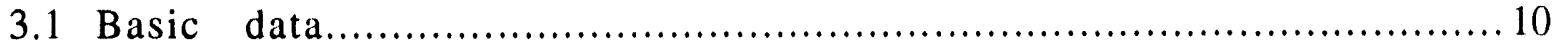

3.1.1 Fractured Well Characteristics ......................................... 10

3.1 .2 Viscosity of Oil ......................................................... 11

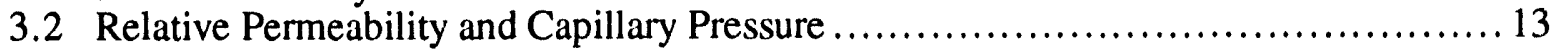

\section{TABLES}

3.1 Thickness, porosity, permeability, and water saturation values of the reservoir .......11

3.2 Crude oil and liquid $\mathrm{CO}_{2}$ viscosity as a function of temperature $\ldots \ldots \ldots \ldots \ldots \ldots \ldots \ldots \ldots$

3.3 Effect of temperature on relative permeability ...................................... 17

\section{ILLUSTRATIONS}

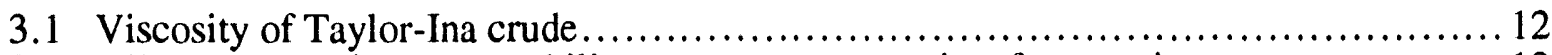

3.2 Oil-water relative permeability vs. water saturation for matrix........................ 13

3.3 Oil-water capillary pressure vs. water saturation for matrix ............................ 14

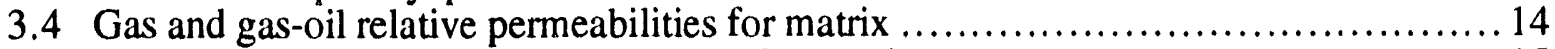

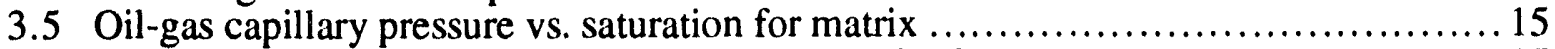

3.6 Oil-water capillary pressure vs. water saturation for fracture $\ldots \ldots \ldots \ldots \ldots \ldots \ldots \ldots \ldots \ldots$

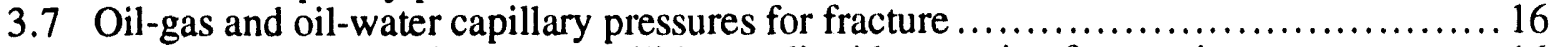

3.8 Gas and gas-oil relative permeabilities vs. liquid saturation for matrix $\ldots \ldots \ldots \ldots \ldots \ldots 16$ 


\section{TABLE OF CONTENTS-Continued}

\section{CHAPTER 4. SIMULATION OF RECOVERY PROCESSES IN THE TAYLOR-INA FIELD}

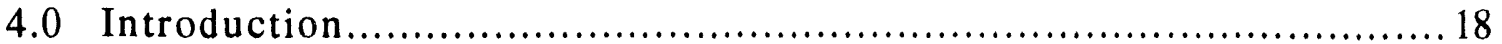

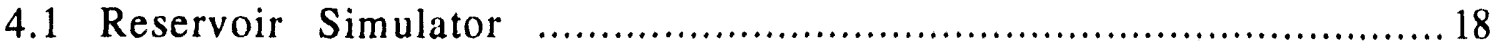

4.2 Pattern Configuration and Grid System ........................................ 18

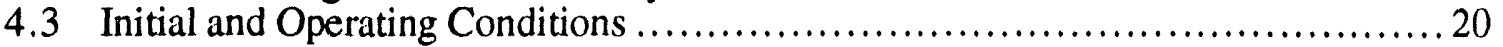

4.4 Waterflood................................................................... 20

4.4.1 Base Case/Small Pattern Area .................................... 20

4.4.2 Sensitivity Study/Big Pattern Area.............................................22

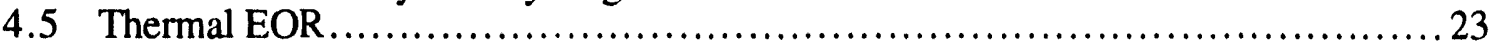

4.5.1 Cyclic Steam Stimulation ............................................. 24

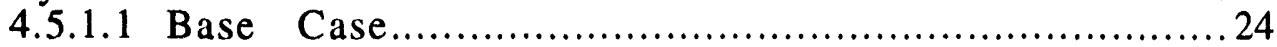

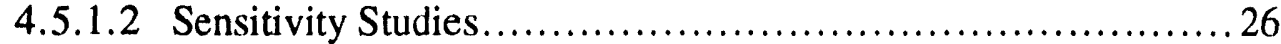

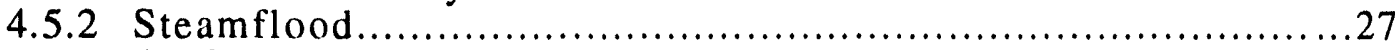

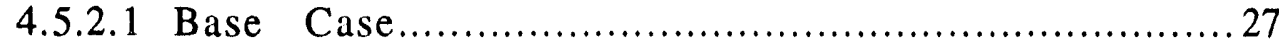

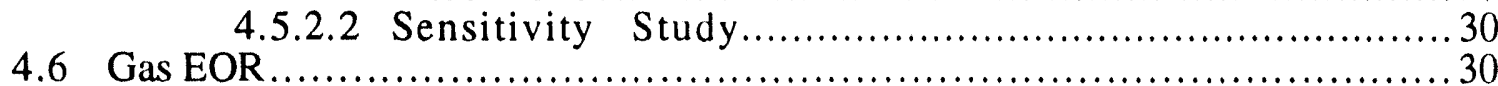

4.6.1 Cyclic $\mathrm{CO}_{2}$ stimulation .......................................... 31

4.6.2 Immiscible $\mathrm{CO}_{2}$-Waterflood.....................................

TABLE

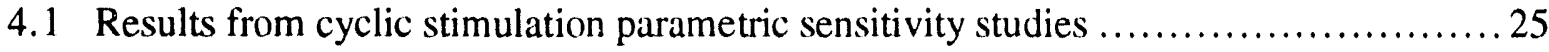

\section{ILLUSTRATIONS}

4.1 Coordinate system and schematic of a pattern showing hydraulically fractured and sand-propped vertical wells ...................................................... 19

4.2 Area and vertical grids of the one-fourth element of symmetry ..................... 19

4.3 Histories of water injection rate, oil production rate, WOR, and cumulative oil

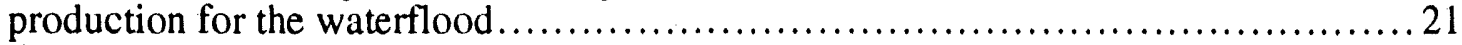

4.4 Oil saturation (fraction), and pressure ( $\mathrm{psi}$ ) contours for the middle layer at 1,400 days

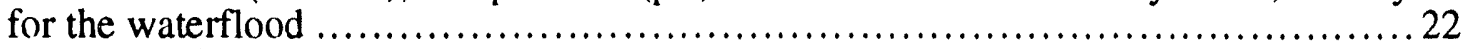

4.5 Histories of water injection rate, oil production, and WOR for the waterflood

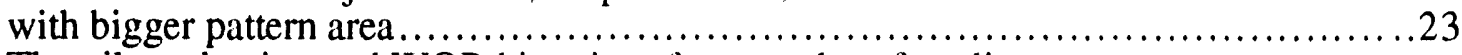

4.6 The oil production and WOR histories of two cycles of cyclic steam

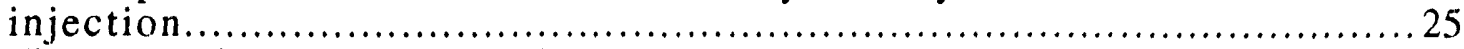

4.7 The cumulative oil production, COSR histories of two cycles of cyclic steam

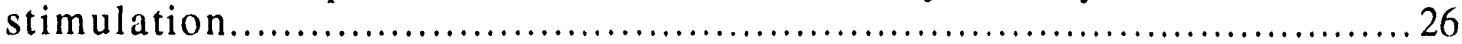

4.8 Histories of water injection rate, oil production, and WOR for the steamflood.......... 28

4.9 Oil saturation (fraction), pressure (psi), temperature and steam saturation contours for the middle layer at 1,400 days for the steamflood......................................2 29

4.10 The oil production and GOR histories of two cycles of gas stimulation.................... 32

4.11 The cumulative oil production and COGR histories for the two cycles of gas

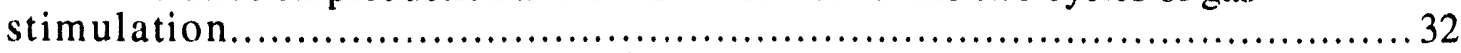

4.12 Water and gas injection rate histories for immiscible $\mathrm{CO}_{2}$ waterflood ...................34

4.13 Oil production, WOR, and GOR histories, and cumulative oil production and

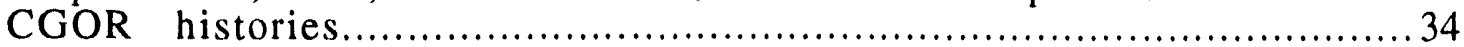

4.14 NPV histories for the big pattern waterflood and immiscible $\mathrm{CO}_{2}$ waterflood.............35 
CHAPTER 5. CONCLUDING REMARKS AND RECOMMENDATIONS

5.0 Summary and Conclusions ...................................................... 36

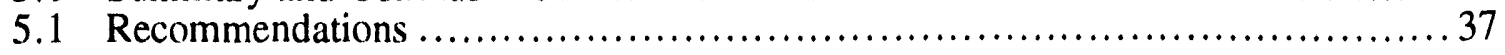

TABLES

A.1 Component Properties ............................................................. 39

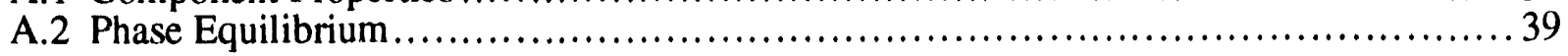

APPENDIX B: ECONOMIC EVALUATION ............................... 41

TABLES

B.1 Detailed Economic Evaluation.......................................................... 41

B.2 Simplified Economic Evaluation................................................. 42

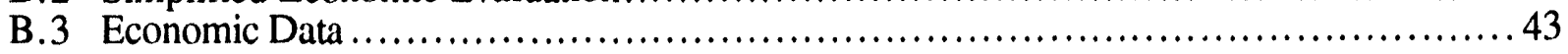

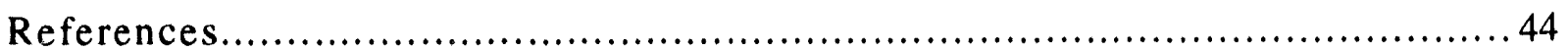

\section{PART II-ASSESSMENT OF AN INDUSTRY DEVELOPED}

STEAMFLOOD PREDICTIVE MODEL by P. S. Sarathi................ 46

CHAPTER 6. EVALUATION OF MOBIL'S PREDICTIVE MODEL

6.0 Objective .................................................................... 47

6.1 Background .................................................................... 47

6.1.1 Model Description........................................................ 48

6.1.1.1 Jones' Model......................................... 48

6.1.1.2 Faroug Ali's Model........................................ 48

6.1.1.3 Miller-Leung Model ......................................... 49

6.1.1.4 Methodology ........................................... 49

6.1.1.5 Model Features........................................... 50

6.1.1.6 Model Evaluation .......................................... 50

6.2 Conclusions and Recommendations.............................................. 51

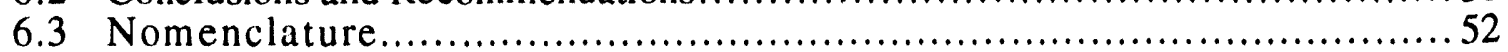

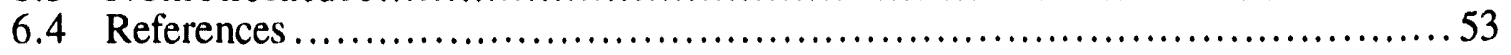

\section{TABLES}

6.1 Data requirements for Mobil's predictive model .................................... 54

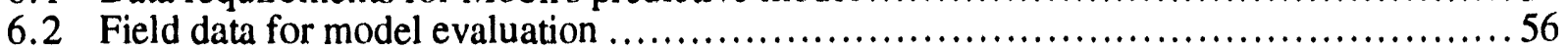




\section{TABLE OF CONTENTS-Continued}

\section{ILLUSTRATIONS}

6.1 Comparison of predicted and observed cumulative oil production-Inglewood Field, CA.

6.2 Comparison of predicted and observed daily oil production - Coalinga

Field, CA.

6.3 Comparison of predicted and observed cumulative oil production - Coalinga

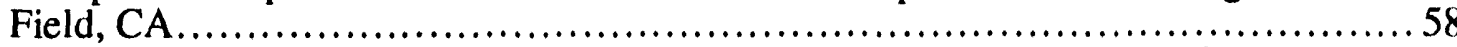

6.4 Comparison of predicted and observed daily oil production-Georgsdorf

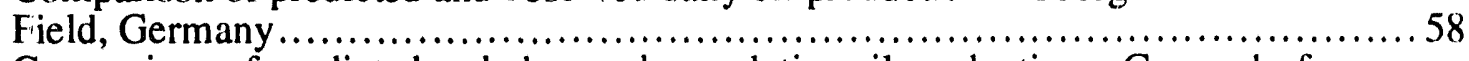

6.5 Comparison of predicted and observed cumulative oil production-Georgsdorf Field, Germany.

6.6 Comparison of predicted and observed daily oil production-Inglewood Field, CA.

6.7 Comparison of predicted and observed daily oil production rates-Kern (Green and Whitter Data) Field, CA

6.8 Comparison of predicted and observed daily oil production rates-Kern (Green and Whitter Data) Field, CA

6.9 Comparison of predicted and observed daily oil production rates - Kern ' $\mathrm{A}$ ' Field, CA.....

6.10 Comparison of predicted and observed cumulative oil production-Kern ' $\mathrm{A}$ '

Field, CA.

6.11 Comparison of predicted and observed daily oil production rates-Mount Poso

Field, CA

6.12 Comparison of predicted and observed cumulative oil production-Mount Poso

Field, CA.

6.13 Comparison of predicted and observed daily oil production rates-San Joaquin (Kern River) Field, CA.

6.14 Comparison of predicted and observed daily oil production rates-San Joaquin (Kern River) Field, CA....

6.15 Comparison of predicted and observed cumulative oil production rates-Schoonebeek Field, The Netherlands ................................................... 64

6.16 Comparison of predicted and observed cumulative oil production-Schoonebeek

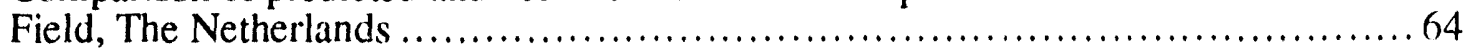

6.17 Comparison of predicted and observed daily oil production rates-South Belridge

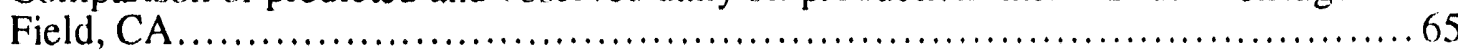

6.18 Comparison of predicted and observed cumulative oil production---South Belridge

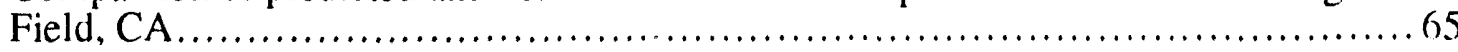

6.19 Comparison of predicted and observed daily oil production rates-Slocum Field, TX....

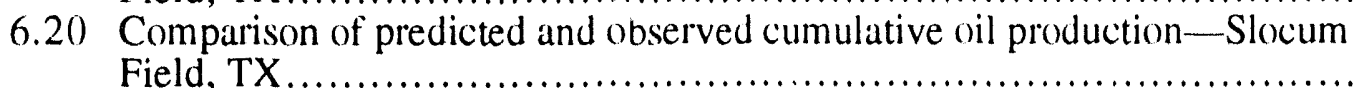

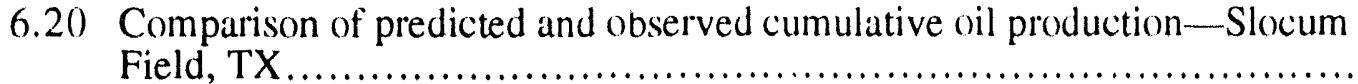

6.21 Comparison of predicted and observed daily oil production rates - Winkleman Dome

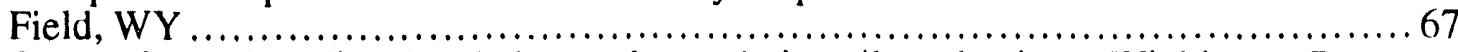

6.22 Comparison of predicted and observed cumulative oil production-Winkleman Dome Field, WY..... 


\title{
THERMAL PROCESSES FOR HEAVY OIL RECOVERY
}

\author{
By A. K. Sarkar and P. S. Sarathi
}

\begin{abstract}
This status report summarizes the project BE11B (Thermal Processes for Heavy Oil Recovery) research activities conducted in FY93 and completes milestone 7 of this project. A major portion of project research during FY93 was concentrated on modeling and reservoir studies to determine the applicability of steam injection oil recovery techniques in Texas Gulf Coast heavy oil reservoirs. In addition, an in-depth evaluation of a steamflood predictive model developed by Mobil Exploration and Production Co. (Mobil E\&P) was performed. Details of these two studies are presented. A topical report (NIPER-675) assessing the NIPER Thermal EOR Research Program over the past 10 years was also written during this fiscal year and delivered to DOE.

Results of the Fulf Coast heavy oil reservoir simulation studies indicated that though these reservoirs can be successfully steamflooded and could recover more than $50 \%$ of oil-in-place, steamflooding may not be economical at current heavy oil prices. Assessment of Mobil E\&P's steamflood predictive model capabilities indicate that the model in its present form gives reasonably good predictions of California steam projects, but fails to predict adequately the performance of non-California steam projects.
\end{abstract}

\section{EXECUTIVE SUMMARY}

The purpose of this report is to document the results of the research on thermal processes for heavy oil recovery, project BE11B, conducted in FY93. The significant findings of the research are as follows:

1. A significant quantity of heavy oil exists in Texas Gulf Coast heavy oil reservoirs.

2. These reservoirs in general are shallow and characterized by thin pay, low-permeability and low oil saturation.

3. Steamflooding is technically viable in this type of reservoir.

4. Because of the thin pay zone and low oil saturation, steamdrive in the candidate reservoir was found to he economicaly unattractive at the current heavy oil prices.

5. Studies, however, indicate that a well-designed cyclic $\mathrm{CO}_{2}$ process may recover oil economically from these reservoirs, but the volume of recoverable oil by this process would be much smaller than that by the thermal method.

6. The industry (Mobil E\&P) developed steamflood predictive model with its user-friendly interface and excellent graphic capabilities was able to predict the performance of California thermal projects reasonably well. 
7. The model, however, was found to be inadequate in predicting the steamflood performance of non-California steamflood projects.

8. It was recommended that DOE acquire this predictive model and place it in the public domain after modifying it to improve its predictive ability for non-California thermal projects.

\section{ACKNOWLEDGMENTS}

This work was sponsored by the U.S. Department of Energy under cooperative agreement DE-FC22-83FE60149 as project BE11B. The authors thank A. R. Strycker, M. K. Tham and T. E. Burchfield of NIPER and T. B. Reid of the DOE Bartlesville Project Office for their critical reviews. Thanks and appreciation are extended to Mr. J. H. Klaeger, an operator of Taylor-Ina field, for providing most of the field data for the simulation studies. Appreciation is also extended to Mr. Gary Wilcox, Winston Shu, and Robert Harrigal of Mobil Exploration and Production Inc., U.S.A. of Bakersfield, CA, for providing a copy of their steamflood predictive model software for evaluation. 
PART I

EVALUATION OF STEAMFLOOD POTENTIAL OF TEXAS GULF COAST HEAVY OIL RESERVOIRS-A SIMULATION APPROACH

\author{
By A. K. Sarkar
}




\section{Chapter 1}

\section{INTRODUCTION}

The heavy oil resource in the U. S. may be as high as 100 billion bbl, which is about $20 \%$ of the total resource of 500 billion bbl. Only $11 \%$ (11 billion bbl) has been produced so far (until 1992). The current (1992) heavy oil production from 131 projects is about $460,691 \mathrm{bbl} / \mathrm{d}$ which is $61 \%$ of total enhanced oil recovery (EOR) production and $6 \%$ of total oil production. Both production and the number of projects have declined since 1986 when heavy oil production was $479,669 \mathrm{bbl} / \mathrm{d}$ and the number of projects was 201 . A study conducted by NIPER for DOE, under project SGP37, identified several heavy oil reservoirs in unconsolidated and friable sandstone reservoirs of Cenozoic and Mesozoic Age in Gulf Coast sedimentary basins. It was suspected that one of the reasons for not implementing thermal EOR technology, which has been proven to be effective and economical in these reservoirs, was the lack of availability of the technology to independent producers who own most of the fields. Moreover, these reservoirs belong to the unstructured deltaic Class I reservoirs, a major target for DOE's Oil Research Program Implementation Plan. Keeping in mind the near-term strategy of DOE, which is to increase U. S. oil production using known implemented oil recovery technology, NIPER proposed that a study be undertaken to determine the potential for increasing heavy oil production from Texas Gulf Coast reservoirs using thermal techniques.

The objectives of this study were to screen Texas Gulf Coast (Districts 1 through 4) heavy oil reservoirs using information from the NIPER heavy oil database for priority ranking and to conduct reservoir studies to determine the applicability of thermal EOR techniques in selected reservoirs. The objectives were extended to include evaluation of applicability of cyclic $\mathrm{CO}_{2}$ stimulation and immiscible $\mathrm{CO}_{2}$-waterflood processes, when economics of steamflood processes were found to be not attractive.

Heavy oil reservoirs in the Texas Gulf Coast area were screened using published screening guides and basic data obtained from the NIPER heavy oil data base. Reservoir information including well logs, core analysis reports, stimulation data, production data, and geological and engineering reports, was collected for prioritized reservoirs. Finally, a single reservoir was selected and characterized for detailed numerical simulation studies. Simulations were conducted using Steam and Additive Reservoir Simulator (STARS) developed by Computer Modeling Group (CMG), Canada, to simulate waterflood, cyclic steam stimulation, steamflood, cyclic $\mathrm{CO}_{2}$ stimulation, and immiscible $\mathrm{CO}_{2}$-waterflood processes. Simplified and detailed economic evaluations were made to evaluate gross economic feasibility of these processes. 


\section{Chapter 2}

\section{SELECTION OF POTENTIAL RESERVOIRS USING SCREENING GUIDES}

\subsection{INTRODUCTION}

Reservoir data were obtained from the NIPER heavy oil data base, and screening was conducted from published screening guides to select potential reservoirs for steam injection processes.

\subsection{RESERVOIR DATA}

Based on the information available in the data base, a total of 73 heavy oil reservoirs were found to exist in Districts 1 through 4 in the Texas Gulf Coast area. Data on depth (d), area, density (API) and viscosity of oil ( $\mu_{\mathrm{o}}$ at reservoir temperature), thickness (h), porosity ( $\emptyset$ ), permeability (k), and cumulative oil production (until 1989) were available, but data on oil saturation $\left(\mathrm{S}_{\mathrm{O}}\right)$ were not available. A value of $65 \%$ was arbitrarily assumed to be the initial oil saturation for all the reservoirs. From these basic data $\varnothing \mathrm{S}_{0}, \mathrm{kh} / \mu$, and oil-in-place (OIP) were calculated.

\subsection{SCREENING GUIDES}

Screening guides proposed by several authors (Chu, Geffen, Ali, Lewin, and Iyoho) are given elsewhere (Table 4.1 in Butler, 1991). Chu's guide, with some modifications, has been used in this work. Reservoirs were screened for minimum thickness (10 ft), maximum depth $(4,000 \mathrm{ft}$ according to Geffen's guide), minimum depth (300 ft), minimum oil saturation (0.40), minimum porosity $(0.20)$, minimum $\varnothing \mathrm{S}_{\mathrm{o}}(0.08)$ and minimum permeability $(100 \mathrm{mD})$. The criterion of minimum depth was relaxed from $400 \mathrm{ft}$ to avoid elimination of a big field with a depth of $350 \mathrm{ft}$. Chu's guide has no criteria for maximum depth and minimum permeability. Although a minimum permeability of $1,000 \mathrm{mD}$ is suggested in Ali's guide, it was relaxed in view of the potential for application of horizontal wells or of hydraulically fractured vertical wells. The cumulative oil-steam ratios (COSR) were calculated following Chu's correlation. A COSR value of 0.2 or more is commonly considered to be favorable (Chu, 19£5) for initiating recovery using steam injection processes.

\subsection{SCREENING RESULTS}

From a total of 73 reservoirs, 16 met all the screening criteria mentioned above (Table 2.1); however, seven of these reservoirs have moderate oil viscosities in the range between 41 and $73 \mathrm{cP}$. Oil recoveries in these reservoirs by primary and secondary means are likely to be high, making these reservoirs less economically attractive for steam injection processes because of low oil saturation. The remaining nine reservoirs have a total OIP of 346 MMSTB. These 


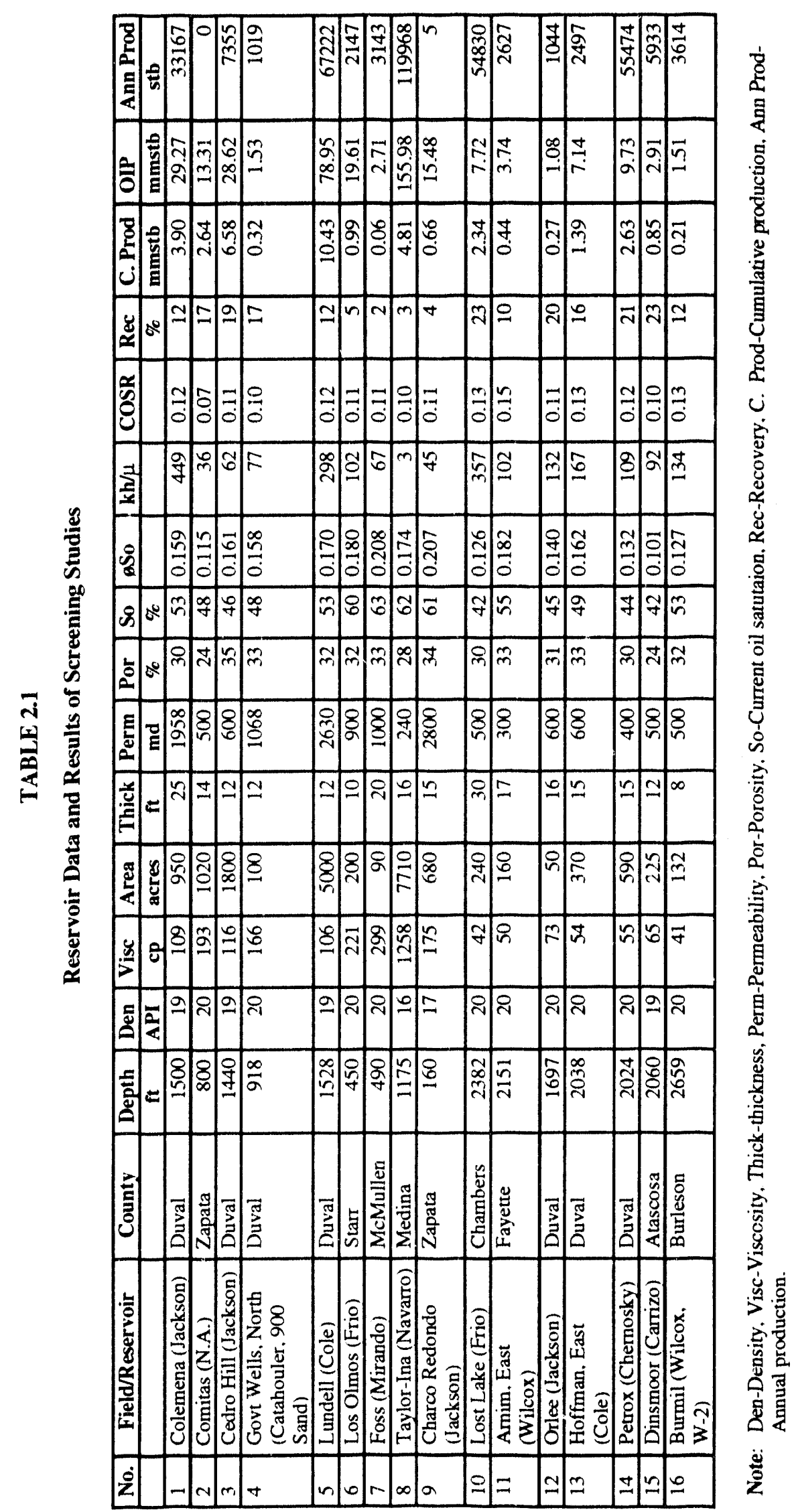


nine reservoirs can be organized into two groups on the basis of their production histories. Group 1 consists of five reservoirs (Nos. 1 through 5)-Colemena, Comitas, Cedro Hill, Govt. Wells North, and Lundell-which are currently being waterflooded. The oil recovered by waterflood operation from heavy oil reservoirs is usually in the range of 5 to 15\% (Kasraie et al., 1993). These fields are most likely to be matured (watered out) in the near-future and will warrant evaluation of feasibility of EOR techniques. A waterflood operation provides important information regarding areal and vertical continuities of a reservoir, which is very important for any displacement process to succeed. Group 2 consists of four reservoirs-Los Olmos, Foss, TaylorIna, and Charco Redendo-which are in the primary stage of oil production. The characteristics of lateral continuity of these reservoirs is revealec less because no displacement operation has been conducted yet.

These screened reservoirs have average net thicknesses ranging from 12 to $25 \mathrm{ft}$. The low average net thicknesses of the reservoirs was an indication that cyclic-steam stimulation alone probably will not recover a significant amount of oil (Sarkar and Sarathi, 1992). Cyclic-steam stimulation, however, is often a necessary precursor to steamflood operations. The estimated COSRs for all of these reservoirs were about 0.1 , which were low and indicated that steamflood using conventional techniques would likely have poor performances. The characteristics of low thicknesses and low permeability seem to be the main reasons for poor performances. Application of horizontal wells for improving the steamflood performance in thin and low-permeability reservoirs has been discussed previously by Sarkar and Sarathi (1992).

Screening guides could not be used for further prioritizing of reservoirs. Moreover, it should be noted that initial oil saturation values were assumed ones. Additional criteria such as amount of target oil, availability of reservoir data, and uniqueness of a reservoir, had to be used to select one or two reservoirs for detailed numerical simulation studies.

Among Group 1 reservoirs, Colemena has the highest steamflood potential because it has the second highest OIP of 29 MMSTB and the maximum thickness of $25 \mathrm{ft}$. Lundell field has the maximum OIP of 79 MMSTB, but the average net thickness is only $12 \mathrm{ft}$.

Among Group 2 reservoirs, Taylor-Ina is an attractive one because it has the highest OIP of 155 MMSTB. It has a depth of $1,175 \mathrm{ft}$, a low net thickness of $16 \mathrm{ft}$, and a low permeability of $240 \mathrm{mD}$. These reservoir properties were examined later for the area of interest (Chapter 3) while conducting the reservoir description study. The operator of this field (few leases) had alread:' provided some data, and close cooperation was expected.

\subsection{DISCUSSION AND CONCLUSION}

Only a limited amount of data were available for Colemena field. A core analysis report indicated that the formation consisted of shaly and silty sand having a low permeability of $400 \mathrm{mD}$. 
Formation thickness was less than $25 \mathrm{ft}$, and sometimes non-pay zones were present at the middle or the bottom part of the zone. On the other hand, a good amount of data and a recently prepared report were available for Taylor-Ina field. A report (Andreen, 1967) on previous attempts of secondary and tertiary recovery methods in the field indicated that a pilot cyclic steam stimulation study was conducted in a well in Hutzler "A" lease in 1966. The well produced $40 \mathrm{bbl} / \mathrm{d}$ in the beginning and then continued to produce at a rate much higher than the unstimulated rate for several months. Similar attempts in other wells failed probably because of sanding problems. Considering the above factors and a large OIP, Taylor-Ina field was selected for evaluation of recovery potential through numerical simulation studies. 


\section{Chapter 3 \\ RESERVOIR DESCRIPTION OF TAYLOR-INA FIELD}

\subsection{INTRODUCTION}

Taylor-Ina field is about 12 miles southeast of Hondo, in the south centra! part of Medina County, Texas. The Navarro producing formation consists of the Olmos sand of Upper Cretaceous Age (Andreen, 1967). The Olmos sand correlates into adjacent West Fairfield and Adams fields, all of which are parts of a producing area of about 15 miles long and 4 miles wide. These fields are located along the Balcones fault system which is a major geological feature of the region. The field is severely faulted with sealing and non-sealing boundaries dividing the field into several reservoirs and limiting the area of a single reservoir in the range between 30 and 110 acres. This study is focused on the Hutzler " $\mathrm{C}$ " lease of Taylor-Ina field because the Olmos sand is better developed and cleaner in this lease than in other leases, and a significant amount of information was available through the operator about this lease. Recently, an engineering and geological evaluation of the Hutzler " $\mathrm{C}$ " lease of the field was conducted by Harper and Drake (1993). A good amount of information regarding geology, rock properties, and production characteristics was obtained from the report. In addition, core analyses and fracture data of a few wells in the lease and viscosity of oil obtained from wells M. Schmidt Nos. 1 and 5 in Fairfield field were used.

The Olmos sand is found at an average subsurface depth of $1,175 \mathrm{ft}$. The zone varies in thickness from 12 to $23 \mathrm{ft}$ and averages $18 \mathrm{ft}$. The net to gross sand thickness ratio is more than 90\%. Reservoir pressure was $300 \mathrm{psi}$ in the beginning but now averages $200 \mathrm{psi}$. The reservoir temperature was estimated to be $85^{\circ} \mathrm{F}$. The oil gravity varies from $15^{\circ}$ to $26^{\circ}$ API and averages $18^{\circ}$ API. The average porosity was estimated to be $32 \%$. The permeability was estimated to be $50 \mathrm{mD}$ for the top $12 \mathrm{ft}$ and $60 \mathrm{mD}$ for the bottom $6 \mathrm{ft}$. The average permeability for the whole zone was estimated to be $53 \mathrm{mD}$, which is about 5 times less than the value mentioned in the data base. The water saturation was found to vary from 46 to $62 \%$ according to core analysis, and from 30 to $32 \%$ according to log evaluation methods. No oil-water contact has been identified; however, the water saturation increases with depth. Average values for initial and residual water saturations were estimated to be 45 and $40 \%$, respectively. Gas saturation was considered to be nil and the average residual oil saturation was estimated to be $25 \%$.

The zone consists of soft, poorly consolidated sand with about 15 to $20 \%$ clays and a trace of dolomite $(<1 \%)$. Core analyses indicated the presence of small lenses of harder shale and dispersed clays. Moderate amount of mixed layer clay, small to moderate amount of smectite and kaolinite, and very small amount of illite constitute the clay fraction. 
The lease with an area of 177 acres was drilled first in 1979, although the Olmos sand was discovered in a surrounding lease in 1958. Of the 50 wells drilled to date (2/93), 39 wells are being produced by swabbing at 1-, 2-, or 3-day intervals, and 11 wells await completion. Six of the wells produce from open-hole completion. Twenty-seven wells were fractured with oil and sand, and the average production potential after fracturing was found to be $10 \mathrm{bbl} / \mathrm{d}$. Currently, wells are producing at an average of $0.75 \mathrm{bbl} / \mathrm{d}$ with water cuts varying from 5 to $10 \%$. Initially (after 30 days of production), wells produced at $7 \mathrm{bbl} / \mathrm{d}$ with very little water cut. The OOIP is 4.6 MMSTB in the Hutzler "C" lease of Taylor-Ina field, 41 MMSTB in West Fairfield field, and about 156 MMSTB for the whole Taylor-Ina area. Cumulative production from the lease (until $2 / 93$ ) is 107,028 STB or $2.3 \%$ of OOIP. For the Taylor-Ina area, annual and cumulative oil production (until 1989) are 119,968 STB and $2.9 \%$ of OOIP or 4.81 MMSTB, respectively.

Harper and Drake (1993) have recommended completing alreaiy drilled 11 wells and developing the rest of the lease area by drilling 36 additional wells on the basis of a spacing of 2 acres per well. The suggested development plan would improve ultimate recovery to $8.2 \%$. Drilling and completing a well costs about $\$ 40,000$, and hydraulic fracturing may cost another $\$ 10,000$ (personal communication with $\mathrm{Mr}$. J. H. Klaeger). The average primary recovery per well in 9 years has been 2744 STB which is equivalent to $\$ 41,160$ based on an oil price of $\$ 15 / \mathrm{bbl}$. It appears that the economics of the development plan will be marginal.

Because of the large remaining OIP in the Olmos sand, various recovery methods including waterflood; cyclic stimulation with steam, hot water, kerosene or combustion products; and in situ combustion were tested between 1962 through 1966. Project reviews indicate that in most cases projects were terminated before conclusive results were obtained and in other cases technical planning, supervision, and operating techniques were poor.

\subsection{BASIC DATA}

The producing zone was divided vertically into three sections, and no areal heterogeneity was considered. The basic reservoir data used in the simulator are summarized in Table 3.1. The vertical permeabilities were assumed to be the half of horizontal permeabilities.

\subsubsection{Fractured Well Characteristics}

Most of the wells in the Hutzler "C" lease were hydraulically fractured and sand propped. Following a similar approach as that of Sarkar and Sarathi (1992), an evaluation of the fracture job in a well (Hutzler " $\mathrm{C}$ " 3) indicated that orientation of the fracture would be vertical. The width and 
TABLE 3.1

Thickness, Porosity, Permeability, and Water Saturation Values of the Reservoir

\begin{tabular}{ccccc}
\hline Zone & $\begin{array}{c}\text { Thickness, } \\
\text { ft }\end{array}$ & $\begin{array}{c}\text { Porosity, } \\
\text { fraction }\end{array}$ & $\begin{array}{c}\text { Permeability, Water Saturation, } \\
\mathbf{m D} \\
\text { fraction }\end{array}$ \\
\hline 1 & 6 & 0.32 & 50 & 0.45 \\
2 & 6 & 0.32 & 50 & 0.45 \\
3 & 6 & 0.32 & 60 & 0.45 \\
\hline
\end{tabular}

length of the fracture were $0.2 \mathrm{in}$. and $312 \mathrm{ft}$, respectively. The permeability of the fracture was 2,000 D and the productivity index (PI) ratio (p. 110, Gidley et al., 1989) was 6.3. The porosity was assumed to be the same as that of the matrix (0.32). This evaluation compares well with that of Harper and Drake (1993), where the predicted fracture length and the skin factor were estimated to be $223 \mathrm{ft}$ and -5.2 , respectively.

\subsubsection{Fluid Characterization}

Three components: water, oil (nonvolatile), and $\mathrm{CO}_{2}$ (condensable gas); and three phases: aqueous, oleic and gas were considered. Both aqueous and oleic phases may contain gas. The viscosity of oil at reservoir pressure (200 psi) and temperature $\left(85^{\circ} \mathrm{F}\right)$ is $344 \mathrm{cP}$. The data for viscosity of oil as a function of temperature were available for surrounding leases and were assumed to be applicable for the Hutzler "C" lease (Table 3.2 and Fig. 3.1). Viscosity of liquid $\mathrm{CO}_{2}$ as a function of temperature was obtained from the literature (Hong and Ault, 1984).

TABLE 3.2

Crude Oil and Liquid $\mathrm{CO}_{2}$ Viscosity as a Function of Temperature

\begin{tabular}{lcc}
\hline \multirow{2}{*}{$\begin{array}{l}\text { Temp } \\
{ }^{\mathbf{F}}\end{array}$} & \multicolumn{2}{c}{ Viscosity, $\mathbf{c P}$} \\
\cline { 2 - 3 } & oil & liquid $\mathbf{C O}_{2}$ \\
\hline 75 & 500.0 & 0.309 \\
77 & 466.0 & 0.306 \\
109 & 146.0 & 0.275 \\
140 & 60.4 & 0.250 \\
210 & 13.0 & 0.209 \\
500 & 1.3 & 0.130 \\
\hline
\end{tabular}




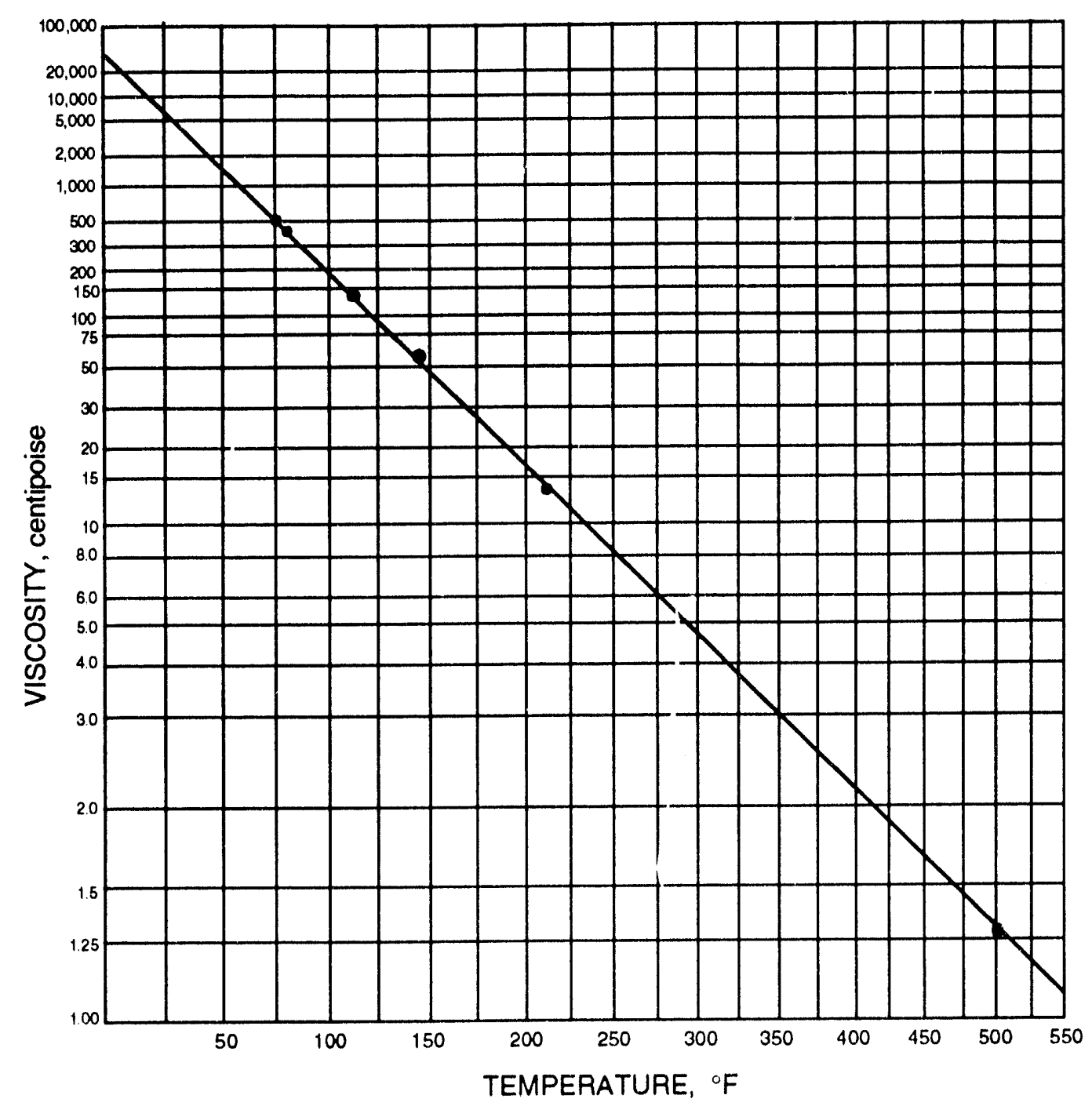

FIGURE 3.1 - Viscosity of the Taylor-Ina crude (after Klaeger, 1993).

Phase equilibrium ratios (K-values) as functions of pressure and temperature were used in the simulator. In the absence of real information regarding solubility of $\mathrm{CO}_{2}$ in Taylor-Ina oil, the data for crude oil from Bartlett field, Kansas, were used (Chung et al., 1988). The use of this data was justified because Chung et al. have indicated that solubility of $\mathrm{CO}_{2}$ in heavy oil depends mainly upon pressure and temperature of the system and to some degree upon the gravity of the crude. Bartlett crude has a gravity of $16.8^{\circ} \mathrm{API}$ which is close to the value for this field. Details for evaluating phase equilibrium ratios (K-values) from solubility data and values of a few important physical properties are given in appendix A. Oleic phase viscosity as a function of solubility are critical data and must be checked with laboratory-measured data before any field trial is conducted. Aqueous and oleic phase densities were obtained by following ideal mixing rules and utilizing 
pure-component densities and phase compositions. Oleic phase viscosities were obtained by using logarithmic mixing rule. An assumption was made that dissolved gas behaves as a liquid.

\subsection{RELATIVE PERMEABILITY AND CAPILLARY PRESSURE}

In the absence of real information regarding relative permeabilities and capillary pressures, appropriate values were assumed. The matrix oil-water relative permeability curves (Fig. 3.2) were assumed to be the same as those given by Morgan and Gordon (1970) for fine-grained sandstone containing clay. The matrix oil-water capillary pressure curves (Fig. 3.3) are similar to those used by Aziz et al. (1987). The matrix gas-liquid relative permeability and capillary pressure curves (Figs. 3.4 and 3.5) were assumed to be similar to those given by Aziz et al. (1987). The oil-water and gas-liquid relative permeabilities and oil-water and gas-oil capillary pressures (Figs. 3.6, 3.7 and 3.8) were assumed to be the same as those given by Kazemi et al. (1976). The gasliquid relative permeabilities for fraciure were assumed to be linear. Based on work by Frizzell (1990), appropriate values for temperature dependent matrix relative permeabilities were assumed (Table 3.3).

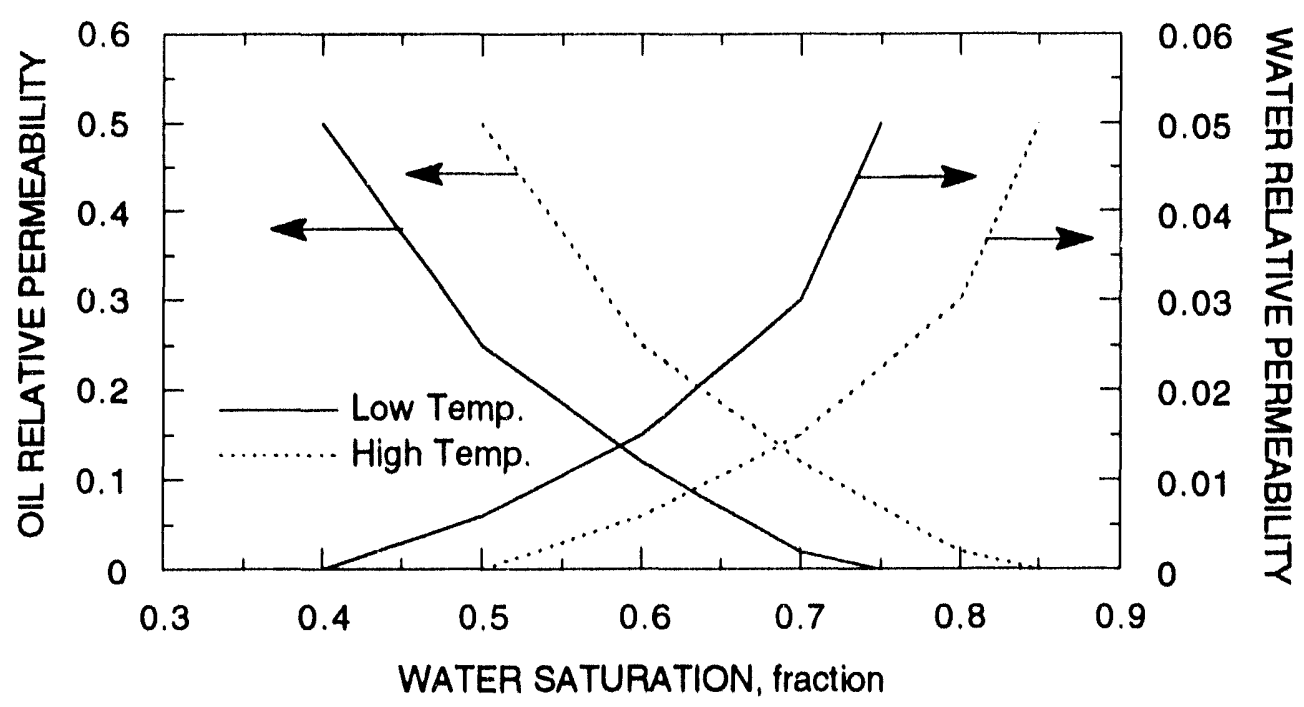

FIGURE 3.2 - Oil-water relative permeabilities for matrix at different temperatures. 


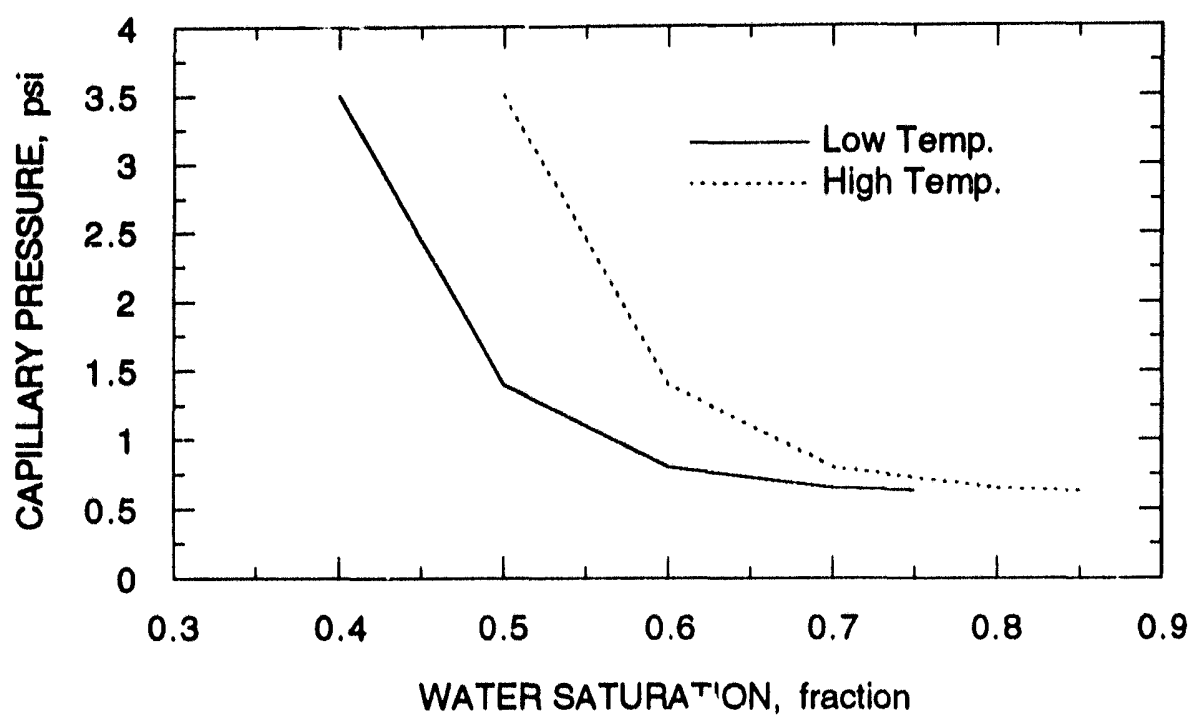

FIGURE 3.3 - Oil-water capillary pressure for matrix at different temperatures .

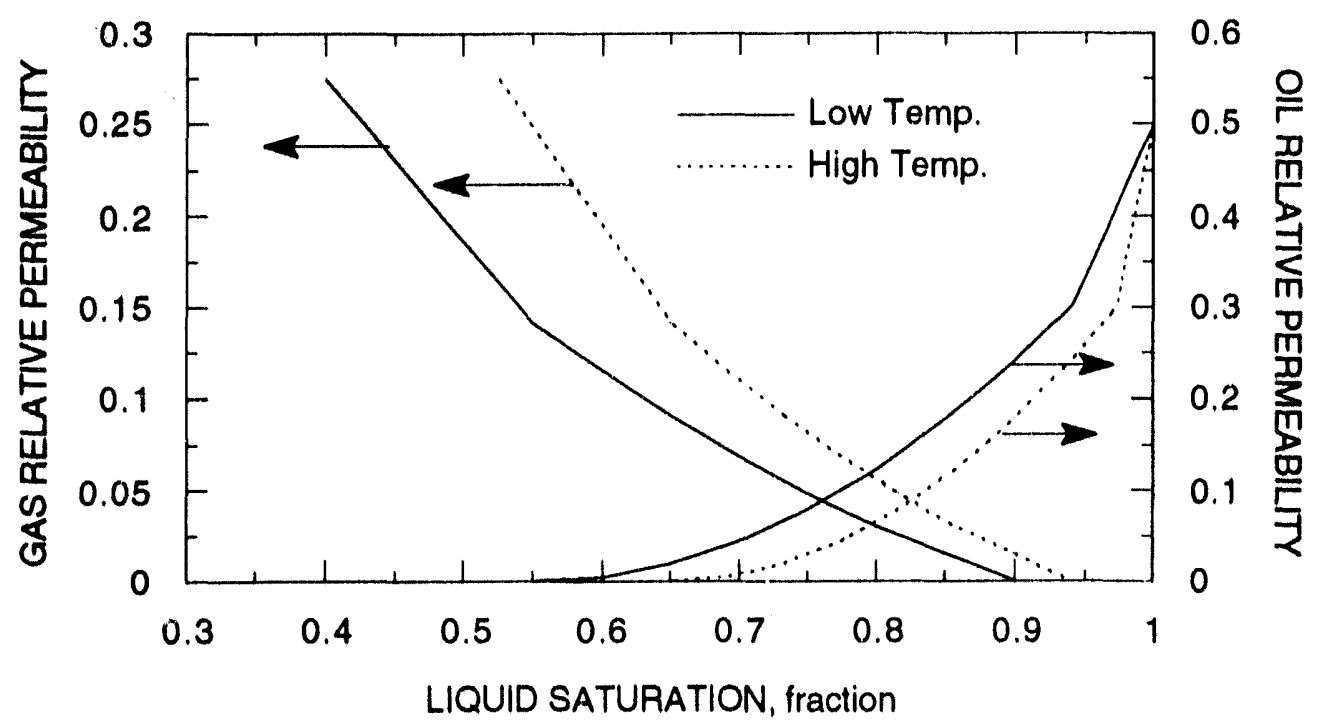

FIGURE 3.4 - Gas-liquid relative permeabilities for matrix at different temperatures. 


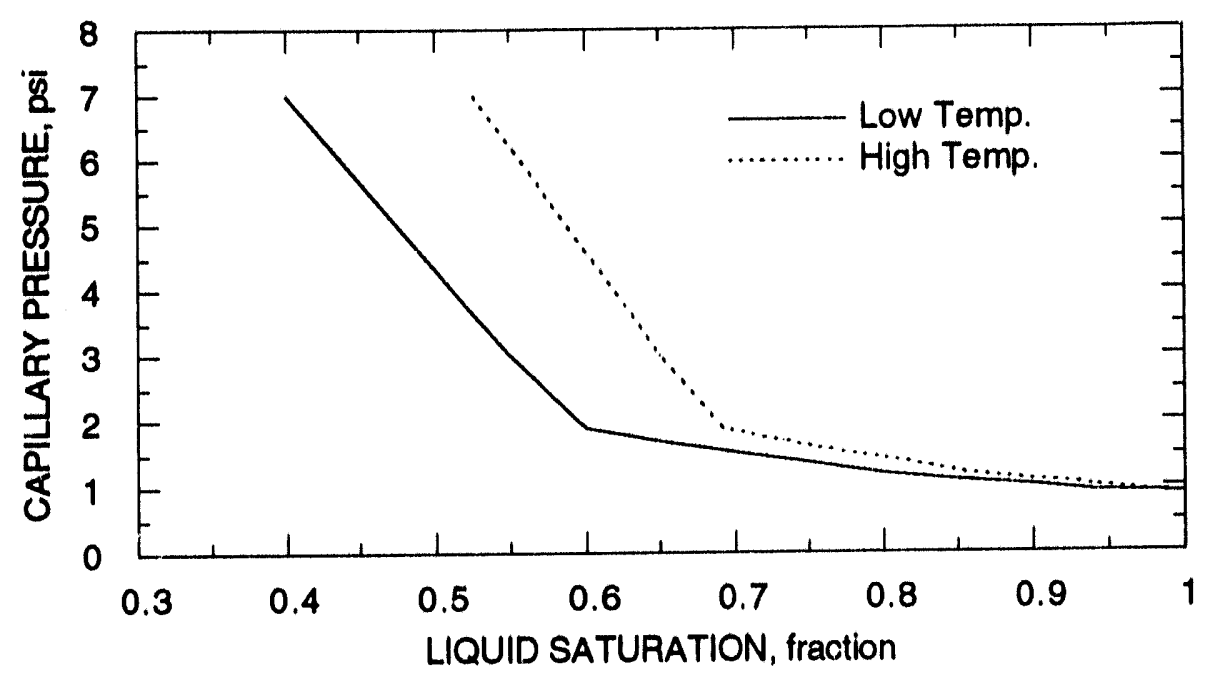

FIGURE 3.5 - Gas-liquid capillary pressures for matrix at different temperatures.

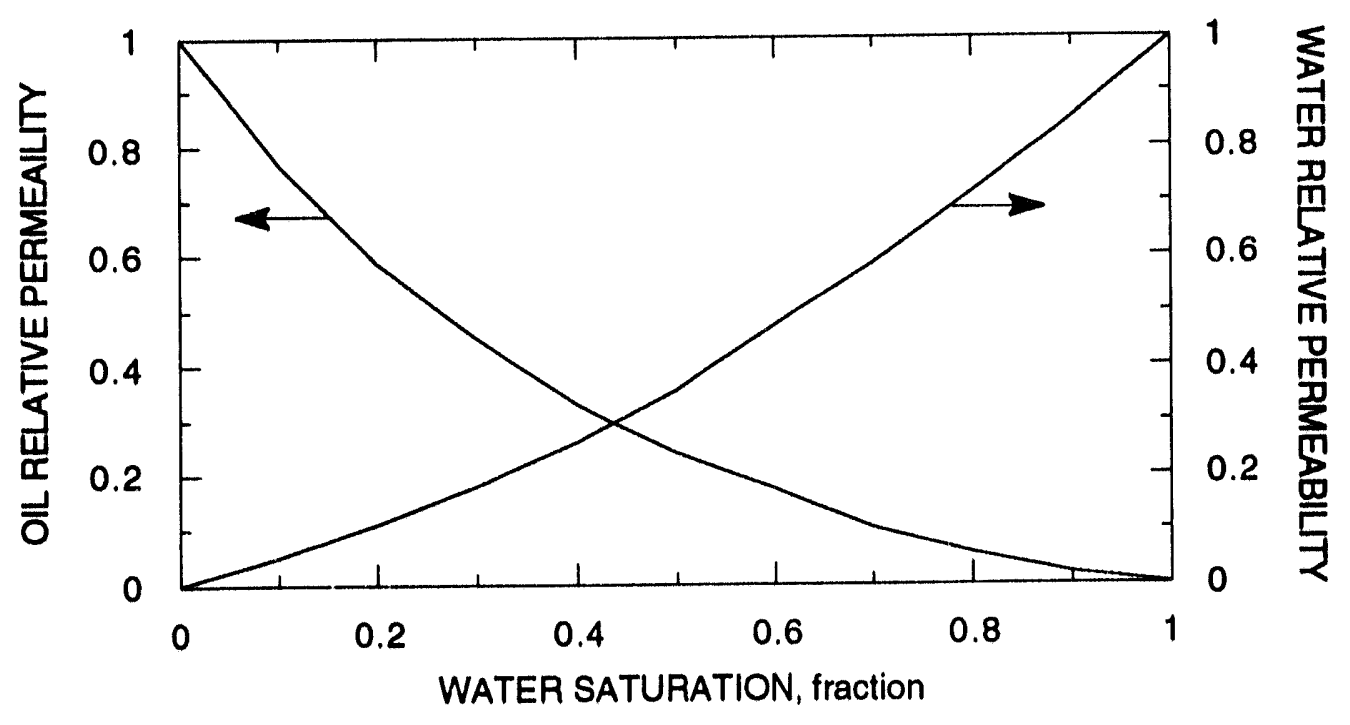

FIGURE 3.6 - Oil-water relative permeabilities for fracture. 


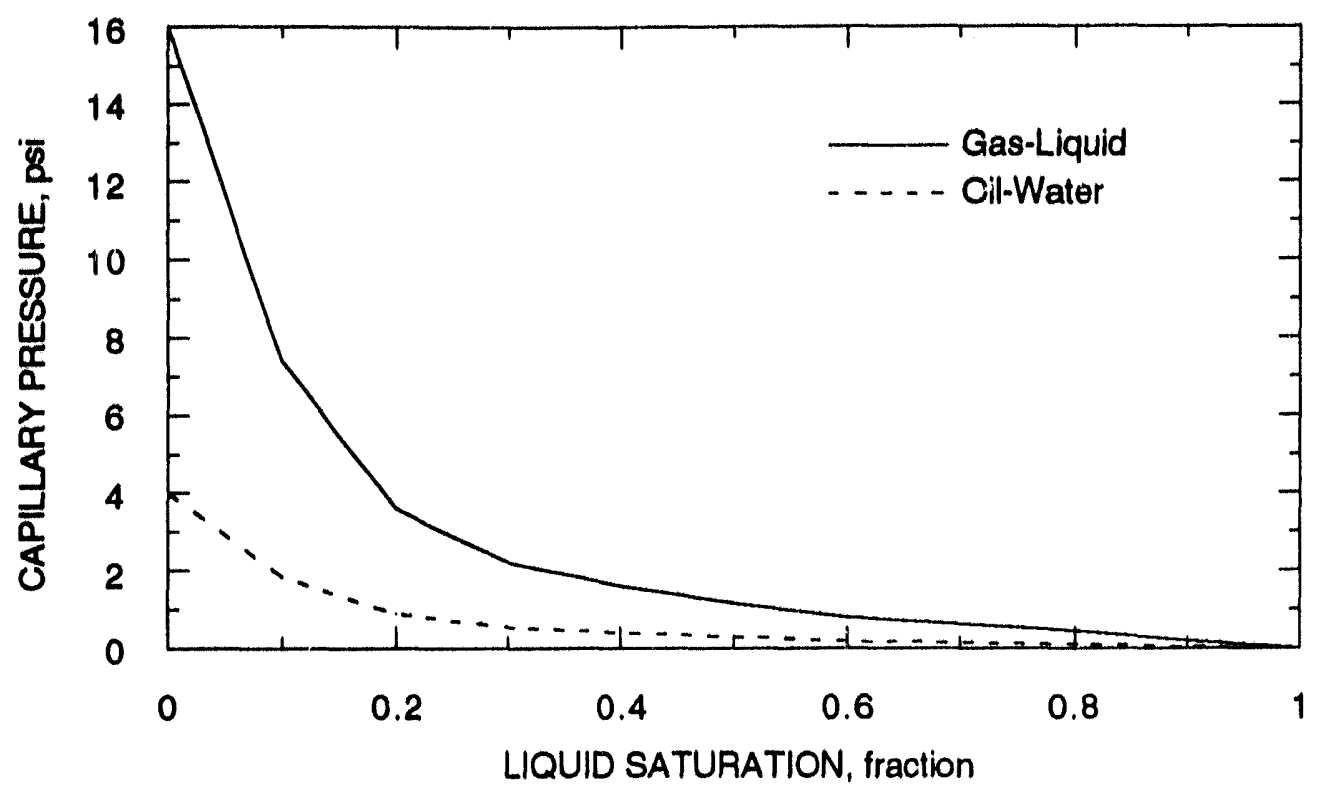

FIGURE 3.7 - Oil-water and gas-liquid capillary pressures for fracture.

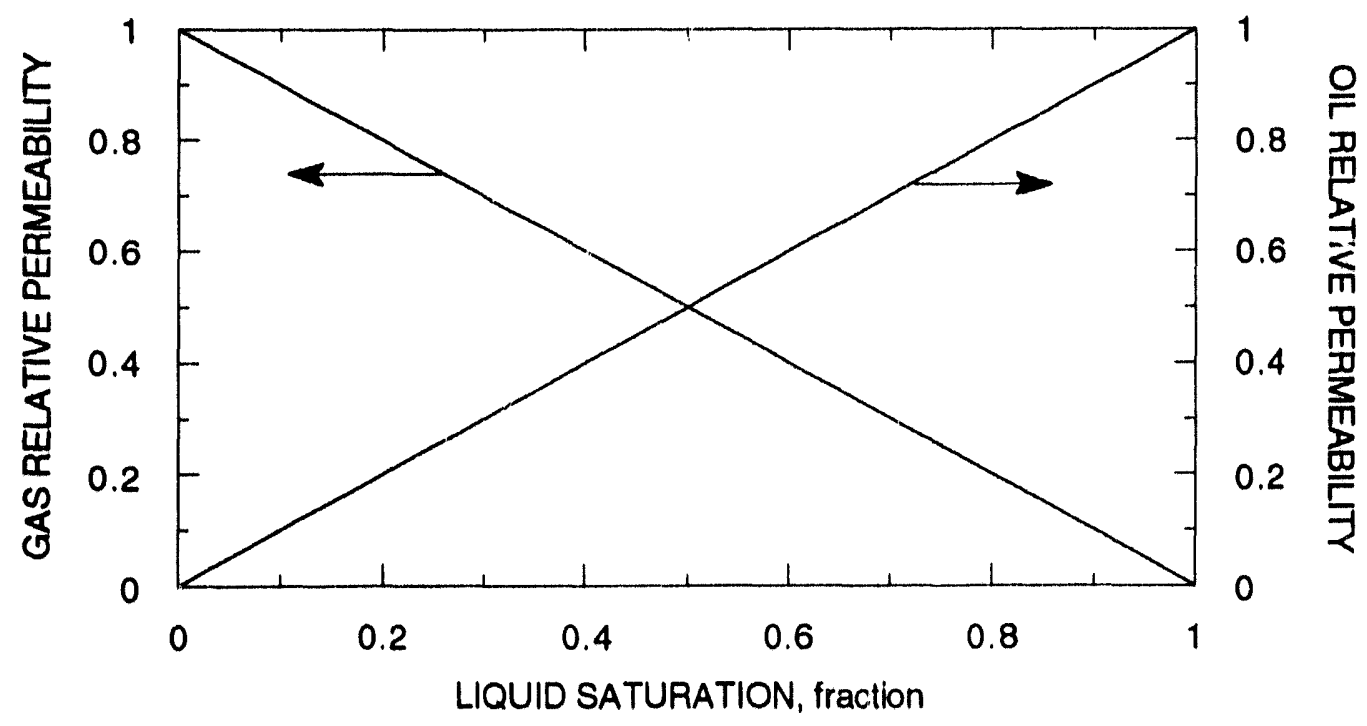

FIGURE 3.8 - Gas-liquid relative permeabilities for fracture. 
TABLE $\quad 3.3$

Effect of Temperature on Relative Permeability

\begin{tabular}{cccc}
\hline $\begin{array}{c}\text { Temperature } \\
{ }^{\circ} \mathbf{F}\end{array}$ & $\begin{array}{c}\mathbf{S}_{\mathbf{w r}} \\
\text { fraction }\end{array}$ & $\begin{array}{c}\mathbf{S}_{\text {orw }} \\
\text { fraction }\end{array}$ & $\begin{array}{c}\mathbf{S}_{\mathbf{g r}} \\
\text { fraction }\end{array}$ \\
\hline $\mathbf{8 5}$ & 0.40 & 0.25 & 0.10 \\
$\mathbf{5 4 5}$ & 0.5 & 0.15 & 0.06
\end{tabular}

Note: S-Saturation; Suffix wr, orw and gr represent residual water; residual oil to water and residual gas saturation, respectively. 


\section{Chapter 4}

\section{NUMERICAL SIMULATION OF RECOVERY PROCESSES IN TAYLOR-INA FIELD}

\subsection{INTRODUCTION}

Different recovery processes evaluated were waterflood, cyclic steam stimulation, steamflood, cyclic $\mathrm{CO}_{2}$ stimulation, and immiscible $\mathrm{CO}_{2}$-waterflood. Reservoir data used for simulations are given in Chapter 3. Simplified and detailed economic evaluations were conducted to determine the economic feasibility of recovery processes. In the simplified evaluation, operation cost and cumulative net revenue were calculated on the basis of cumulative injection and production data and the time period of operation. In the detailed evaluation, histories of net present value (NPV) or cumulative, discounted cashflows were calculated on the basis of histories of injection and production data. Details of the procedure and economic data for conducting economic evaluations are given in appendix B. Simplified economic evaluations were done for all of the simulation cases and detailed economic evaluations were done only for the 9-acre waterflood and immiscible $\mathrm{CO}_{2}$-waterflood cases, because these two cases involved lengthy time perind of operation and were found to be attractive.

\subsection{RESERVOIR SIMULATOR}

Steam and Additive Reservoir Simulator (STARS) developed by Computer Modeling Group, Canada, was used for making all the runs simulating waterflood and thermal and gas EOR processes. This is a fully implicit, multiphase, multicomponent, finite-difference thermal simulator. Interblock flow is calculated using a single-point upstream fluid mobility and enthalpy applied to a five- or nine-point block-centered finite difference scheme on cartesian, radial, variable thickness and curvilinear grids (Aziz et al., 1987).

\subsection{PATTERN CONFIGURATION AND GRID SYSTEM}

Figure 4.1 shows the sketch of the rectangular coordinate system and the type of pattern (5spot) used in this study. Figure 4.2 shows sketches of the areal (Fig. 4.2a) and the vertical grids (Fig. 4.2 b) of the one-fourth element of symmetry of the pattern. This grid definition $(8 \times 8 \times 3)$ and size of the pattern ( $312 \mathrm{ft} \times 312 \mathrm{ft}$ or 2.23 acre) was used in all the simulation cases unless mentioned otherwise. In the vertical direction three grid blocks of equal thickness of $6 \mathrm{ft}$ were used. The layer at the top is referred to as the first layer. The $8 \times 8$ areal grid system gives block dimensions of $22.29 \mathrm{ft} \times 22.29 \mathrm{ft}$. The rectangular grid system was used for cyclic stimulation runs as well. The dual porosity option in the simulator was used to represent vertically oriented, hydraulically fractured, and sand propped wells (Oballa et al., 1991). Five-point finite 


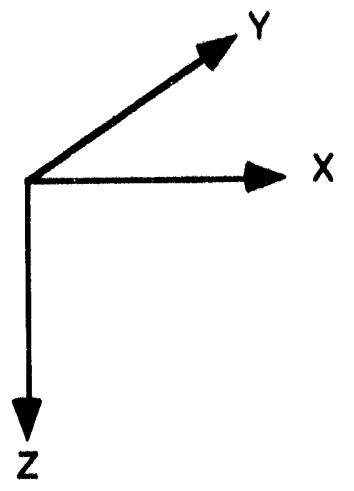

(a) Coordinate System

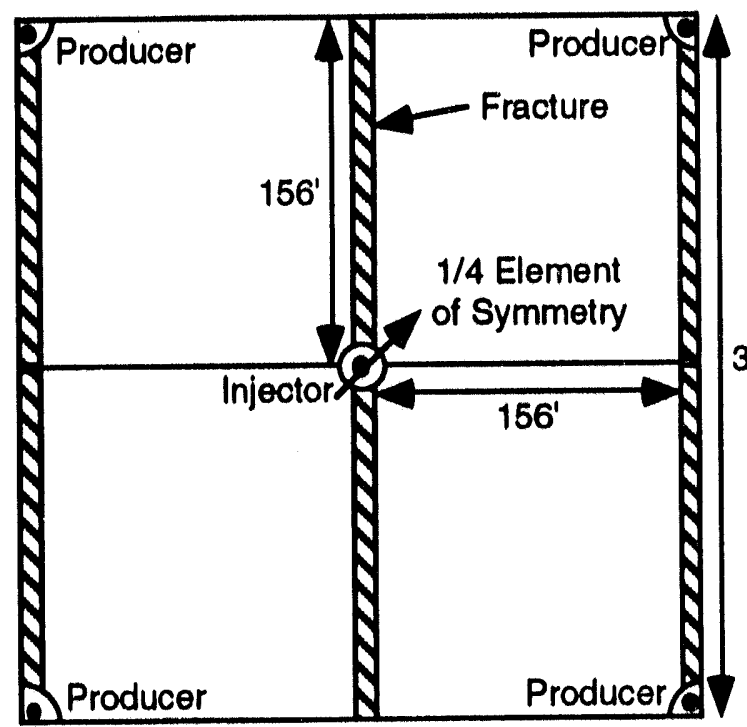

(b) Schematic of the pattern

FIGURE 4.1 - Coordinate system and schematic of a pattern showing hydraulically fractured and sand propped vertical wells.

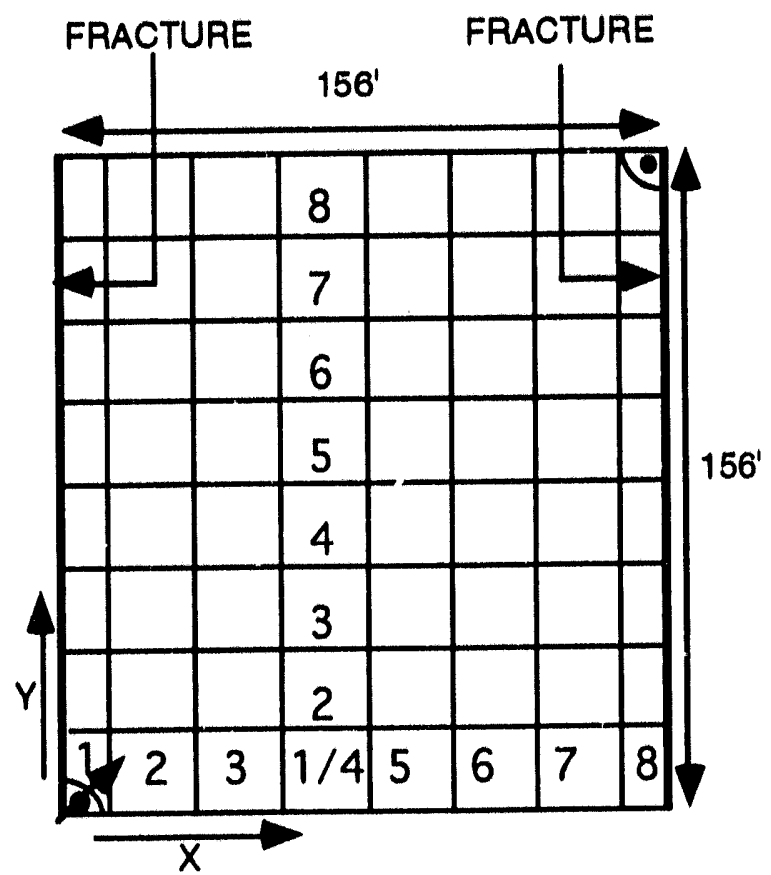

(a) Areal grid

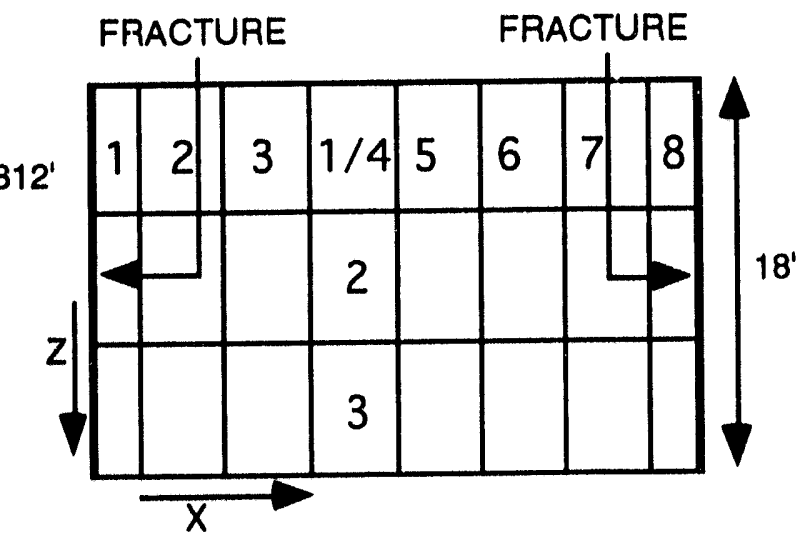

(b) Vertical grid

FIGURE 4.2 - Area and vertical grid of the one-fourth element of symmetry. 
differencing was used because of the limitation in the simulator that the nine-point finite differencing option cannot be used with the dual porosity option. No grid sensitivity study was conducted.

Currently, the patterns are of 9-spot type with an approximate area of 9 acres. Although most of the simulation runs were made using a 5-spot, 2.23-acre pattern, few runs were made using a 5-spot, 9-acre pattern. The fracture analysis indicated that the fracture length would be $312 \mathrm{ft}$. Under these conditions, it was assumed that the side wells would connect the fractures created by the corner wells and would not significantly affect recovery performances for the side well not being counted in a 9-acre pattern.

\subsection{INITIAL AND OPERATING CONDITIONS}

For all simulation runs, initial reservoir temperature and pressure were specified to be $85^{\circ} \mathrm{F}$ and $200 \mathrm{psi}$, respectively. The maximum bottomhole pressure (BHP) at injection wells was specified to be 1,000 psi because the formation fracture pressure was about 1,000 psi. For production wells, the minimum BHP and the maximum liquid production rate were specified to be $17 \mathrm{psi}$ and 1,000 bbl/d, respectively. A closed-pattern area, i.e., no fluid enters or leaves through the boundary of the pattern, was assumed. Additional operational conditions are mentioned later in relevant sections.

\subsection{WATERFLOOD}

No waterflood has been conducted in the field but was also considered. Approximately 22,000 and $10,000 \mathrm{bbl}$ of water were injected in two wells in two surrounding leases, and no response to this injection was noted. Loss of injected water through fault planes, diversion of water to other formations because of formation damage from fresh water sensitivity of Olmos sand, or injection of insufficient amounts of water were thought to be the reasons for poor waterflood performance (Andreen, 1967). The problem of fresh water sensitivity can be solved by selecting appropriate injection water salinity (Scheuerman and Bergersen, 1990). Two waterfloods were simulated; one with a pattern area of 2.23 acres (base case) which is about one-fourth of the existing pattern area and another with the existing pattern area of 9 acres (sensitivity case). An $11 \times 11 \times 3$ numerical grid system was used for the 9 -acre case.

\subsubsection{Base Case/Small Pattern Area}

Figure 4.3 shows the histories of rates of water injection and oil production, WOR, and cumulative oil production for a time period of 1,400 days. The injection rate decreased from $400 \mathrm{bbl} / \mathrm{d}$ to a minimum value of $83 \mathrm{bbl} / \mathrm{d}$ at 238 days and then gradually increased to $104 \mathrm{bbl} / \mathrm{d}$ at 1,400 days. The average injection rate was about $100 \mathrm{bbl} / \mathrm{d}$. Oil production reached a maximum 


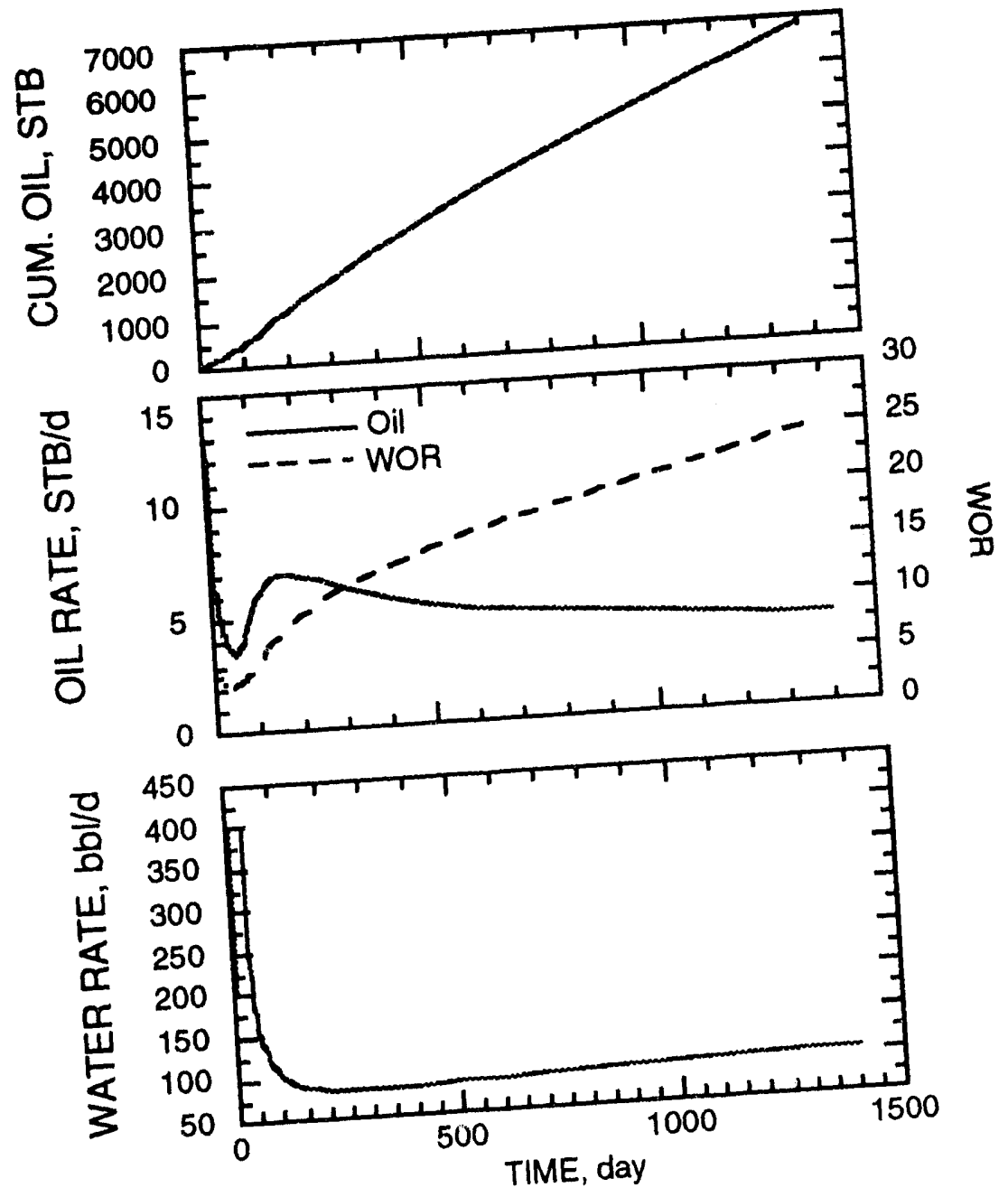

FIGURE 4.3 - Histories of water injection rate, oil production, WOR, and cumula
case waterflood.

value of $7 \mathrm{STB} / \mathrm{d}$ at 150 days and averaged $5 \mathrm{STB} / \mathrm{d}$. The WOR increased steadily to a maximum value of $7 \mathrm{STB} / \mathrm{d}$ at 150 days and averaged $5 \mathrm{STB} / \mathrm{d}$. The
value of 25 at the end of 1,400 days. The cumulative oil production and water injected were $13 \%$
$(6,873 \mathrm{STB})$ and $1.4 \mathrm{PV}(144 \mathrm{MBBL})$, respectively, at the end of 1,400 days.

Figure 4.4 shows oil saturation and pressure contours for the middle layer at 1,400 days. Gravity underride is not a problem in this thin reservoir with little variation in horizontal permeability among different layers. Areal sweep efficiency is good probably because the wells are fractured. This type of low oil recovery is expected from a heavy oil reservoir. The main are fractured. This type of low oil recovery is expected from a heation are limited
problem in this type of low-permeability reservoir is that injection and production rates are the
to low values affecting the economics of the recovery process in an unfavorable way. The 


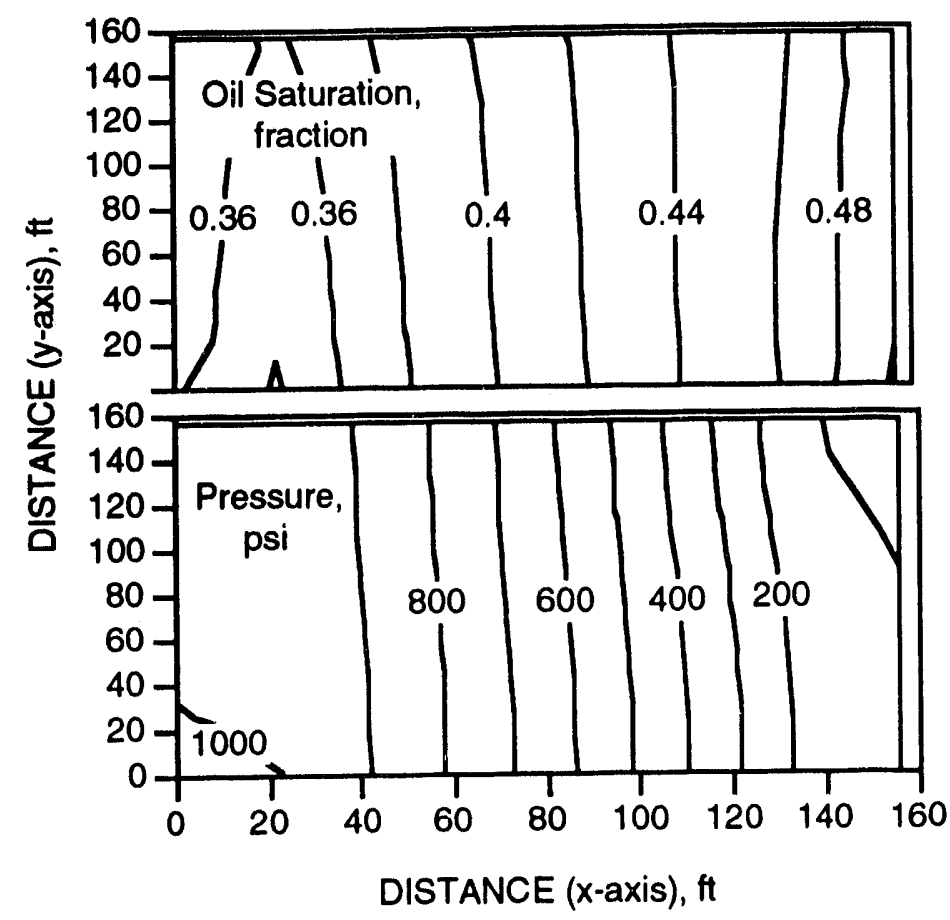

FIGURE 4.4 - Oil saturation (fraction), and pressure (psi) contours for the middle layer at 1,400 days for the base case waterflood.

operating cost and cumulative net revenue were $\$ 9.06 / / \mathrm{bbl}$ and $\$ 40,824$ (or $\$ 163,296$ on a 9-acre basis), respectively. This amount of revenue may not be sufficient to meet the drilling, completion and stimulation expenses of an infill well of about $\$ 45,000$.

\subsubsection{Sensitivity Study/Big Pattern Area}

Figure 4.5 shows the histories of rates of water injection and oil production, WOR and cumulative oil production for a period of 5,000 days. The injection rate decreased from $400 \mathrm{bbl} / \mathrm{d}$ in the beginning to a minimum value of $69 \mathrm{bbl} / \mathrm{d}$ at 1,400 days and then gradually increased to 80 $\mathrm{bbl} / \mathrm{d}$ at 5,000 days. The maximum rate of oil production was found to be only $5 \mathrm{STB} / \mathrm{d}$ at 1,200 days. The WOR decreased to 5 at 200 days and then gradually increased to a maximum value of 21 at the end of 5,000 days. The total amount of water injected was $1.05 \mathrm{PV}(418 \mathrm{MBBL})$ and the cumulative oil production was $10 \%(21,147 \mathrm{STB})$ at the end of 5,000 days. The operating cost and net revenue were $\$ 9.77$ and $\$ 110,578$, respectively. Detailed economic calculations indicated that the NPV was $\$ 26,692$ at 5,000 days.

In contrast to the results from small pattern area, injection/production rates were smaller because the pressure gradient between injection and production wells was smaller. Both oil recovery and the amount of water injected were lower, but COWRs (Cumulative Oil Water Ratio) 


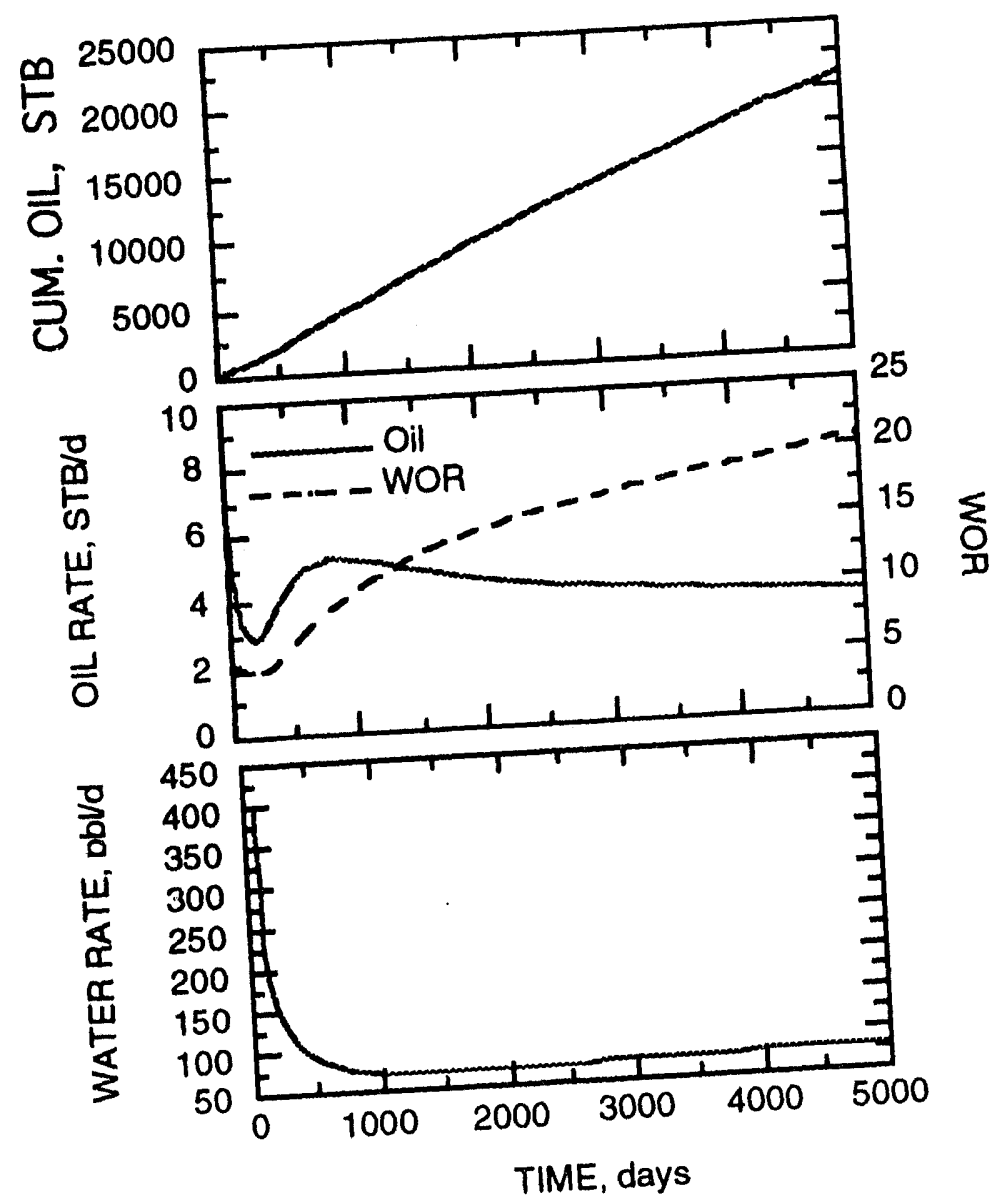

FIGURE 4.5 - Water injection rate, oil production rate, cumulative oil production, and WOR histories for the waterflood with bigger pattern area.

were similar (about 0.05 ). Because of longer time of operation, cashflow values were reduced by a larger amount. The assumpiions of uniform layered model and perfect communication between wells have higher chances of being incorrect because of larger distance between wells and the faulted nature of the reservoir.

\subsection{THERMAL EOR}

Cyclic steam stimulation and steamflood processes were simulated. The bottomhole steam quality was assumed to be $70 \%$ at $1,000 \mathrm{psi}$ and the maximum steam injection rate was limited to $400 \mathrm{BBL} / \mathrm{d}$. To simulate an occurrence of higher initial temperatures around the wellbore (from the effect of cyclic steam operations, generally conducted before a steamflood) in a steamflood run, the temperature of the blocks containing a well and of the adjacent blocks to the well was increased arbitrarily by $100^{\circ}$ and $50^{\circ} \mathrm{F}$, respectively. 


\subsubsection{Cyclic Steam Stimulation}

\subsubsection{Base Case}

A single case of two cycles of cyclic steam stimulation were simulated. Results from cyclic steam stimulations, along with the results from cyclic $\mathrm{CO}_{2}$ stimulations described later, are summarized in Table 4.1 (only first cycle). Figure 4.6 shows histories of rate of oil production and WOR for the two cycles. In the first cycle of this case (Run No. 1a) 3,000 bbl of steam was injected in a well over a period of 8 days. After a brief soak period, the well was put on production. The rate of oil production reached $52 \mathrm{STB} / \mathrm{d}$ after 7 days of production, but declined very quickly and finally reached a low value of $2 \mathrm{STB} / \mathrm{d}$ after 153 days of production. In a previous attempt, 2,709 bbl of steam was injected in a well in a nearby lease in 1966 and the well was found to flow back at a rate in excess of $40 \mathrm{STB} / \mathrm{d}$ in the beginning (Andreen, 1967). It seems there is a match of early oil rates observed in simulated and field results. Figure 4.7 shows histories of cumulative oil production and COSR (cumulative oil steam ratio) for the two cycles. The cumulative oil production was $1,452 \mathrm{bbl}$ and the COSR was 0.484 . The WOR changed very little and remained around 4.

At the end of injection maximum changes occurred in the injection block of the top layer. In the block, the pressure increased from 200 to $523 \mathrm{psi}$ and the temperature increased from $85^{\circ}$ to $204^{\circ} \mathrm{F}$. The viscosity of oil decreased from 345 to $15 \mathrm{cP}$. Water saturation increased from 45 to $57 \%$ and the oil saturation decreased from 55 to $43 \%$. No free gas (steam) saturation was developed in the matrix. At the end of production, the temperature decreased to $126^{\circ} \mathrm{F}$ and oil viscosity increased to $89 \mathrm{cP}$. During the injection phase, the majority of steam went into the top layer and a minor fraction went into the middle layer. The oil production through the top, middle and bottom layers were 37,44 and $19 \%$, respectively. Water production through the layers were 32,38 and $30 \%$, respectively. The operating cost and cumulative net revenue were $\$ 8.47 / \mathrm{STB}$ of oil and $\$ 9,482$, respectively.

In the second cycle, the same volume of steam was injected and the well was operated under similar operating constraints. The rate of oil production reached $41 \mathrm{STB} / \mathrm{d}$ after 7 days of production and finally reached a low value of $2 \mathrm{STB} / \mathrm{d}$ after 41 days of production. The production period was less than one-third of that in the first cycle. The cumulative oil production was $825 \mathrm{STB}$ and the COSR was 0.275 . The WOR changed from 2 to 9. As expected, the second cycle performance was poorer than the first cycle performance.

In the injection block of the top layer, the pressure increased from 19 to $370 \mathrm{psi}$ and the temperature increased from 127 to $331^{\circ} \mathrm{F}$. The viscosity of oil decreased from 89 to $4 \mathrm{cP}$. Water saturation increased from 45 to $63 \%$ and the oil saturation decreased from 55 to $37 \%$, respectively. No free gas (steam) saturation was developed in the matrix. At the end of production the temperature in the block decreased to $196^{\circ} \mathrm{F}$ and oil viscosity increased to $17 \mathrm{cP}$. 
TABLE 4.1

Results from cyclic stimulation parametric sensitivity studies

\begin{tabular}{llllcccccc}
\hline $\begin{array}{l}\text { Run } \\
\text { No. }\end{array}$ & Description & $\begin{array}{c}\text { Agent Vol. } \\
\text { BBL/mof* }\end{array}$ & $\begin{array}{c}\text { Prodn } \\
\text { Time, d }\end{array}$ & $\begin{array}{c}\text { Oil Rate } \\
\text { STB/d }\end{array}$ & WORf GORf & $\begin{array}{c}\text { COSR/ } \\
\text { COGR }\end{array}$ & $\begin{array}{c}\text { Cumulative } \\
\text { Oil, STB }\end{array}$ \\
\hline 1 a & Steam: base case & 3000 & 162 & 152 & 5 & - & 0.48 & 1452 \\
1 b & Steam: low volume & 1500 & 168 & 132 & 4 &.- & 0.61 & 1056 \\
1 c & Steam: high volume & 6000 & 140 & 180 & 6 & $\cdots$ & 0.35 & 2086 \\
2 & Carbon Dioxide & $2700^{*}$ & 389 & 247 & 2 & 35 & 1.00 & 2679 \\
\hline
\end{tabular}

1 - After 7 days of production. $\quad 2$ - After 15 days of production.

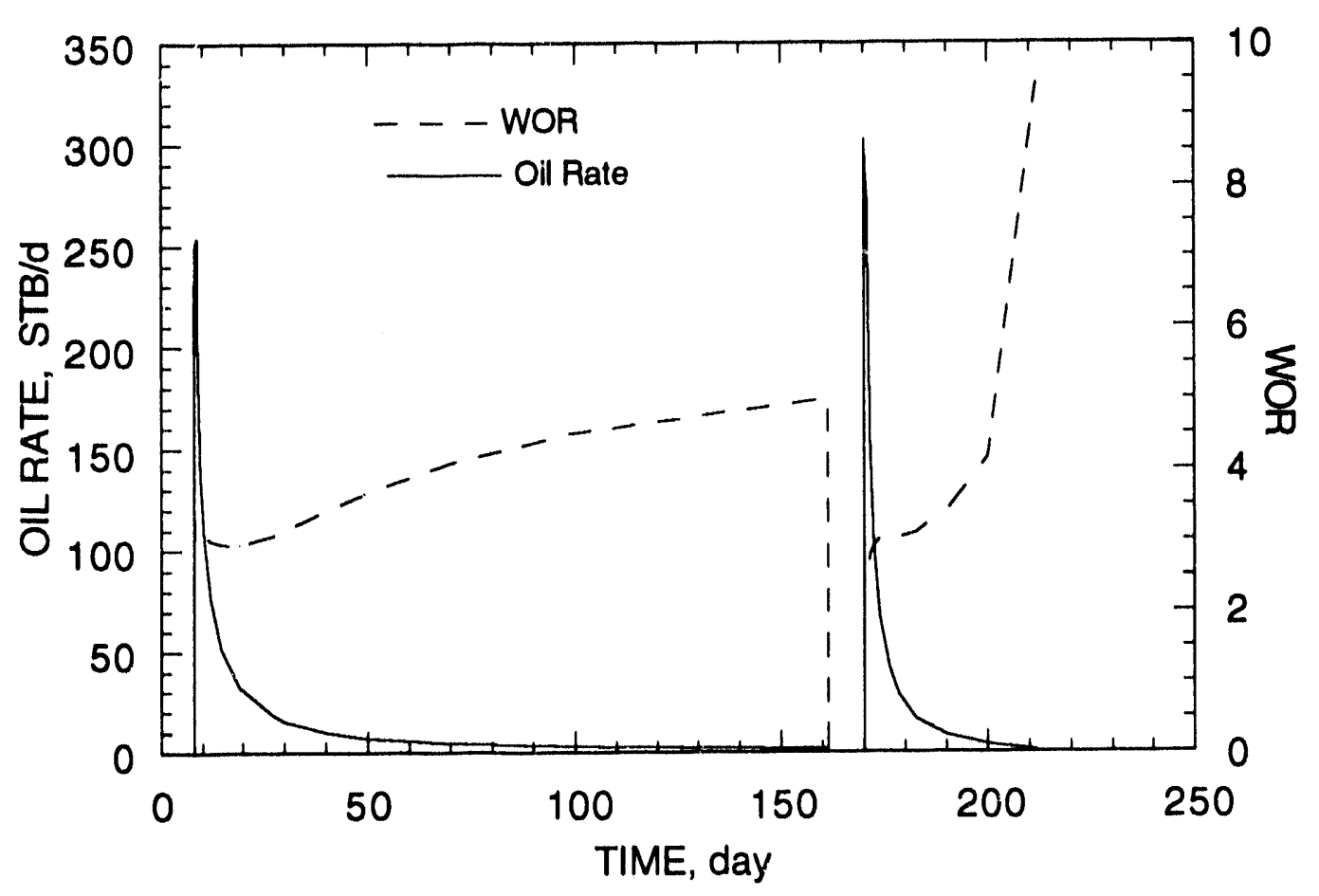

FIGURE 4.6 - The rate of oil production and WOR histories of two cycles of cyclic steam injection. 


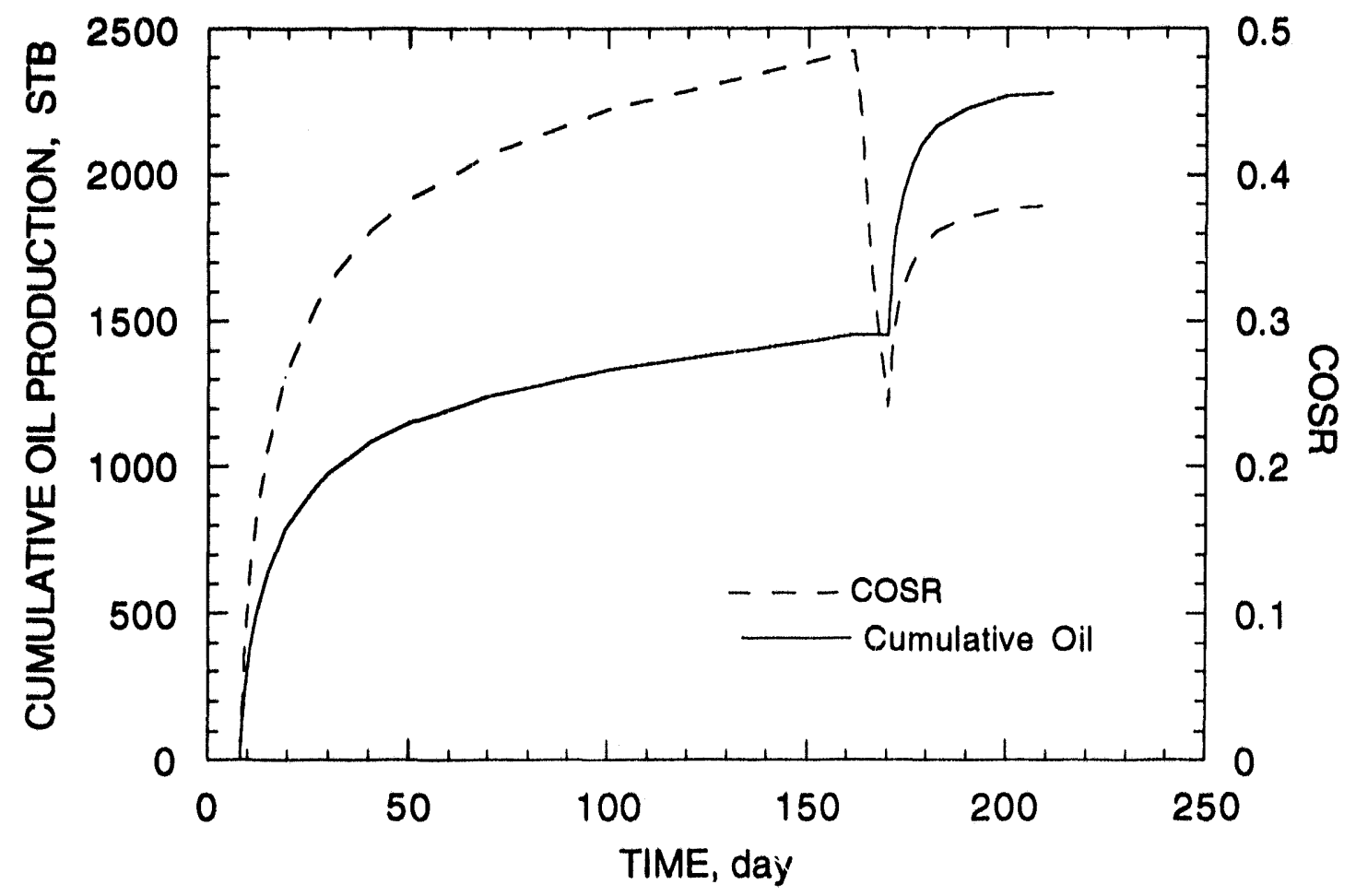

FIGURE 4.7 - The cumulative oil production and COSR histories of two cycles of cyclic steam stimulation.

Combining the results from two cycles, the cumulative oil production and COSR were $2,277 \mathrm{bbl}$ and 0.38 , respectively. The operating cost and cumulative net revenue were $\$ 8.86 / \mathrm{STB}$ of oil and $\$ 13,976$, respectively. The cost of a thermally completed well is in the range of $\$ 100,000$ (Sarathi and Olsen, 1992); hence the economics of the steam stimulation process by itself is not favorable. Even a recompletion of an existing well into a thermal well may cost about $\$ 65,000$. The economics of steamflood process must be favorable and the cyclic stimulation may be considered as a precursor for the steamflood process.

\subsubsection{Sensitivity Studies}

Two sensitivity runs with only one cycle in each case were made by changing the volume of steam injected and the results are compared with the base case results. In the low-volume case (Run No. 1b), 1,500 bbl of steam was injected in a well over a period of 4 days. The cumulative oil production and COSR were $1,056 \mathrm{bbl}$ and 0.704 , respectively. The WOR changed very little and remained around 4. At the end of steam injection the pressure and the temperature in the injection block of top layer increased by smaller amount resulting in a smaller decrease in viscosity 
of oil. Water and oil saturations changed by $5 \%$. No free gas saturation was developed in the matrix. The operating cost and cumulative net revenue were $\$ 8.70 / \mathrm{STB}$ and $\$ 6,653$, respectively.

In the high-volume case (Run No. 1c), 6,000 bbl of steam was injected in a well over a period of 15 days. The cumulative amount of oil production and COSR were 2,086 bbl and 0.348 , respectively. The WOR changed very little and remained around 6 . At the end of steam injection, the pressure in the injection block of top layer increased to $704 \mathrm{psi}$. Water and oil saturations changed by $18 \%$. No free gas saturation was developed in the matrix. The operating cost and the cumulative net revenue were $\$ 8.57 / \mathrm{STB}$ and $\$ 13,413$, respectively.

The COSR decreased, but the cumulative oil production increased with an increase in the steam injection volume. Among the three cases of different injection volumes, the base case results in the lowest operating cost, but the high-volume case results in the highest net revenue. A detailed parametric sensitivity study on cyclic steam stimulation in a thin and low-permeability reservoir (Sarkar and Sarathi, 1992) indicated that the characteristic of low permeability is one of the main reasons for poor reservoir performance. Thickness and vertical permeability of the reservoir are major factors controlling the amount of oil recovered and the net revenue.

\subsubsection{Base Case}

\subsubsection{Steamflood}

Figure 4.8 shows histories of rates of steam injection and oil production, WOR, cumulative oil production and COSR. The rate of steam injection was limited to about $110 \mathrm{bbl} / \mathrm{d}$ during the first 500 days, and reached $400 \mathrm{bbl} / \mathrm{d}$ at the end of 1,100 days when steam breakthrough was about to occur. Oil production reached a maximum value of $108 \mathrm{STB} / \mathrm{d}$ at 1,100 days and then decreased to 52 STB/d at 1,177 days. The WOR initially increased to 12 by 400 days, decreased to 5 at 1,000 days, and then continually increased to 8 at the end of 1,400 days. Around 1,177 days the operating strategy should be changed by reducing the steam injection rate to improve the subsequent COSR values. The cumulative results given here are based on this time. The total amount of steam injected was 2 PV (197 MBBL) and the cumulative oil production was $54 \%$ $(29,772$ STB). The COSR reached a maximum value of 0.152 at 1,177 days. The operating cost and the cumulative net revenue were $\$ 13.53 / \mathrm{bbl}$ and $\$ 43,550$ ( $\$ 174,200$ on a 9 -acre basis with four patterns), respectively. Theoretically, there are two wells in a 5-spot pattern and they would require about $\$ 200,000$ for drilling and completion. Therefore, the net revenue generated would not be sufficient to meet the high well costs. The main problems in this type of reservoir are (1) low injectivity/productivity and ineffective reservoir heating (Sarkar and Sarathi, 1992) which result in a low COSR, and (2) low thickness or low pattern area which results in a net revenue value insufficient to meet the capital costs. Figure 4.9 shows oil saturation, pressure, temperature, 


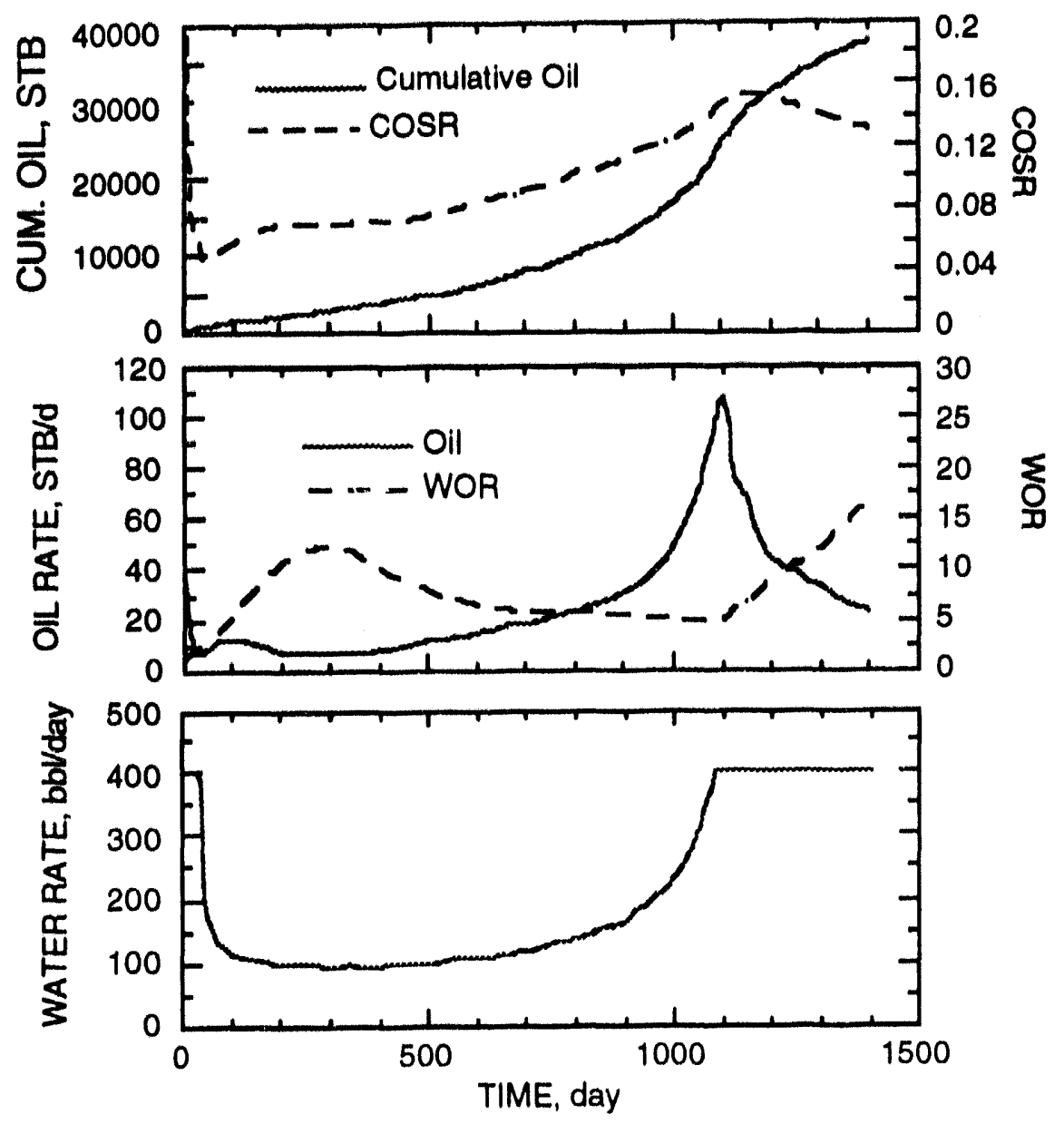

FIGURE 4.8 - Water injection rate, oil production rate and WOR histories for the steamflood. 


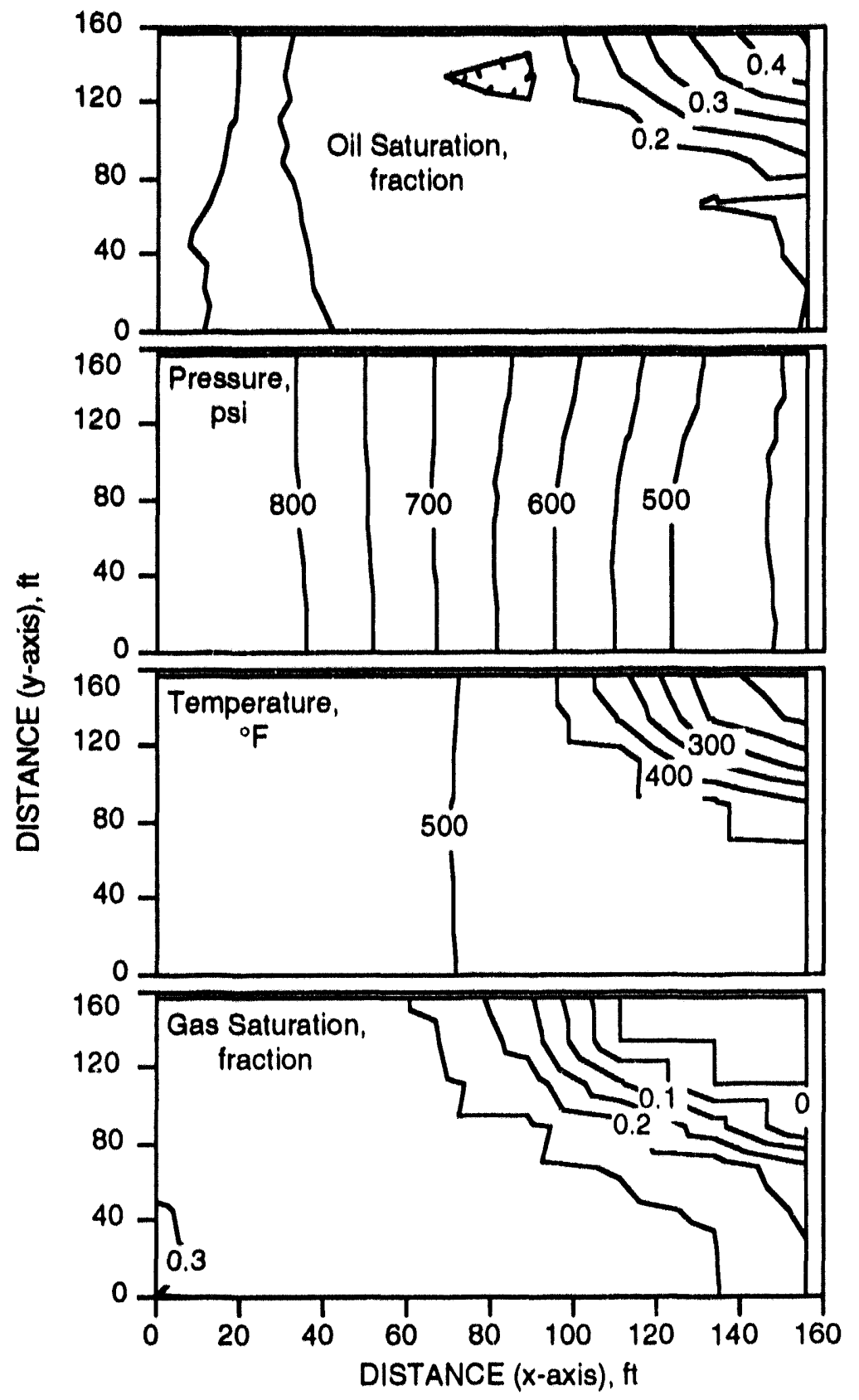

FIGURE 4.9 - Oil saturation (fraction) pressure (psi), temperature and steam saturation contours for the middle layer at 1,400 days for the steamflood.

and steam saturation contours for the middle layer at 1,400 days. Areal and vertical sweep efficiencies are good. Oil recovery was good and conductive heat losses to overburden and underburden was $56 \%$. 


\subsubsection{Sensitivity Study}

In this simulation case, both horizontal and vertical matrix permeabilities were increased to twice the value of the original permeability. The injectivity/productivity were improved and the recovery process was accelerated. The time period of operation was reduced by half $t 01,400$ days. The lowest rate of steam injection remained at a higher level of about $175 \mathrm{bbl} / \mathrm{d}$. The rate of oil production reached a maximum value of $183 \mathrm{STB} / \mathrm{d}$ at 538 days and then decreased to 70 STB/d at 600 days. The WOR initially remained low and then increased to 6 at 600 days. Around 600 days the operating strategy should be changed by reducing the steam injection rate to improve subsequent $\operatorname{COSR}$ values. The cumulative results given here are based on this time. The total amount of steam injected was reduced by $42 \mathrm{MBBL}$ but the cumulative oil production was similar to that in the base case. The operating cost was reduced by $\$ 2.50 / \mathrm{bbl}$ of oil and the cumulative net revenue was increaser hy $\$ 72,366$ to a total value of $\$ 115,916$. The cumulative net revenue was still not enough to meet the well capital costs.

\subsection{GAS EOR}

Gas EOR, compared to thermal EOR, is very likely to recover significantly less oil from a heavy oil reservoir (Moffit and Zornes, 1992). However, when a reservoir is thin and has low permeability, the application of thermal EOR using steam may not be economically feasible; especially to meet high completion costs of a thermal well. Gas EOR, on the other hand, is an isothermal process and the existing wells (excluding those with open hole completion) may as well be used for the recovery process. Gas EOR using cyclic stimulation (single well process) and/or flond (multiple wells are used for injection and production) type of operations and $\mathrm{CO}_{2}$ gas have been applied in several fields including Lick Creek. Arkansas (Reid and Robinson., 1981; Moffit et al., 1992); Wilmington, California (Sunner and Patton, 1986); Halfmoon, Wyoming, (Olenick et al., 1992), and Bati Raman, Turkey (Karanguz et al., 1989; Kantar et al., 1985). In an Amoco field, rich gas consisting of natural gas with $20 \%$ propane was used for cyclic stimulations (Shelton and Morris, 1973). Technical feasibility was found to be favorable in all the cases, but the economic feasibility was claimed to be favorable only in Lick Creek and Bati Raman (OOIP of $1.85 \times 10^{9} \mathrm{STB}$ ) fields. The cumulative gas oil ratio (CGORs, mct/bbl) or gas utilization factors for the two projects were 12 and 7.5 , respectively. For the Lick Creek project, $\mathrm{CO}_{2}$ was available at a low price from an ammonia plant, and for the Bati Raman project the gas was available from a nearby $\mathrm{CO}_{2}$ field. The availability and cost of $\mathrm{CO}_{2}$ were critical factors in selecting a project. $A$ simple economic calculation shows the economic $\mathrm{CGOR}\left(\mathrm{CGOR}_{\mathrm{ec}}\right)$ values considering only the operating costs of a project: 
Oil Price $(\$ / b b l)=$ CGORec $(m c f / b b l) * \frac{\text { Gas Cost }(\$ / m c f)}{G C F}$,

or

\section{$\mathrm{CGOR}_{\mathrm{ec}}=$ Oil Price $* \mathrm{GCF} / \mathrm{Gas}$ Cost}

where GCF is the gas cost as a fraction of the total operating cost. The cost of $\mathrm{CO}_{2}$ is about $\$ 1.00 / \mathrm{mcf}$ when available in pipeline (in the west Texas area), and about $\$ 3.00 / \mathrm{mcf}$ when available through tankers. Assuming an oil price of $\$ 15$ and a $\mathrm{GCF}(0.60)$, the $\mathrm{CGOR}_{\mathrm{cc}}$ for pipeline $\mathrm{CO}_{2}$ is 9 and that for tanker-hauled $\mathrm{CO}_{2}$ is 3 .

In a previous attempt, $6,880 \mathrm{mcf}$ (400 tons) of $\mathrm{CO}_{2}$ was injected over a period of 18 days in a well in a nearby lease in 1963 (Andreen, 1967). No response to this injection was noted, but it is not clear whether the recovery operation attempted was of cyclic or flond type. Previous to that water was injected in the same well and was thought to have been lost to other formations. It shows that $\mathrm{CO}_{2}$ and water can be injected into the formation, but no analysis of previous recovery performances is possible with very little information available.

\subsubsection{Cyclic $\mathrm{CO}_{2}$ Stimulation}

A single case of two cycles of cyclic stimulation with $\mathrm{CO}_{2}$ was simulated. Figure 4.10) shows histories of rate of oil production and GOR and Fig. 4.11 shows histories of cumulative oil production and COGR ( $1 / \mathrm{CGOR}, \mathrm{bbl} / \mathrm{mcf}$ ) for the case. In the first cycle of this run $2,700 \mathrm{mcf}$ of $\mathrm{CO}_{2}$ was injected in a well over a period of 60) days (@45 mct/d). After a brief soak period (hours) the well was produced back with an operating constraint of minimum bottomhole pressure of $17 \mathrm{psi}$ or a maximum gas production rate of $45 \mathrm{mct} / \mathrm{d}$. Higher backpressure was found to produce poor performance by Patton et al. (1982). The maximum rate of oil production was 47 STB/d after 15 days production and the rate declined to $2 \mathrm{STB} / \mathrm{d}$ after 329 days of production. The cumulative amount of oil produced was $2,679 \mathrm{bbl}$ and the COGR was 1.0. The amount of gas produced back was $52 \%$. The GOR (scf/bbl) decreased continuously from 1685 in the beginning to 197 in the end. The WOR always remained low at about 1.5. The operating cost and cumulative net revenue were $\$ 9.18 / \mathrm{bbl}$ of oil and $\$ 15,591$, respectively.

Maximum changes occurred, as in the case with cyclic steam stimulation, in the injection block of the top layer. At the end of injection, pressure in the block increased from 200 to $388 \mathrm{psi}$ and the viscosity of oil decreased from 345 to $38 \mathrm{cP}$. Water and oil saturations decreased from 45 to 39 and from 55 to $45 \%$, respectively. Free gas saturation developed in the injection block $(16 \%)$ and in the two adjacent blocks (13 and $8 \%$, respectively) of the top layer. At the end of production phase, water and oil saturations increased to 42 and $48 \%$, respectively, and the free gas saturation decreased to $10 \%$. The pressure decreased to $19 \mathrm{psi}$ and the oil viscosity increased to 


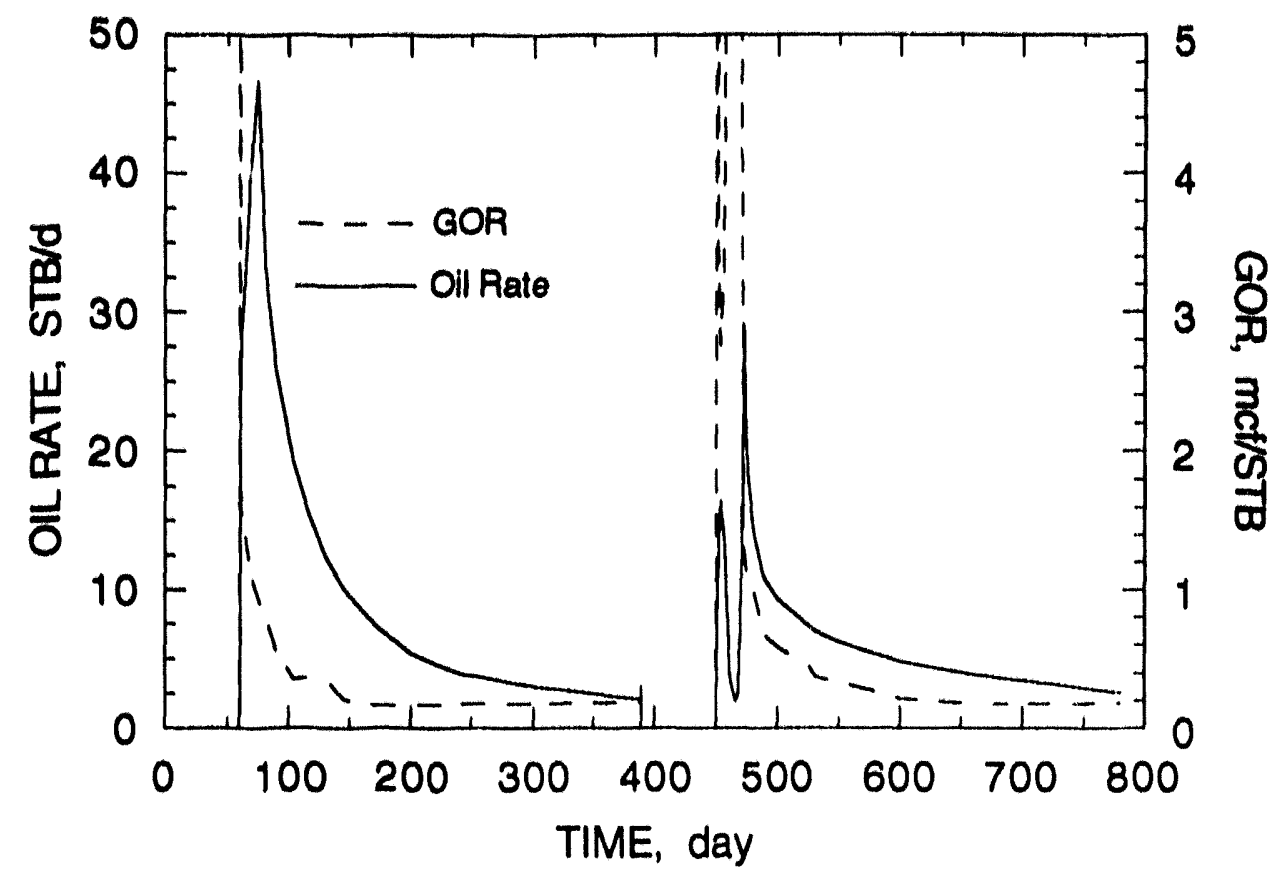

FIGURE 4.10 - The rate of oil production and GOR histories of two cycles of gas stimulation.

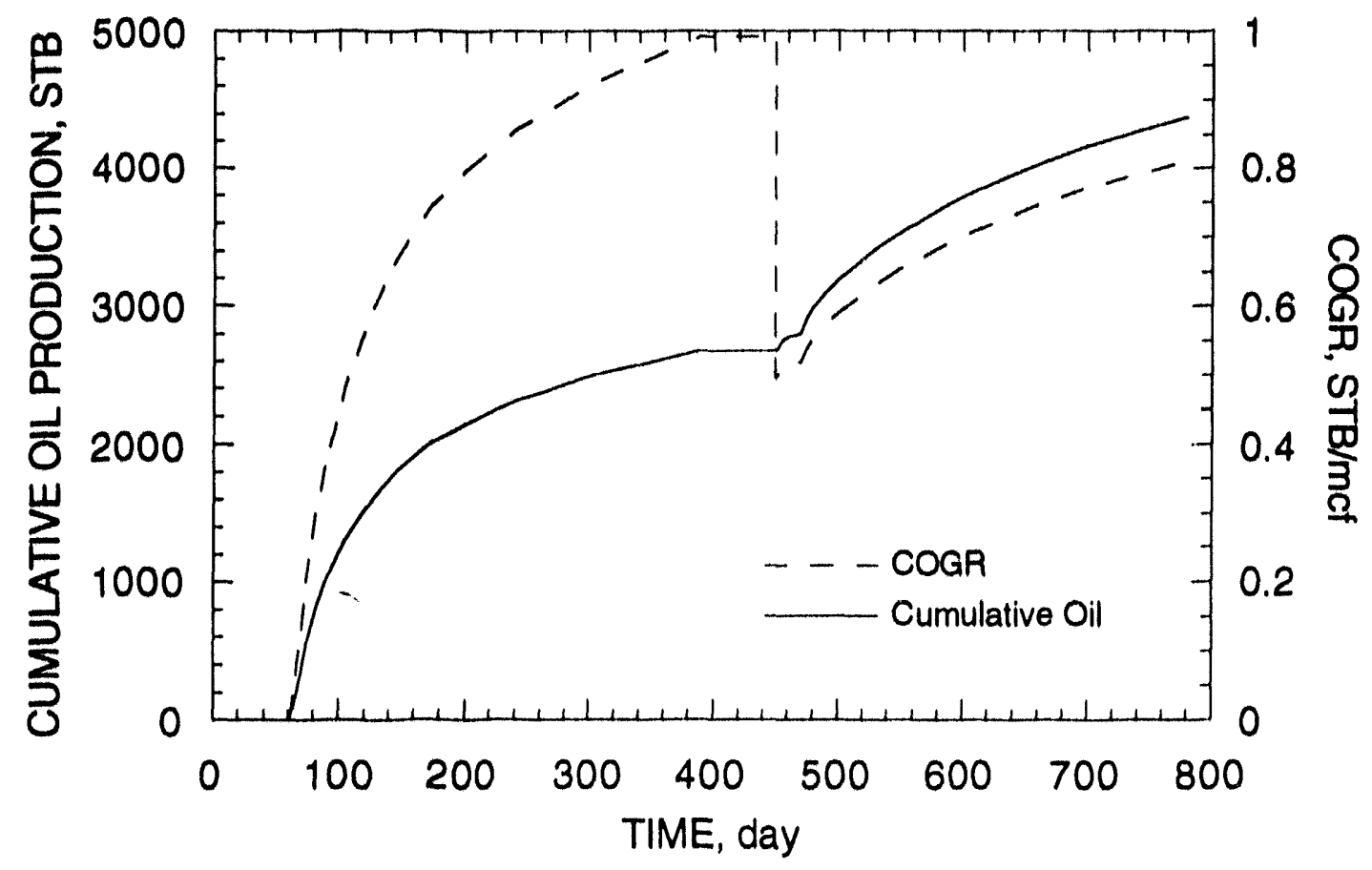

FIGURE 4.11 - The cumulative oil production and COGR histories for the two cycles of gas stimulation. 
$90 \mathrm{cP}$. During the production phase the gas production through the top, middle and bottom layers were 75,16 and $9 \%$, respectively. The oil production through the layers were 44,44 and $12 \%$, respectively. The water production through the layers were 22,33 and $45 \%$, respectively.

In the second cycle the same volume of $\mathrm{CO}_{2}$ was injected and the well was operated under similar conditions. The maximum rate of oil production was $29 \mathrm{STB} / \mathrm{d}$ after 24 days and the rate declined to $2 \mathrm{STB} / \mathrm{d}$ after 341 days of production. The total amount of oil produced was 1,696 STB (37\% less compared to the first cycle) and the COGR was 0.63 . The amount of gas produced back was $8 \%$ higher. The GOR decreased continuously from 8,681 in the beginning to 185 in the end. The WOR always remained low $(\sim 1)$. The operating cost and cumulative net revenue were $\$ 13.06 / \mathrm{bbl}$ of oil and $\$ 3,283$ (79\% less), respectively.

Compared to the results from the first cycle, the pressure increase and the viscosity reduction in the top layer injection block at the end of injection were smaller. Water and oil saturations decreased by similar amounts, but the free gas saturation reached a higher level of $26 \%$. At the end of production, water, oil and gas saturations reached the same level as in the first cycle. The oil production through the top layer decreased by $6 \%$ and that through the bottom layer increased by $6 \%$. The gas production through the top layer increased by $4 \%$.

Combining the results of two cycles, the oil production was 4,375 STB and the COGR was 0.81 . The overall operating cost and net revenue were $\$ 10.69 / \mathrm{bbl}$ of oil and $\$ 18,871$, respectively. Compared with the steam stimulation cases, the operating cost is higher but the net revenue is higher and the high cost of a thermally completed well can be avoided. The cyclic gas stimulation may be an economic operation by itself, without reference to a gasflood or other recovery operations to be applied in the future.

\subsubsection{Immiscible Carbon Dioxide-Waterflood}

An immiscible $\mathrm{CO}_{2}$-waterflood was simulated in a 9-acre, 5-spot pattern. The same grid system $(11 \times 11 \times 3)$ was used as in the case of waterflood in a 9-acre pattern was used. Water was injected in the beginning for arbitrarily 60 days to increase the pressure of the reservoir. Pressure in the near wellbore area increased from 200) psi in the beginning to $780 \mathrm{psi}$. Then gas and water were injected and finally only water was injected continuously. In each of 5 slugs of gas and water (cycle of 30 days, gas and water were injected for the same time period of 15 days). The maximum rate for gas and water were limited to $200 \mathrm{mcf} / \mathrm{d}$ and $400 \mathrm{bbl} / \mathrm{d}$, respectively. Figure 4.12 shows histories of rates of gas and water injection. Figure 4.13 shows the rate of oil production, WOR, GOR, cumulative oil production and CGOR histories. The full rate of gas injection was achieved in all the slugs but the rate of water injection started decreasing from the 


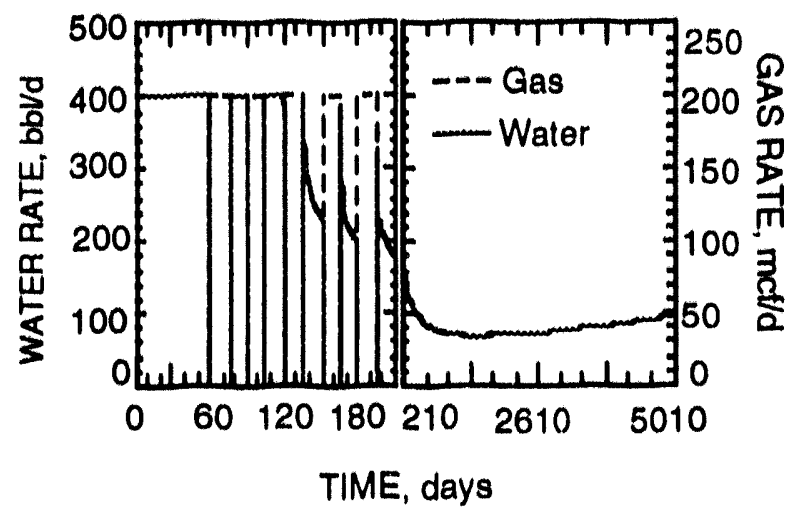

FIGURE 4.12 - Water and gas injection rate histories for immiscible $\mathrm{CO}_{2}$ waterflood.

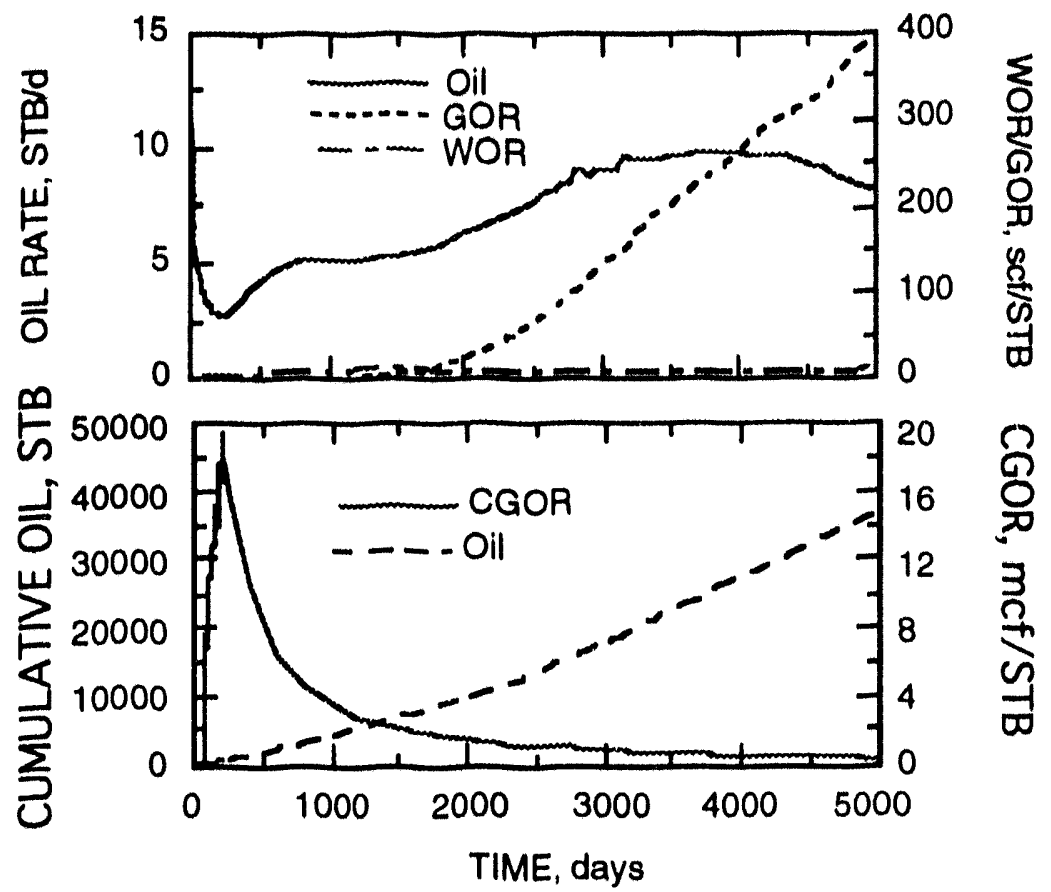

FIGURE 4.13 - Oil production, WOR, and GOR histories, and cumulative oil production and CGOR histories. 
third slug. The final rates at the end of third, fourth, and fifth slugs were 230,200 , and $179 \mathrm{bbl} / \mathrm{d}$, respectively. The rate of water injection reached a minimum value of $69 \mathrm{bbl} / \mathrm{d}$ at 1,700 days and then increased to $95 \mathrm{bbl} / \mathrm{d}$ at 5,000 days.

The rate of oil production reached a maximum value of $10 \mathrm{STB} / \mathrm{d}$ at 3,900 days and then decreased to $8 \mathrm{STB} / \mathrm{d}$ at 5,000 days. The WOR was about 5 for 230 days and then increased to 11 at 5,000 days. The cumulative results were based on 5,000 days of operation. The total amount of water and gas injected were 1.08 PV (430 MBBL) and 11.4\% HCPV (15,000 mcf), respectively. The final cumulative oil production was 36,624 STB (16.6\%). The operating cost and cumulative net revenue were $\$ 5.88 / \mathrm{bbl}$ of oil and $\$ 150,811$, respectively. Detailed economic calculations indicated that the NPV was $\$ 30,440$.

Figure 4.14 shows NPV (Net Present Value) histories for this case and the 9-acre waterflood case. In contrast to the waterflood, the oil recovery was $7 \%$ higher and the NPV was $14 \%$ $(\$ 3,748)$ higher. The cost of $\mathrm{CO}_{2}$ behaves like a capital investment of $\$ 45,000$ because the injection was done in the beginning, but its effect on improved production was felt after 3,000 days and the payout period was about 3,350 days. The risk of the project should be evaluated before selecting the immiscible $\mathrm{CO}_{2}$-waterflood over the straight waterflood project.

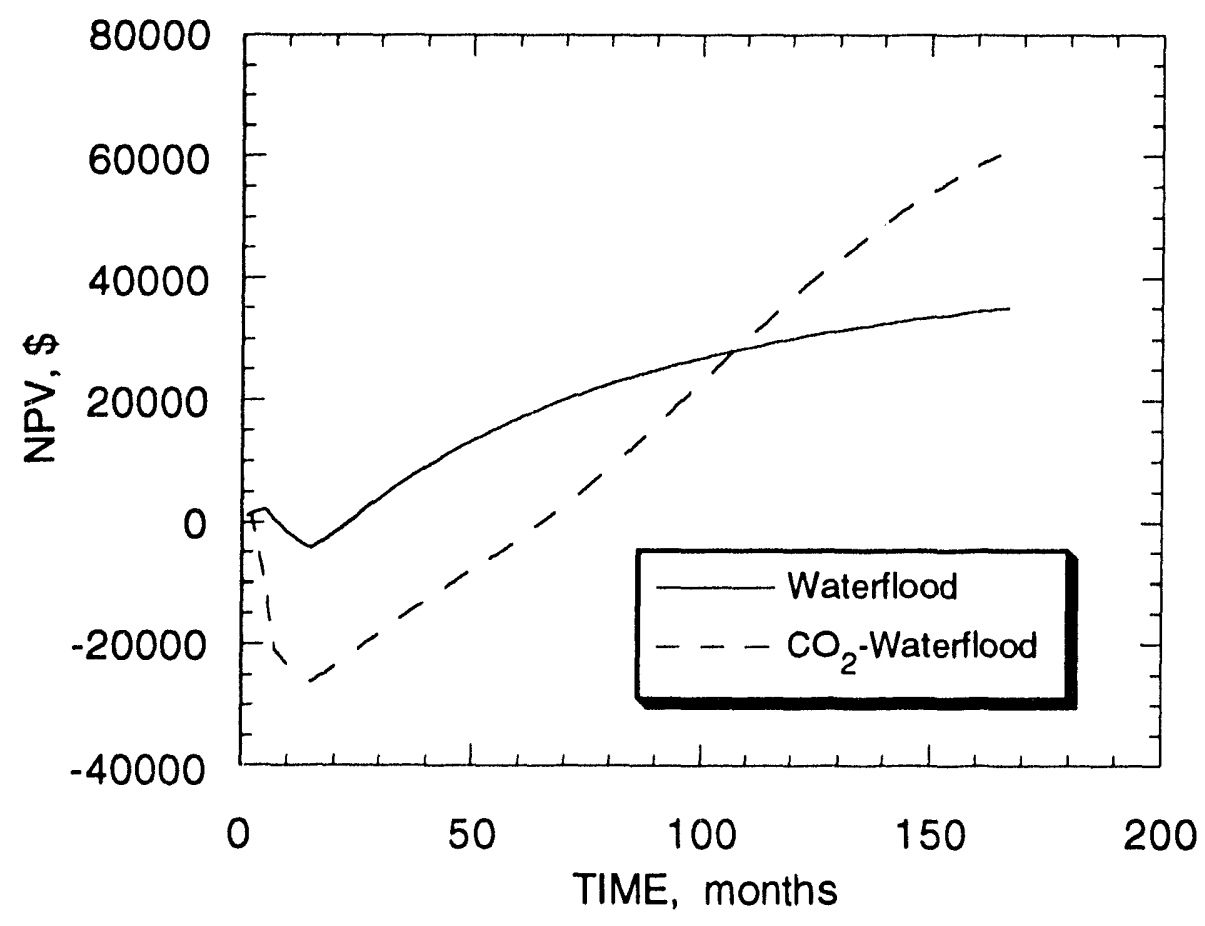

FIGURE 4.14 - NPV histories for the big pattern waterflood and immiscible $\mathrm{CO}_{2}$ waterflood. 


\section{Chapter 5}

\section{CONCLUDING REMARKS AND RECOMMENDATIONS}

\subsection{SUMMARY AND CONCLUSIONS}

1. An evaluation using screening guides and basic data obtained from the NIPER heavy oil database indicated that Taylor-Ina and Colemena, among all the heavy oil fields in the Texas Gulf Coast area (Districts 1 through 4), possess the highest potentials for application of steam injection processes. Limited amount of direct information including core analyses and welllogs on Colemena indicated its potential is less than reported in the database. Taylor-Ina was selected for detailed evaluation of recovery potential through use of numerical simulators because of the presence of a large oil-in-place (155 MMSTB) and the availability of information about the reservoir through a close cooperation with the operator.

2. Hutzler " $\mathrm{C}$ " lease, which is a cleaner and thicker part of the Olmos sand in Taylor-Ina field, was characterized on the basis of information available from core analyses, well-log evaluations, characteristics of the fractured wells, production characteristics of the reservoir, and a recent engineering and geological evaluation report on the lease. A three layer model was assumed and no areal heterogeneity was considered. The average values for thickness, porosity, oil saturation and permeability are $18 \mathrm{ft}, 32 \%, 55 \%$, and $53 \mathrm{mD}$, respectively. The data for viscosity of oil vs. temperature was reliable; however, the data for viscosity of oil vs. dissolved $\mathrm{CO}_{2}$ concentration was assumed. Appropriate values for oil-water and gas-liquid relative permeability and capillary pressures for matrix and fracture were assumed.

3. A simplified fracture analysis of a typical well showed that fracture orientation was vertical and the PI ratio was 6.3. The length, width and permeability of the fracture were estimated to be $312 \mathrm{ft}, 0.2$ inch, and 2,000 D, respectively. The lateral and vertical continuities within the reservoir can not be inferred from primary production characteristics of the field. The oil recovery (until 2/93) from the lease was about $2.3 \%$.

4. A simulation of waterflood in a 9-acre pilot showed that the cumulative oil production and cumulative water injection at 5,000 days were $10 \%(21,147$ STB) and 1.05 PV, respectively. The areal and vertical sweep efficiency were good but the displacement characteristics were poor because of unfavorable mobility ratio. A detailed economic evaluation indicated that the operation would be economic.

5. A simulation of cyclic steam stimulation showed that the cumulative oil production and COSR were 2,277 STB and 0.38 , respectively. The liquid expansion drive and increase in mobility of the oil seem to be the main oil recovery mechanisms, while the gravity drainage mechanism is unlikely to have any influence here. The characteristics of low permeability and low thickness are the major reasons for poor reservoir performances. The cyclic steam stimulation 
may be used as a precursor for steamflood processes, but not as a process by itself for recovering a significant amount of oil in thin reservoirs such as Taylor-Ina. All the simulation runs for the project were conducted using STARS, a numerical simulator developed by Computer Modeling Group, Canada.

6. A simulation of steamflood in a 2.23-acre pilot showed that the cumulative oil production and COSR at 1,177 days were $54 \%(29,772$ STB) and 0.15 , respectively. The steamfront progressed almost like a piston with very little gravity override because the thickness of the oil zone is small and the variation of permeabilities in the vertical direction are small. The characteristic of low-permeability of the reservoir seems to have the most negative influence on the reservoir performance causing ineffective reservoir heating where the mass and energy of injected steam is consumed for raising the pressure and temperature of the reservoir to a much higher level without gaining much from the reduction in viscosity of oil. A simplified economic analysis indicated that the operating cost may be less than the selling price of oil, but the revenue generated may not be enough for meeting the high cost of thermal wells.

7. A simulation of $\mathrm{cj}_{\mathrm{y}} \mathrm{clic} \mathrm{CO}_{2}$ stimulation showed that the cumulative oil production and $\mathrm{CGOR}$ (mcf/STB) were 2,679 STB, and 1.00, respectively. The reduction of crude oil viscosity and increase in reservoir energy are the main oil recovery mechanisms. The inability to achieve gas-oil contact at the bottom part of the reservoir is a major reason for low recovery performance. The cyclic gas stimulation may be used by itself for economically recovering a significant amount of oil by stimulating all the closely spaced wells in the field.

8. A simulation of immiscible $\mathrm{CO}_{2}$-waterflood in a 9-acre pilot showed that the cumulative oil production and cumulative water and $\mathrm{CO}_{2}$ injection at 5,000 days were $17 \%(36,624 \mathrm{STB})$, 1.08 PV and 11.4\% HCPV, respectively. A detailed economic evaluation indicated that compared to waterflood the net present value would be $14 \%$ higher but the payout would be 3,350 days. Risks involved should be considered before selecting immiscible $\mathrm{CO}_{2}$-waterflood over waterflood.

\subsection{RECOMMENDATIONS}

1. Recovery of tertiary heavy oil through application of steam injection processes may be uneconomical in today's environment for thin and low permeability reservoirs. Well designed cyclic $\mathrm{CO}_{2}$ stimulation should be field tested to recover additional oil economically. The process may not recover significant amount of oil per well but considering the number of wells the total amount of oil recovered may be very significant. Some activity will keep open the wells which otherwise may be plugged off and abandoned.

2. Research should be conducted to improve the performance of cyclic $\mathrm{CO}_{2}$ stimulation processes. All the heavy oil reservoirs considered during FY92 and other heavy oil reservoirs 
considered during FY93 should be re-evaluated for applicability of gas EOR processes, especially cyclic $\mathrm{CO}_{2}$ stimulation. Feasibility of heating the near wellbore area by using microwave, infrared techniques, or other methods should be explored.

3. Feasibility of developing small size mobile $\mathrm{CO}_{2}$ recycle plants which can be connected with mobile oil-gas separators (like ones used for well testing purposes) should be evaluated. This will improve the economics of the processes because a significant amount (about $50 \%$ ) of $\mathrm{CO}_{2}$ is produced back during stimulation processes and the cost of $\mathrm{CO}_{2}$ per mcf are about $\$ 3.00$ for fresh gas available through tanker but only about $\$ 0.45$ for recycled gas.

4. In the long-term, research in the area of in situ combustion methods which is specially suitable for deep and thin reservoirs for recovering a significant amount of oil, should be continued. 


\section{Appendix A \\ COMPONENT PROPERTIES AND PHASE BEHAVIOR}

\section{A.1 Component Properties}

Oil and $\mathrm{CO}_{2}$ component properties are given in the following table.

TABLE A.1

Oil and $\mathrm{CO}_{2}$ properties

\begin{tabular}{|c|c|c|}
\hline Properties & OII & $\mathrm{CO}_{2}$ \\
\hline $\begin{array}{l}\text { Molecular Weight } \\
\text { Gas properties: }\end{array}$ & 440.0 & 44.0 \\
\hline Critical Pressure, psi & -. & 1071 \\
\hline Critical Temperature, ${ }^{\circ} R$ & -. & 87.89 \\
\hline $\begin{array}{l}\text { Liquid properties: } \\
\text { Molecular Density, lb mole/ft } \\
\text { Mechanical Compressibility, } \mathrm{psi}^{-1}\end{array}$ & $\begin{array}{l}0.1333 \\
5.0 \mathrm{E}-6\end{array}$ & $\begin{array}{c}1.17 \\
50.0 \mathrm{E}-6\end{array}$ \\
\hline Thermal Compressibility, ${ }^{\circ} \mathrm{F}^{-1}$ & $4.43 \mathrm{E}-4$ & $44.3 \mathrm{E}-3$ \\
\hline Liquid Heat Capacity, Btu/(lb mole $\left.{ }^{\circ} \mathrm{R}\right)$ & 409.0 & 22.0 \\
\hline Gas Heat Capacity, Btu/(lb mole $\left.{ }^{\circ} \mathrm{F}\right)$ & 0.50 & 0.25 \\
\hline
\end{tabular}

Gas phase viscosity of $\mathrm{CO}_{2}$ as a function of temperature $\left(\mathrm{T},{ }^{\circ} \mathrm{R}\right)$ is estimated using, $\mu_{g i}=a_{i} * T^{b i}$

where the values for two empirical constants $\mathrm{a}$ and $\mathrm{b}$ for are 5.0E-5 and 0.9 , respectively.

Rock properties (reservoir, overburden or underburden)

Mechanical compressibility, $\mathrm{psi}^{-1} \quad 5.0 \times 10^{-9}$

Heat capacity, $\mathrm{Btu} / \mathrm{ft}^{3 /}{ }^{\circ} \mathrm{F} \quad 35.0$

Thermal conductivity, Btu/ft/d/ ${ }^{\circ} \mathrm{F} \quad 29.0$

\section{A.2 Phase Equilibrium}

Details of the procedure for converting solubility data into equilibrium K-values are given here.

Gas-Liquid K-Values: Assuming a negligible fraction of oil in the gas phase $K_{\text {go }}$ may be expressed as,

$$
\begin{aligned}
& \mathrm{K}_{\mathrm{go}}=\frac{1}{\mathrm{x}_{\mathrm{go}}} \\
& \mathrm{x}_{\mathrm{go}}=\frac{\mathrm{n}_{\mathrm{go}}}{\left(\mathrm{n}_{\mathrm{go}}+\mathrm{n}_{\mathrm{o}}\right)}
\end{aligned}
$$




$$
\mathrm{n}_{\mathrm{go}}=\frac{\mathrm{S}_{\mathrm{go}}}{379}, \quad \mathrm{n}_{\mathrm{o}}=0.7536 \mathrm{lb} \text { mole } / \mathrm{bbl}
$$

where the subscripts $o, w$, and $g$ represent oil, water, and gas $\left(\mathrm{CO}_{2}\right)$, respectively. $\mathrm{n}, \mathrm{S}$ and $\mathrm{x}$ represent the number of moles, solubility $(\mathrm{SCF} / \mathrm{bbl})$ and mole fraction, respectively. $\mathrm{N}_{\mathrm{go}}$, as an example, represents number of moles of gas per bbl of oil. As mentioned before, values for solubility of $\mathrm{CO}_{2}$ in oil (SCF/bbl) were taken from data provided by Chung et al.(1988).

Similarly, assuming a negligible fraction of water in the gas phase $\mathrm{K}_{\mathrm{gw}}$ may be expressed as,

$$
\begin{aligned}
& \mathrm{K}_{\mathrm{gw}}=\frac{1}{\mathrm{x}_{\mathrm{gw}}} \\
& x_{g w}=\frac{n_{g w}}{\left(n_{g w}+n_{w}\right)} \\
& \mathrm{n}_{\mathrm{gw}}=\frac{\mathrm{S}_{\mathrm{gw}}}{379}, \quad \mathrm{n}_{\mathrm{W}}=19.46 \mathrm{lb} \text { mole } / \mathrm{bbl}
\end{aligned}
$$

Values for solubility of $\mathrm{CO}_{2}$ in water is given by Lake (1989: Fig. 7-23).

Liquid-Liquid K-Values: K-Values were calculated by using the following equation,

$$
\mathrm{K}_{\mathrm{ow}}=\frac{\mathrm{K}_{\mathrm{gw}}}{\mathrm{K}_{\mathrm{go}}}
$$




\section{Appendix B \\ ECONOMIC EVALUATION}

Procedures for detailed and simplified economic evaluations and economic data are given as follows:

\section{B.1 Detailed Economic Evaluation}

A spreadsheet program was developed for evaluating discounted cash flow (DCF) and net present value (NPV) of an oil recovery project on the basis history of injection and production data. The equations used in the model are briefly described here (Van Rensburg, 1986).

I. CAPITAL INVESTMENT

Capital Cost, $\$=$ Tangible Drilling Cost, $\$+$ Plant \& Equipment Cost, $\$+$ Working Capital, \$

II. GROSS REVENUE

Gross /Oil Revenue $(\$ /$ time $)=$ Oil Price $(\$ / b b l) \times$ Oil Production Rate $(b b l / t i m e)$

\section{TAXES}

Taxes $(\$ /$ time $)=$ Severance Tax $(\$ /$ time $)+$ Federal Income Tax $(\$ /$ time $)$ where,

Severance $\operatorname{Tax}=$ Severance Tax Rate $\mathrm{x}$ Gross Revenue

Federal Income Tax $=$ Federal Income Tax Rate $\mathrm{x}$ Taxable Income (\$/time)

Taxable Income $=$ Gross Revenue - Deductible Costs (\$/time) - Severance Tax

Deductibles $=$ Fixed Operating Costs $(\$ /$ time $)+$ Variable Operating Costs $(\$ /$ time $)+$ Financial Costs $(\$ /$ time $)+$ Intangible Drilling Costs $(\$ /$ time $)+$ Depreciation Allowance (\$/time) + Depletion Allowance (\$/time)+ Severance Tax

Fixed Operating Costs $=\mathrm{C}_{\mathrm{F}} \times$ Time,$\quad \mathrm{C}_{\mathrm{F}}=$ Fixed Operating Cost data $(\$ /$ day $)$

Variable Operating Costs:

Oil Treatment Costs (\$/time) $=C_{\text {Vo }} \times$ Oil Production Rate

Water Disposal Costs (\$/time) $=$ CVwD $\times$ Water Production Rate

Where $C_{V O}$ and $C_{V W D}$ are variable operating cost data for produced oil $(\$ / b b l)$ and water $(\$ / b b l)$, respectively.

Water Costs $(\$ /$ time $)=\mathrm{C}_{V W} \times$ Water Injection Rate (bbl/time)

Steam Costs $(\$ /$ time $)=$ CVs $\times$ Steam Injection Rate (bbl/time)

Gas Costs (\$/time) $=C_{V G} \times$ Gas Injection Rate (mcf/time)

Where $\mathrm{CVW}_{V \mathrm{~W}}, \mathrm{C}_{V S}, \mathrm{C}_{V G}$ are variable operating cost data for injected water $(\$ / \mathrm{bbl})$, steam $(\$ / \mathrm{bbl})$ and gas $(\$ / \mathrm{mcf})$, respectively. 
Only financial cost considered was the interest and the royalty was assumed to be zero because the lease owner was the operator.

Interest $=$ Interest Rate $\mathbf{x}($ Loan Amount - Cumulative Loan Payment), \$

Depreciation Allowance: Straight Line Method

Depreciation $=($ Purchase Price - Salvage Value $), \$$ / Expected Item Life

Salvage value was assumed nil and expected item life was considered to be 5 years or the life of the project.

Depletion Allowance: Percent Depletion Method

Depletion $=0.15 \times$ (Gross Revenues - Royalties)

To maintain simplicity only this method was considered.

IV. PROFIT

Profit $=$ Taxable Income - Federal Income Tux

V. LOAN PAYMENT

Loan Payment $=\frac{\text { Loan Amount }}{\text { Time Period of Payment }}$

VI. CASH FLOW ANALYSIS

Cash Flow $=$ Profit + Capital Recovery - Capital Investment - Loan Principal

Capital Recovery $=$ Depreciation + Depletion + Working Capital Return

Capital Investment $=$ Tangible Drilling Costs + Plant \& Equipment + Working Capital +

Amortized Capital

Discounted Cash Flow $=\frac{\text { Cash Flow }}{(1+\text { Discount Rate })^{1-1}}$

Net Present Value $=\mathrm{S}$ Discounted Cash Flow

\section{B.2 Simplified Economic Evaluation}

A simplified procedure was developed for conducting overall economic calculations on the basis of cumulative injection and production data and the time period of operation. First cumulative revenue and costs were calculated and then operating costs $(\$ / \mathrm{bbl})$ and net revenue $(\$)$ were estimated. These two parameters were used for comparing different projects. No history of DCF or NPV were estimated.

Total Operating Cost, $\$=$ Fixed Operating Costs, $\$+$ Variable Operating Costs, $\$$

Fixed and variable operating costs were estimated following the same procedure as mentioned above in detailed economic evaluation procedure but using cumulative data instead of monthly history data.

Operating Costs, $\$ / b b l=$ Total Operating Cost, $\$ /$ Cumulative Oil Production, bbl 
Net Revenue, $\$=($ Oil Price, $\$ / \mathrm{bbl}$ - Operating Cost, $\$ / \mathrm{bbl}) *$ Cumulative oil Production, bbl

\section{B.3 Economic Data}

Following economic data were assumed (Dowd, Kuuskraa and Godec, 1988),

Oil Price $=\$ 15.00 / \mathrm{bbl}$ Fixed Operating Cost $=\$ 25.00 /$ day

Oil Treatment Cost $=\$ 2.50 / \mathrm{bbl}$ Water Disposal Cost $=\$ 0.025 / \mathrm{bbl}$

Water Injection Cost $=\$ 0.05 / \mathrm{bbl}$ Steam Injection Cost $=\$ 1.50 / \mathrm{bbl}$

$\mathrm{CO}_{2}$ Injection Cost $=\$ 1.00 / \mathrm{mcf}$; when available through pipeline

$\mathrm{CO}_{2}$ Injection Cost $=\$ 3.00 / \mathrm{mcf}$, when available through tankers

$\mathrm{CO}_{2}$ Injection Cost $=\$ 0.45 / \mathrm{mcf}$, when available as recycled gas

Loan Amount $=\$ 10,000$

Severance Tax Rate $=5 \%$

Interest Rate on Loan $=10 \%$
Discount Rate $=10 \%$

Federal Income Tux rate $=33 \%$ 


\section{REFERENCES}

Andreen, G. M. An Evaluation of Oil Reserves, West Fairfield Field, Medina County, TX. A report prepared for Hydrocarbon Operating Company of America, 1967.

Aziz, K., B. Ramesh, and P. T. Woo. Fourth SPE Comparative Solution Project: A comparison of Steam Injection Simulators, JPT, December 1987, pp. 1576-1584.

Butler, R. M. Thermal Recovery of Oil and Bitumen, Prentice-Hall, Englewood Cliffs, New Jersey, October 1991.

Chu, C., State-of-the-Art Review of Steamflood Field Projects, JPT, October, 1985, pp. 1887 1902.

Chung, F. T. H., R. A. Jones, and H. T. Nguyen. Measurement and Correlations of the Physical properties of $\mathrm{CO}_{2} /$ Heavy-Crude-Oil Mixtures, SPERE, Aug. 1988, pp. 822-828.

Dowd, W. T., V. A. Kuuskraa and M. L. Godec. A Technical and Economic Assessment of Domestic Heavy Oils, DOE Report DOE/BC/1084()-1, January 1988.

Frizzell, D. F. Analysis of 15 years of Thermal Laboratory Data: Relative Permeability and Saturation Endpoint Correlations for Heavy Oils, SPE 20528, pres. at 65th ATCE of the SPE in New Orleans, LA, Sept. 23-26, 1990.

Gidley, J. L., S. A. Holditch, D. E. Nierode and R. W. Reatch Jr. Recent Advances in Hydraulic Fracturing, Monograph Series, SPE, Richardson, TX, 1989.

Harper, $M$ and S. Drake. An Evaluation of Oil Reserves, Hutzler " $C$ " Lease, Taylor-Ina Field, Medina County, Texas, a report prepared for J. H. Klaeger, February, 1993.

Hong, K. C and J. W. Ault. Effect of Noncondensible Gas Injection on Oil Recovery by Steamflooding, JPT, December, 1984, pp. 216()-2170.

Kantar, K., D. Karaoguz, K. Issever and K. Varana. Design Concepts of a Heavy-Oil Recovery Process by an Immiscible $\mathrm{CO}_{2}$ Application, JPT, February 1985, pp. 275-283.

Karaoguz, D., K. Issever, N. Pamir and A. Tirek. Performance of a Heavy-Oil Recovery Process by an Immiscible $\mathrm{CO}_{2}$ Application, Bati Raman Field, SPE 18002, pres. at MEOTCE of the SPE in Manama, Bahrain, Mar. 11-14, 1989.

Kasraie, M., P. H. Sammon and P. J. Jespersen. Field Development Options for a Waterflooded Heavy-Oil Reservoir, JPT, September 1993, p. 888.

Kazemi, H., L. S. Merrill, Jr., K. L. Porterfield and P. R. Zeman. Numerical Simulation of Water-Oil Flow in Naturally Fractured Reservoirs, SPEJ, December 1976, pp. 317-326.

Klaeger, J. H. Personal Communication, August 1993.

Martin, F. D. and J. J. Taber. Carbon Dioxide Flooding, JPT, April 1992, pp. 396-400.

Moffit, P. D. and D. R. Zornes. Postmortem Analysis: Lick Creek Meakin Sand Unit Immiscible $\mathrm{CO}_{2}$ Waterflood Project, SPE 24933, pres. at 67th ATCE of the SPE in Washington, DC, Oct. 4-7, 1992. 
Morgan, J. T. and D. T. Gordon. Influence of Pore Geometry on Water-Oil Relative Permeability, JPT, October 1970, pp. 1199-1208.

Oballa, V., D. A. Coombe and W. L. Buchanan. Factors Affecting The Thermal Response of Naturally Fractured Reservoirs, paper No. CIM/AOSTRA 91-53, pres. at the CIM/AOSTRA Technical Conference in Banff, Apr. 21-24, 1991.

Olenick, S., F. A. Schroeder, H. K. Haines and T. G. Monger-McClure. Cyclic $\mathrm{CO}_{2}$ Injection for Heavy-Oil Recovery in Halfmoon Field: Laboratory Evaluation and Pilot Performance, SPE 24645, pres. at 67th ATCE of the SPE in Washington, DC, Oct. 4-7, 1992.

Patton, J. T., K. H. Coats and K. Spence. Carbon Dioxide Well Stimulation: Part 1-A Parametric Study, JPT, August 1982, pp. 1798-1804.

Patton, J. T., P. Sigmund, B. Evans, S. Ghose and D. Weinbrandt. Carbon Dioxide Well Stimulation: Part 2 - Design of Aminoil's North Bolsa Strip Project, JPT, August 1982, pp. 1805-1810.

Reid, T. B. and H. J. Robinson. Lick Creek Meakin Sand Unit Immiscible $\mathrm{CO}_{2}$-Waterflood Project, SPE/DOE 9795, pres. at 2nd Joint EOR Symposium of the SPE in Tulsa, OK. Apr. 5-8, 1981.

Saner, W. B. and J. T. Patton. $\mathrm{CO}_{2}$ Recovery of Heavy Oil: Wilmington Field Test, JPT, July 1986, pp. 769-776.

Sarkar, A. K. and P. S. Sarathi. Feasibility of Steam Injection Processes in a Thin, Low. Permeability Heavy Oil Reservoir of Arkansas-A Numerical Simulation Study, a topical report, NIPER-661, December 1992.

Scheuerman, R. F. and B. M. Bergersen. Injection-Water Salinity, Formation Pretreatment, and Well-Operations Fluid-Selection Guidelines, JPT, July 199(), pp. 836-845.

Shelton, J. L. and E. E. Morris. Cyclic Injection of Rich Gas Into Producing Wells To Increase Rates From Viscous-Oil Reservoirs, JPT, August 1973, pp. 89()-896.

Stneppelwerth, G. P. Exhaust Gas Provides Alternative Gas Source for Cyclic EOR, Oil \& Gas Journal, Apr. 26, 1993, p. 68.

Van Rensburg, W. C. J. Economic Analysis in the Petroleum Industry, PEN 389 notes, University of 'Texas, Austin, TX, 1986. 
PART II

ASSESSMENT OF AN INDUSTRY DEVELOPED STEAMFLOOD PREDICTIVE MODEL

\author{
By P. S. Sarathi
}




\section{Chapter 6}

\section{EVALUATION OF MOBIL'S STEAMFLOOD PREDICTIVE MODEL}

\subsection{OBJECTIVE}

The objective of this task is to evaluate the steamflood performance prediction model developed by the Mobil Exploration and Production Company (Mobil E\&P) for its adequacy in describing the field performance and to make recommendations to DOE.

\subsection{BACKGROUND}

The steam injection technique has proven to be an effective means of recovering crude oil. Forecasts of reservoir response to steam are critical to an engineering evaluation of a proposed steam injection project. The engineering evaluation involves estimating overall project performance and economics. Although steamflood simulators can be used to forecast future reservoir performance and formulate operations strategy, they are computationally expensive, require the service of an experienced and knowledgeable engineer to interpret results and require information generally not readily available. Therefore, the sophisticated thermal simulators are inappropriate tools during the planning, screening and preliminary design stages of a thermal project. Thus, the incentive exists to develop simple models for screening candidate reservoirs for steam projects and forecasting reservoir behavior with less time and expense.

For steamflood projects, evaluation work requires models which accurately predict parameters such as oil production rate, steam injection requirements, oil/steam ratios (OSR), etc. Several predictive models exist in the literature for predicting these project performance indicators. A few of these models were developed using the reservoir characteristics of selected field projects and as such are useful in predicting performance of similar reservoirs. Others are quasi analytical models based on certain simplified assumptions, and these assumptions can greatly influence performance predictive ability of these models. The reported empirical and analytical predictive models, though capable of closely matching field production trends of projects whose process conditions are similar to the ones used in the model development, can fail completely if the situation is much different. Hence, nev'er models that strive to improve the predictive capability regardless of process conditions have continued to appear in the literature periodically.

Recently, Mobil E\&P developed a steamflood performance predictive model to improve the reliability of the performance estimates of their steam injection operations. This model was designed to run on a personal computer with minimum of data. Mobil has successfully tested this model using selected in-house field data and concluded that the model's results are superior to those reported in the literature. Mobil expressed their desire to place this model in the public domain through DOE and request NIPER to assess the model's capabilities. 
An in-depth evaluation of the predictive capabilities of the model was performed under varying conditions and its reliability assessed. The economic and field development options of the model were not tested. The results of that evaluation and recommendations are detailed in this chapter.

\subsubsection{Model Description1,2}

The predictive model utilizes three existing analytical steamflood models to determine steamflood performance. These include (a) the Jones ${ }^{3}$ frontal advanced model; (b) Farouq Ali's ${ }^{4}$ modified frontal advanced model, and (c) Miller and Leung's 5 vertical gravity override model. Major modifications were made to these basic models to better predict the field performance. The changes that were made to these models are those proposed by Chen and Sylvester. ${ }^{6}$ The principal features of these models are briefly discussed.

\subsubsection{Jones' Model $^{3}$}

Jones presented a steamdrive model based on the work of Van Lookeren ${ }^{7}$ and Myhill and Stegemeier. ${ }^{8}$ The model employs Van Lookeren's procedure to calculate the optimum steam injection rate and degree of steam override and a modified Myhill-Stegemeier approach to calculate oil production history for a given set of steam and reservoir parameters. The model estimates the average thermal efficiency of the steam zone using the Marx and Langenheim ${ }^{9}$ solution for the early time (i.e., prior to the critical time) and the Mundl-Volek ${ }^{10}$ procedure for the later time when the heat transfer due to condensation becomes significant. The model employs a number of empirical factors to account for the three major stages of production which have been observed in most commercial steamdrive.

The first stage is dominated by the initial oil viscosity and the oil production lags due to fill up of any gas volume or to the formation of an oil bank. The second stage of oil production is dominated by hot oil mobility and the production rate is essentially the displacement rate. The peak production rate occurs at this stage and the duration of this stage is controlled by the amount of oil left in the pattern and heating efficiency. The third stage is characterized by a decline in oil production and the duration of this stage is determined by the remaining mobile oil in place.

The empirical parameters in the Jones' model are determined by adjusting the field performance data.

\subsubsection{Farouq Ali's Model ${ }^{4}$}

Farouq Ali's model is a modified frontal advanced model that accounts for steam gravity override and other dominant steamflood mechanisms. Unlike the Jones' model, it does not employ any empirical parameters. Like Jones, the model utilizes Van Lookeren's method to calculate the vertical conformance of steam, and the Mandl-Volek method for calculating the steam zone 
volume. The model uses material and energy balances to account for preheating of the unswept formation. It also takes into consideration the relative-permeability effects and the lateral and vertical advancement of steam zone with time. At any instant of time during the production, the model predicts both oil and water production, displacement rates, steam zone shape, thickness and volume, the heated zone average temperature and the oil and water saturations. The model calculates the relitive permeabilities using correlations presented by Gomma. ${ }^{11}$ Since Gomma's correlations were derived using Kern River field data, the original Farouq Ali's model predicts the performance of reservoirs similar to Kern River better than other fields.

Farouq Ali's model though superior to other analytical model in its predictive ability requires several parameters such as residual oil saturation $\left(S_{\text {or }}\right)$, steamflood residual oil saturation ( $\left.S_{\text {orst }}\right)$, steam saturation in the steam zone $\left(\mathrm{S}_{\mathrm{Sr}}\right)$ etc., which are normally unknown and must be estimated or defaulted using acceptable values. Also, the model predictions are very sensitive to the relative permeability data and as such must be adjusted to obtain a satisfactory production rate and saturation profile. The original model as presented by Farouq Ali had several errors. Chen ${ }^{12}$ modified the model by correcting these errors and added features that removed some of the shortcomings of the original model.

\subsubsection{Miller-Leung Model ${ }^{5}$}

This is a simple gravity override steamflood model and is based on the concept presented by Neuman 13,14 and Vogel. ${ }^{15}$ The model assumes a complete vertical overlaying of steam zone with a steam-condensate zone between the steam zone and the oil zone below. The temperature distribution within the condensate and oil zones are calculated using a one-dimensional unsteadystate heat conduction expression. The modei utilizes a gravity drainage type mechanism augmented by oil viscosity reduction (because of the conductive heating from the steam zone) to calculate oil production. This model also takes into consideration the oil produced from the condensate zone. This region, neglected by other models, contributes substantially to production in reservoirs with high initial oil saturation.

Miller and Leung found thei model to be most applicable to thick reservoirs $(>50 \mathrm{ft}$ ) with small dip angles $\left(<10^{\circ}\right)$, low oil gravity (10-20 API), small patterns ( $<10$ acres) and moderate oil viscosity $(1,000-5,000 \mathrm{cP})$. The model utilizes two empirical factors to estimate the condensate zone thickness and areal sweep efficiency. Both of these factors have a substantial effect on the calculated oil production rate and must be adjusted to obtain a satisfactory history match.

\subsubsection{Methodology}

The following general calculation procedure was adopted by Mobil in their model to determine the fluid production. ${ }^{1}$ This methodology is similar to the one proposed by Farouq Ali. ${ }^{4}$

1. The vertical conformance was estimated using the Van Lookeren's ${ }^{7}$ method. 
2. The volume of the steam zone and its content were calculated using the Mandl-Volek procedure. ${ }^{10}$ Material and energy balances were utilized to estimate the amount of heat that goes into the unswept formation and to calculate the average temperature of the heated zone.

3. The volume of oil and water displaced from the steam zone, the steam zone thickness and its volume were calculated using Farouq Ali's procedure. The relative permeabilities for the upswept zone were estimated with Gomma's generalized correlations and the fluids produced according to their mobility. Finally, the saturations in the unswept zone (after production) were updated before calculations for the next time interval are begun.

4. The steam zone growth is assumed downward after steam breakthrough. The steam zone growth rate is estimated based on net heat injection after allowing for either steam venting out of the producer or steam leaving the pattern boundaries.

5. The calculations are terminated when the steam zone reaches the bottom of the pay zone.

\subsubsection{Model Features}

Based on the above methodologies, Mobil E\&P designed a user-friendly, menu driven steamflood predictive model that permits an engineer to rapidly evaluate the performance of a reservoir under continuous steam injection. The program interface was designed to accommodate novice engineers who are unfamiliar with the process.

The program is driven from a central menu panel. From this panel, the various calculation routines are accessed. These include (a) minimum steam requirements, (b) steam zone shapes, (c) performance prediction, (d) economic calculations, and (e) field development plans. The production performance or the economic calculations can be displayed graphically using the plot option. The model can be utilized to:

- determine the minimum heat requirements

- perform parametric sensitivity studies

- import externally developed production data

- export a report for external manipulation

- scale-up or plan a phased field development

- forecast project economics

- assess the impact of risk.

Further details on the model features and options can be found in references 1 and 2.

\subsubsection{Model Evaluation}

A compiled version of the program was obtained from Mobil E\&P and its predictive ability was evaluated by comparing model's results with actual performance of 13 steamdrive projects. This included 9 California reservoirs and 4 non-California reservoirs. Data for all field cases were collected from the literature. The missing data were estimated. A template of the model's data 
requirement is shown in Table 6.1. The field data are shown in Table 6.2. No attempt was made to history match the field production data. Instead, the evaluation was made by comparing the model's production trend with that of the field and to check whether the model qualitatively exhibited the same trend as the field. The computation time for all cases investigated was less than a minute on a $486 / 33$ PC.

The performance prediction for a few selected cases studied are compared with the field results in Figs. 6.1 through 6.22. These comparisons were for Farouq Ai's model, since no empirical factors or adjustable parameters were needed for this model. With minor tuning of selected parameters, the model was able to predict the production trend of California reservoirs. It was also found that in general, Farouq Ali's model was superior to Jones' or Miller-Leung's model in predicting production trends.

None of the analytical methodology in the model, however, was able to adequately predict the production trend of non-California reservoirs. Two reasons may be cited for the model's inferior predictive capabilities with respect to non-California steam projects. First, the model was able to describe the California steam projects more effectively because the various correlations used in the model to describe oil production and other performance indicators were developed using the reservoir characteristics and operating conditions of California steamdrive projects. Second, the steam injection projects implemented in the non-California reservoirs were designed to accommodate the unique features of those reservoirs. For example, in the Slocum field, Anderson County, Texas, steam is injected into the aquifer and the oil is mobilized by the conduction of heat from the aquifer and not by frontal displacement. Since the model does not account for this unique operating feature, its predictive capability is inadequate to describe the performance of such projects.

\subsection{CONCLUSIONS AND RECOMMENDATIONS}

1. Mobil's steamflood predictive model with its user-friendly interface and excellent graphic capabilities incorporate many options that are absent from other similar models and would be a valuable for users in the petroleum industry.

2. The model in its current form gives reasonably good prediction and can be used to predict performance of steamflood projects in California.

3. The model poorly predicts the steamflood performance of projects whose reservoir and operating characters are vastly different from the California type projects.

4. For California reservoirs, use of the Farouq Ali model is recommended for predicting steamflood production when field production history is not available.

5. The user's manual that accompanied the program lacks in detail and needs to be revised.

6. It : recommended that DOE acquire this model and modify it to improve its predictive capability for non-California projects before placing it in the public domain. 


\subsection{NOMENCLATURE}
$A=$ Area, acres
API $=$ specific gravity of oil at $60^{\circ} \mathrm{F}$, dimensionless
$\mathrm{C}_{\mathbf{i}}=$ specific heat of phase $\mathrm{i}, \mathrm{Btu} / \mathrm{lbm}-{ }^{\circ} \mathrm{F}$
$\mathrm{f}_{\mathrm{cp}}=$ condensed steam produced, fraction
$\mathrm{h}_{\mathrm{n}}=$ net zone thickness, $\mathrm{ft}$
$\mathrm{h}_{\mathrm{t}}=$ gross zone thickness, $\mathrm{ft}$
$i_{\text {st }}=$ steam injection rate, cold water equivalent, BWPD
$\mathrm{K}_{\mathrm{h}}=$ thermal conductivity of cap rock and base rock, Btu/ft-hr- ${ }^{\circ} \mathrm{F}$
$\mathrm{K}_{\mathrm{ro}}=$ relative permeability to oil, fraction
$\mathrm{K}_{\mathrm{rw}}=$ relative permeability to water, fraction
$q_{0}=$ oil production rate, $B O P D$
$\mathrm{q}_{\mathrm{oi}}=$ pre-steam oil production rate, $\mathrm{BOPD}$
$\mathrm{q}_{\mathrm{w}}=$ water production rate, $\mathrm{BWPD}$
$S_{0}=$ oil saturation, fraction
$S_{\text {oi }}=$ initial oil saturation, fraction
$S_{\text {or }}=$ residual oil saturation, fraction
$S_{\text {orst }}=$ steamflood residual oil saturation, fraction
$S_{\text {os }}=$ steam zone oil saturation, fraction
$S_{\text {st }}=$ steam saturation in the steam zone, fraction
$S_{w}=$ water saturation, fraction
$S_{\text {wir }}=$ irreducible water saturation, fraction
$\mathrm{T}_{\mathrm{s}}=$ steam temperature, ${ }^{\circ} \mathrm{F}$
$\mathrm{T}_{\mathrm{R}}=$ initial formation temperature, ${ }^{\circ} \mathrm{F}$

\section{Creek Symbols}

$\alpha=$ reservoir thermal diffusivity, $\mathrm{ft}^{2} /$ day

$\phi \quad=$ porosity, dimensionless

$\rho=$ density of phase $\mathrm{i}, \mathrm{lbm} / \mathrm{ft}^{3}$

$\tau=$ lag time, days

$\mu=$ viscosity, $\mathrm{cP}$

$\mu_{\mathrm{oi}}=$ oil viscosity at initial reservoir condition, $\mathrm{cP}$

Subscript
avg = temperature condition
$\mathbf{s}=$ steam phase
$\mathrm{n}=$ net
sdh $=$ steam at downhole condition
$\mathrm{R}=$ rock phase
$\mathrm{t}=$ total, gross
$0=$ oil phase
$\mathbf{w}=$ water phase 


\subsection{REFERENCES}

1. Harrigal, R. L. and G. G. Wilcox. An Improved Steamflood Analytical Modeling Tool: Updating Old Methodologies with New Approaches to Increase Engineering Productivity, pres. at the Seventh SPE Petroleum Computer Conference, Houston, TX, July 19-22, 1992. Paper SPE 24434.

2. Harrigal, R. L. and G. G. Wilcox. SCOPE, User's Manual, Mobil E\&P U.S. Inc., Bakersfield, CA.

3. Jones, J. Steam Drive Model for Hand-Held Programmable Calculators, J. Pet. Tech., September 1981, pp. 1583-1598.

4. Farouq Ali, S. M. Steam Injection Theories-A Unified Approach, pres. at California Regional Meeting of the SPE, San Francisco, CA, Mar. 24-26, 1982. SPE paper 10746.

5. Miller, M. A. and W. K. Leung. A Simple Gravity Override Model of Steamdrive, pres. at the 60th Annual Tech. Conf. and Exhib. of the SPE held in Las Vegas, Sept. 22-25, 1985. SPE paper 14241.

6. Chen, H. L. and N. D. Sylvester. Appraisal of Analytical Steamflood Models, pres. at the 60th California Regional Meeting, Ventura, CA, Apr. 4-6, 1990. SPE paper 20023.

7. van Lookeren, J. Calculation Methods for Linear and Radial Steam Flow in Oil Reservoir, pres. at the 52nd Tech. Conf. and Exhib., Denver, CO, Oct. 9-12, 1977. SPE paper 6788.

8. Myhill, N. A. and Stegemeier, G. A. Steam-Drive Correlation and Prediction, J. Pet. Tech., February 1978, pp. 173-182.

9. Marx, J. W. and G. A. Langenheim. Reservoir Heating by Hot Fluid Injection, Trans., AIME, 1959, v. 216, pp. 312-315.

10. Mandl, G. and C. W. Volek. Heat and Mass Transport in Steam-Drive Processes, Soc. Pet. Eng. J, March 1969, v. 46, pp. 59-79; Trans., AIME.

11. Gomma, E. E. Correlation for Predicting Oil Recovery by Steamflood, J. Pet. Tech., February 1980, pp. 325-332.

12. Chen, H. L. Analytical Modeling of Thermal Oil Recovery by Steam Simulation and Steamflooding, Ph.D. Dissertation, The University of Tulsa, Tulsa, OK, 1987.

13. Neuman, C. H. A Mathematical Model of Steam Drive Process-Application, pres. at the California Regional Meeting of the SPE, Ventura, Apr. 2-4, 1975. SPE paper 4757.

14. Neuman, C. H. A Gravity Override Model of Steamdrive, J. Pet. Tech., January 1985, pp. 163-169.

15. Vogel, J. V. Simplified Heat Calculations for Steamfloods, J. Pet. Tech., July 1984, pp. $1127-1135$. 
TABLE 6.1

Template of Data Requirements for Mobil's Predictive Model

Case Name:

Case Description:

Pattern area, acres

Gross thickness, $\mathrm{ft}$

Net thickness, $\mathrm{ft}$

Porosity, fraction PV

Current oil saturation, fraction PV

Current water saturation, fraction PV

Current reservoir temperature, ${ }^{\circ} \mathrm{F}$

Volumetric heat capacity of reservoir, Btu/cu- $\mathrm{ft}-{ }^{\circ} \mathrm{F}$

Volumetric heat capacity of overburden (OB), Btu/cu-ft- ${ }^{\circ} \mathrm{F}$

Thermal conductivity of $\mathrm{OB}, \mathrm{Btu} / \mathrm{hr}-\mathrm{ft} \cdot{ }^{\circ} \mathrm{F}$

Diffusivity of $\mathrm{OB}$, sq-f $\mathrm{f} / \mathrm{hr}$

Injection wellbore radius, $\mathrm{ft}$

Injection well skin

steam injection rate, BSPDCWE

Downhole steam quality, fraction

Steam temperature, ${ }^{\circ} \mathrm{F}$

Irreducible water saturation, fraction PY

Residual oil saturation to water, fraction

Residual oil saturation to steam, fraction

API gravity of oil

Oil viscosity at reservoir temperature, $\mathrm{cP}$

Oil viscosity at steam temperature, $\mathrm{cP}$

Steam permeability, Darcies

Areal sweep efficiency, fraction

\section{Additional Input Requirement for Vogel-Miller-Leung Model}

Pre-steam oil rate, bbl/d

Gross production limit, bbl/d

Fraction of condensate production, 0.6 to 1.0

Additional Input Requirement for Jones Mode]

Base oil rate, bbl./d

Base oil rate, nominal decline, bbl/d

Base steam rate, nominal decline, $\% / y r$

Empirical Equation Inpus

Defaults Provided are Modifications of Original Jones Method

Stage 1 Capture Adiustment:

Gas saturation fill-up exponent. (default=1.0)

Stage 2 Capture Adiustment:

Hot oil mobility exponent. (default $=1.0$ )

Stage 3 Capture Adiustment:

Oil bank arrival factor. (default-2.32) 
TABLE 6.1-Continued

Data Requirements for Mobil's Predictive Model

$\begin{array}{ll}\text { Input Requirement for Faroua Ali Model } \\ \text { Permitted Range } \\ \text { Min } & \text { Max } \\ 1.25 & 10.0 \\ 50.0 & 500.0 \\ 50.0 & 500.0 \\ 0.25 & 0.38 \\ 0.52 & 0.75 \\ 0.25 & 0.48 \\ 0.0 & 0.15 \\ 80.0 & 135.0 \\ & \\ 30.0 & 42.0 \\ 33.0 & 42.0 \\ 0.7 & 1.2 \\ 0.02 & 0.03 \\ 0.33 & 0.53 \\ -3.0 & 3.0 \\ 50.0 & 3000.0 \\ 0.5 & 0.8 \\ 300.0 & 600.0 \\ & \\ 0.15 & 0.35 \\ 0.4 & 0.15 \\ 0.0 & 0.35 \\ & \\ 10.0 & 15.0 \\ 500.0 & 100 \mathrm{M} \\ 0.5 & 10.0 \\ & \\ 0.1 & 0.5 \\ 0.75 & 1.0 \\ 5.0 & 1000.0 \\ & \\ & \\ & \\ & \\ & \\ & \\ & \\ & \end{array}$

Description

Pattern area, acres

Gross thickness, $\mathrm{ft}$

Net thickness, $\mathrm{ft}$

Porosity, fraction

Current oil saturation, fraction

Current water saturation, fraction

Current gas saturation, fraction

Current reservoir temperature, ${ }^{\circ} \mathrm{F}$

\section{Thermal-Rock Data}

Volumetric heat capacity of sand. (Btu/cu-ft- ${ }^{\circ} \mathrm{F}$ )

Volumetric heat capacity of $\mathrm{OB}\left(\mathrm{Btu} / \mathrm{cu}-\mathrm{ft}-{ }^{\circ} \mathrm{F}\right)$

Thermal conductivity of $\mathrm{OB}\left(\mathrm{Btu} / \mathrm{hr}-\mathrm{ft}-{ }^{\circ} \mathrm{F}\right)$

Thermal diffusivity of $\mathrm{OB}$ (sq $\mathrm{fthr}$ )

Injection well radius, $\mathrm{ft}$

Injection well skin, dimensionless

Injection rate, BPDCWE

Steam quality, fraction

Steam temperature, ${ }^{\circ} \mathrm{F}$

Belative Permeability Data

Irreducible water saturation, fraction, PV

Residual oil saturation to water, fraction, PV

Residual oil saturation to steam, fraction, PV

\section{Qil Data}

Oil API gravity

Oil viscosity at reservoir temperature, $\mathrm{cP}$

Oil viscosity at steam temperature, $\mathrm{cP}$

Qther Miscellaneous Data

Effective permeability to steam, Darcy

Areal sweep efficiency, fraction

Steam vent rate, post SBT, BSCWEPD 


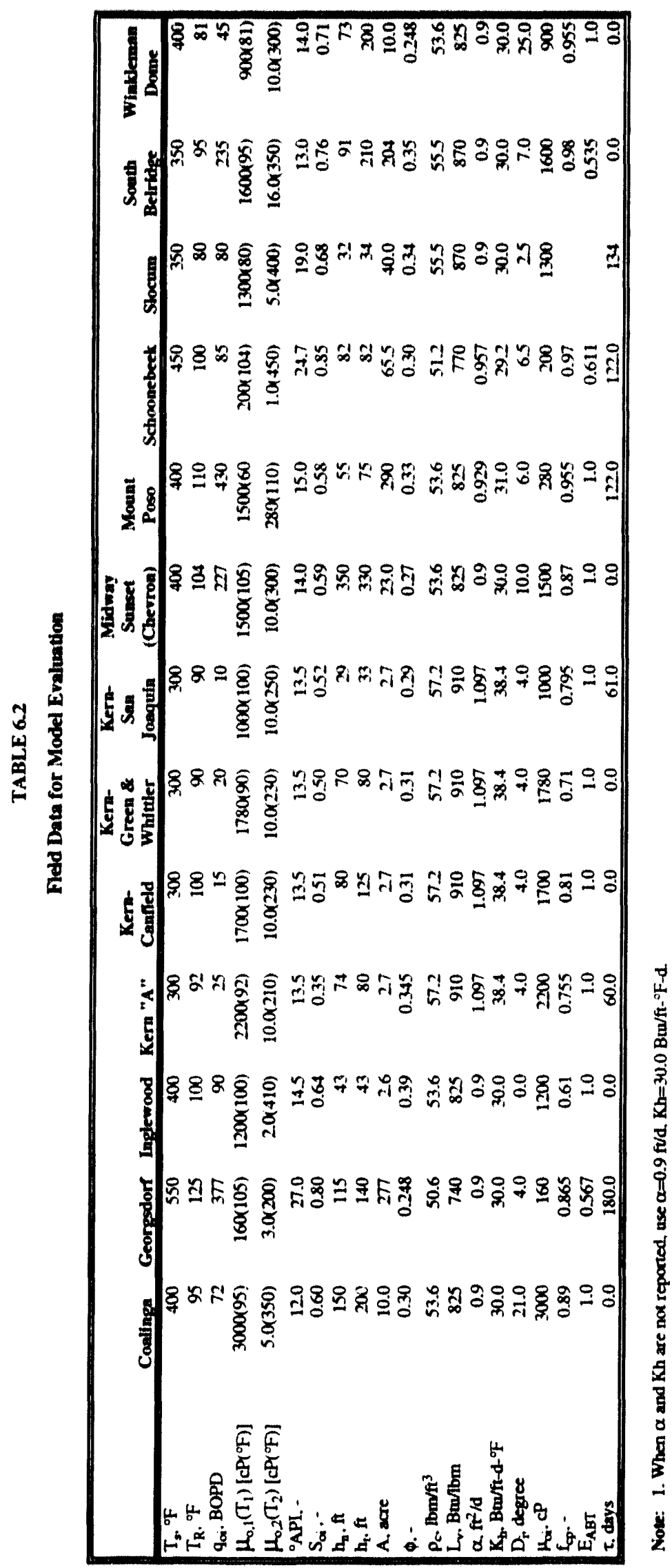




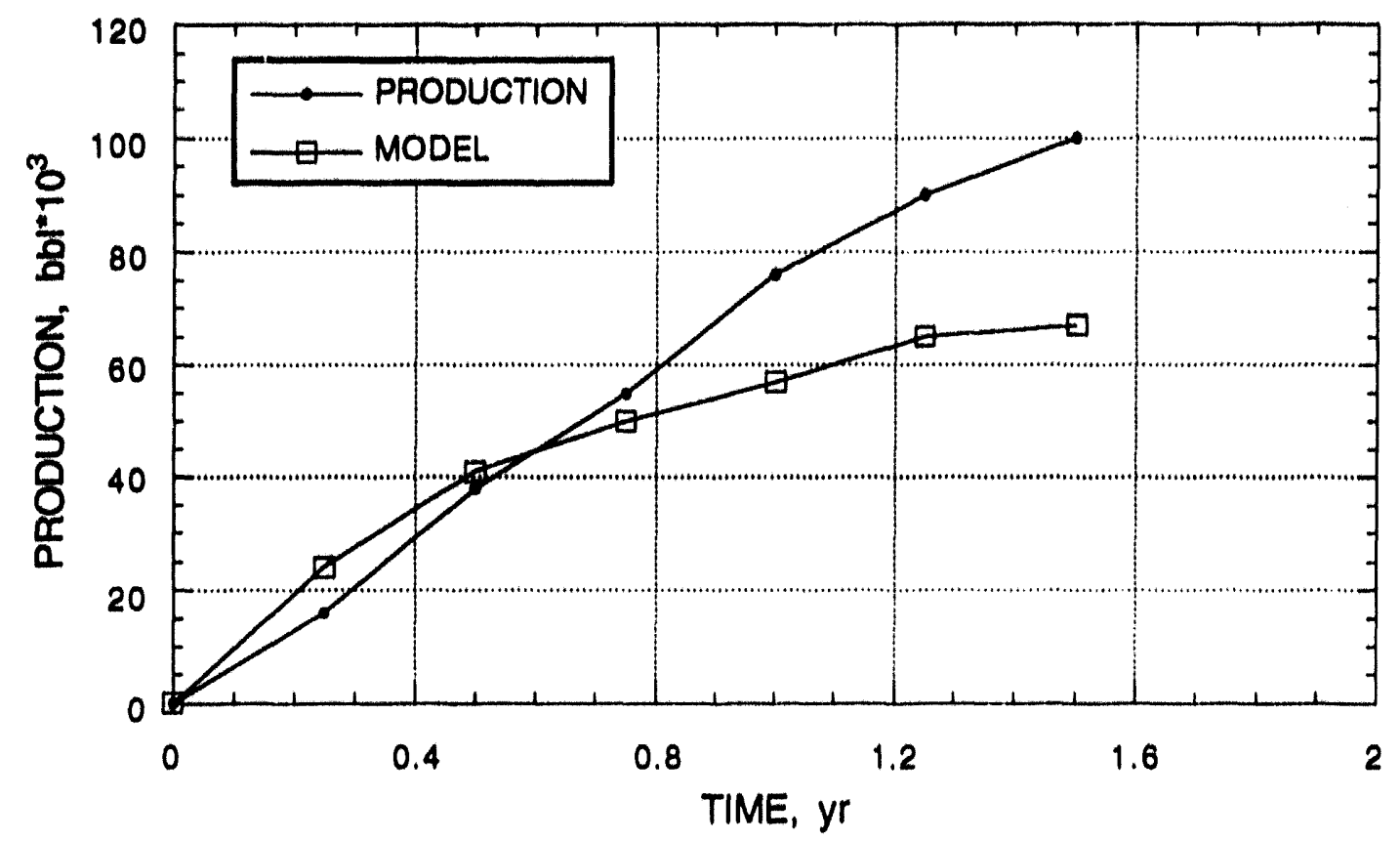

FIGURE 6.1 - Comparison of predicted and observed cumulative oil productionInglewood Field, CA.

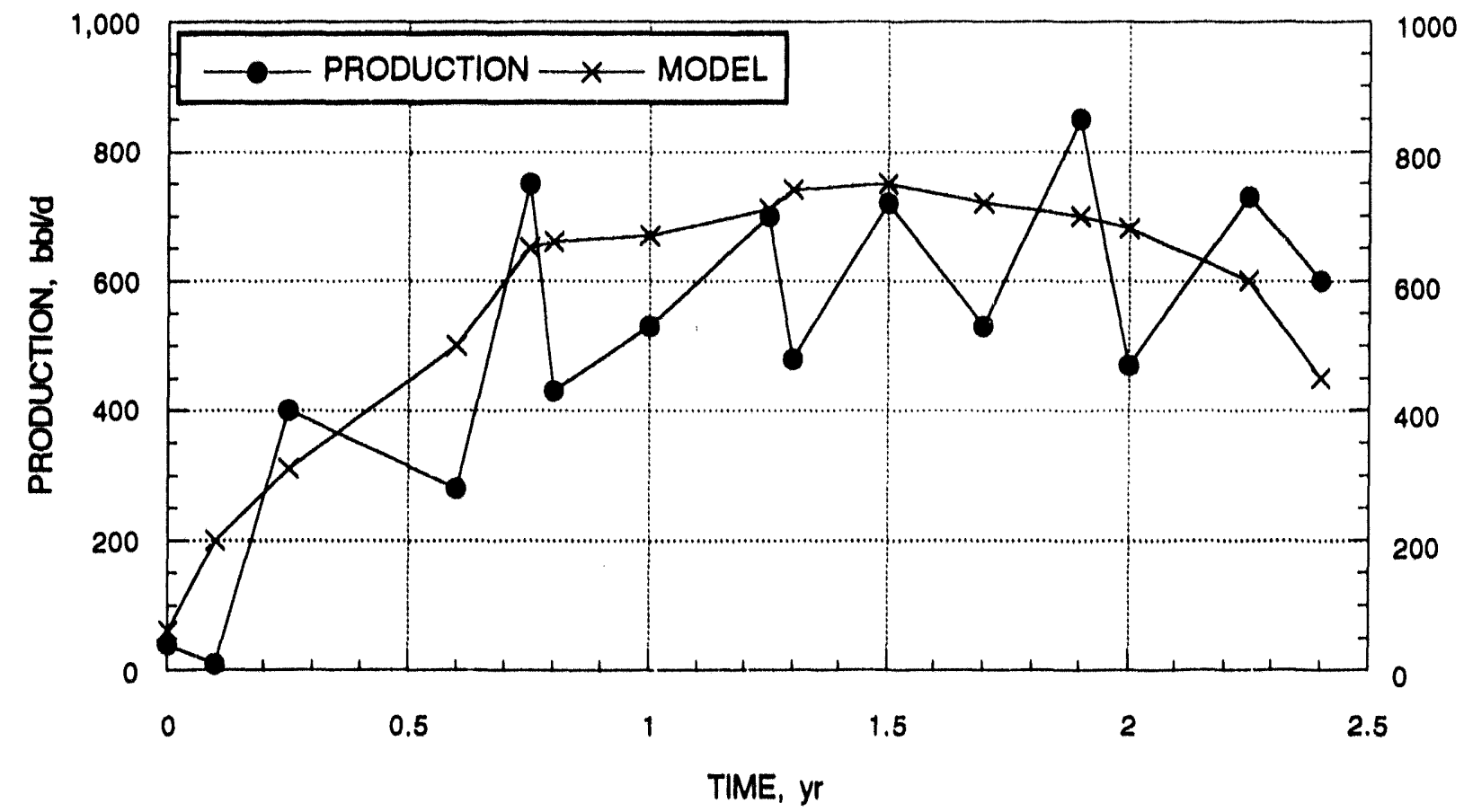

FIGURE 6.2 - Comparison of predicted and observed daily oil production rate-Coalinga Field, CA. 


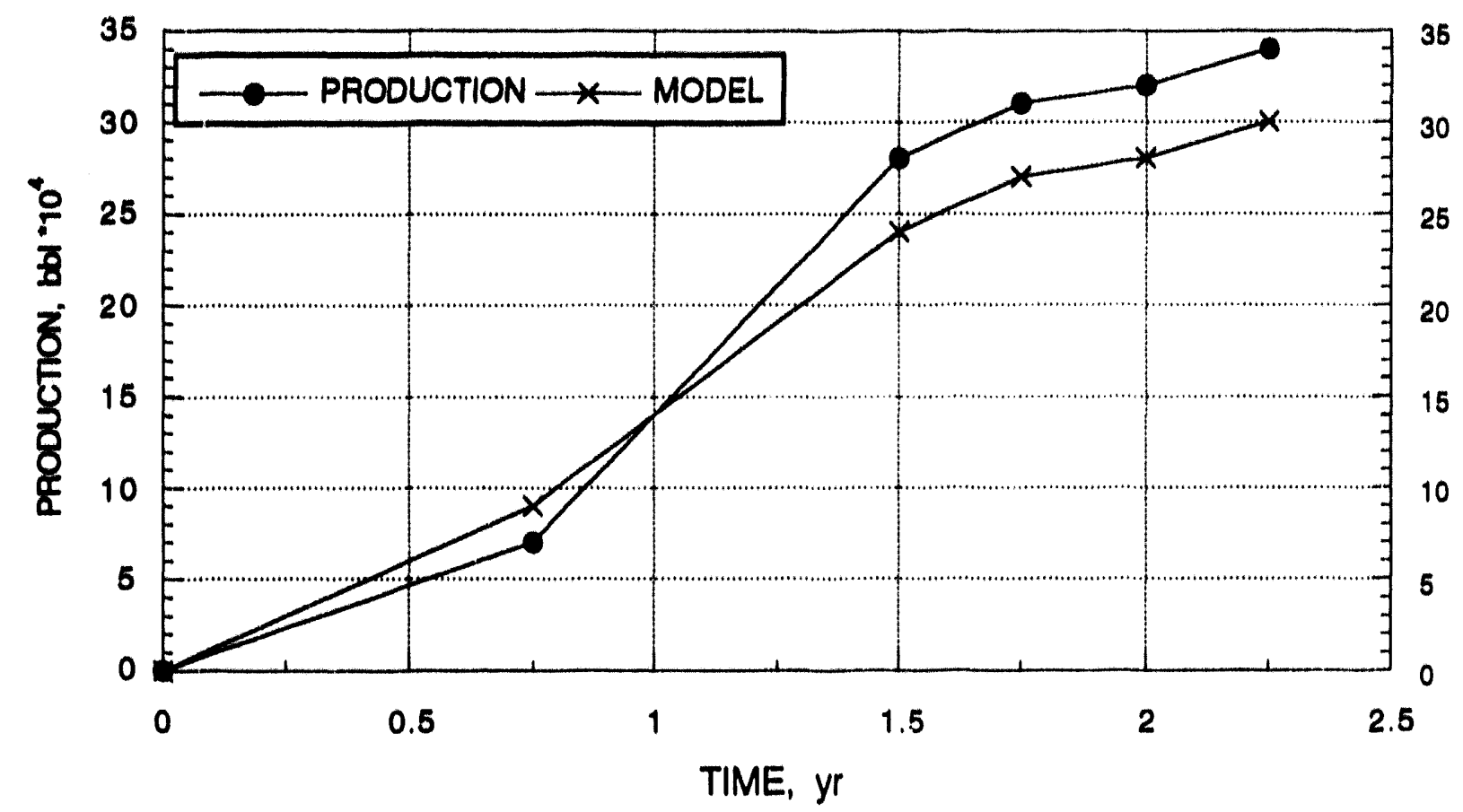

FIGURE 6.3 - Comparison of predicted and observed cumulative oil production-Coalinga Field, CA.

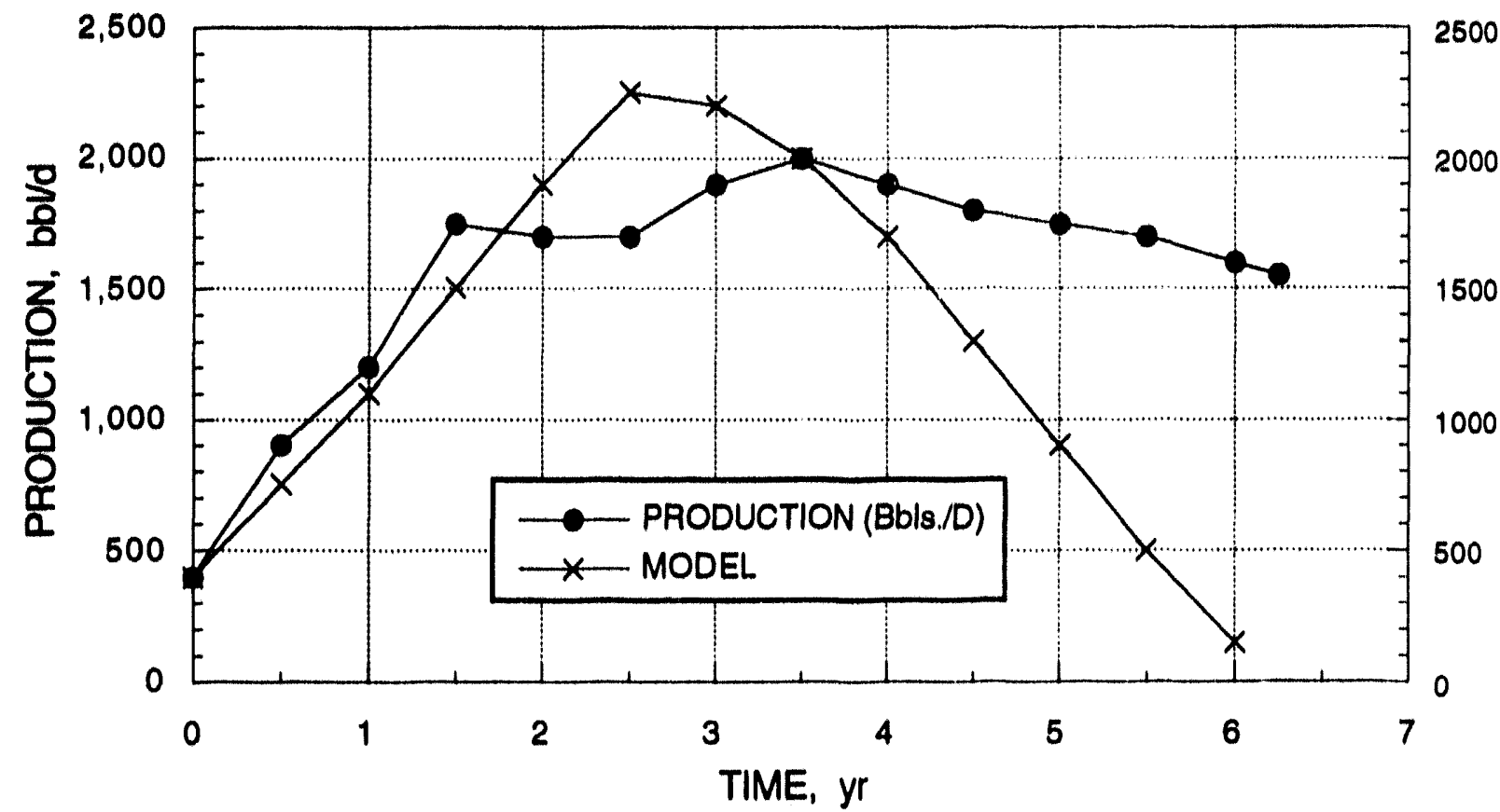

FIGURE 6.4 - Comparison of predicted and observed daily oil production rate-Georgsdorf Field, Germany. 


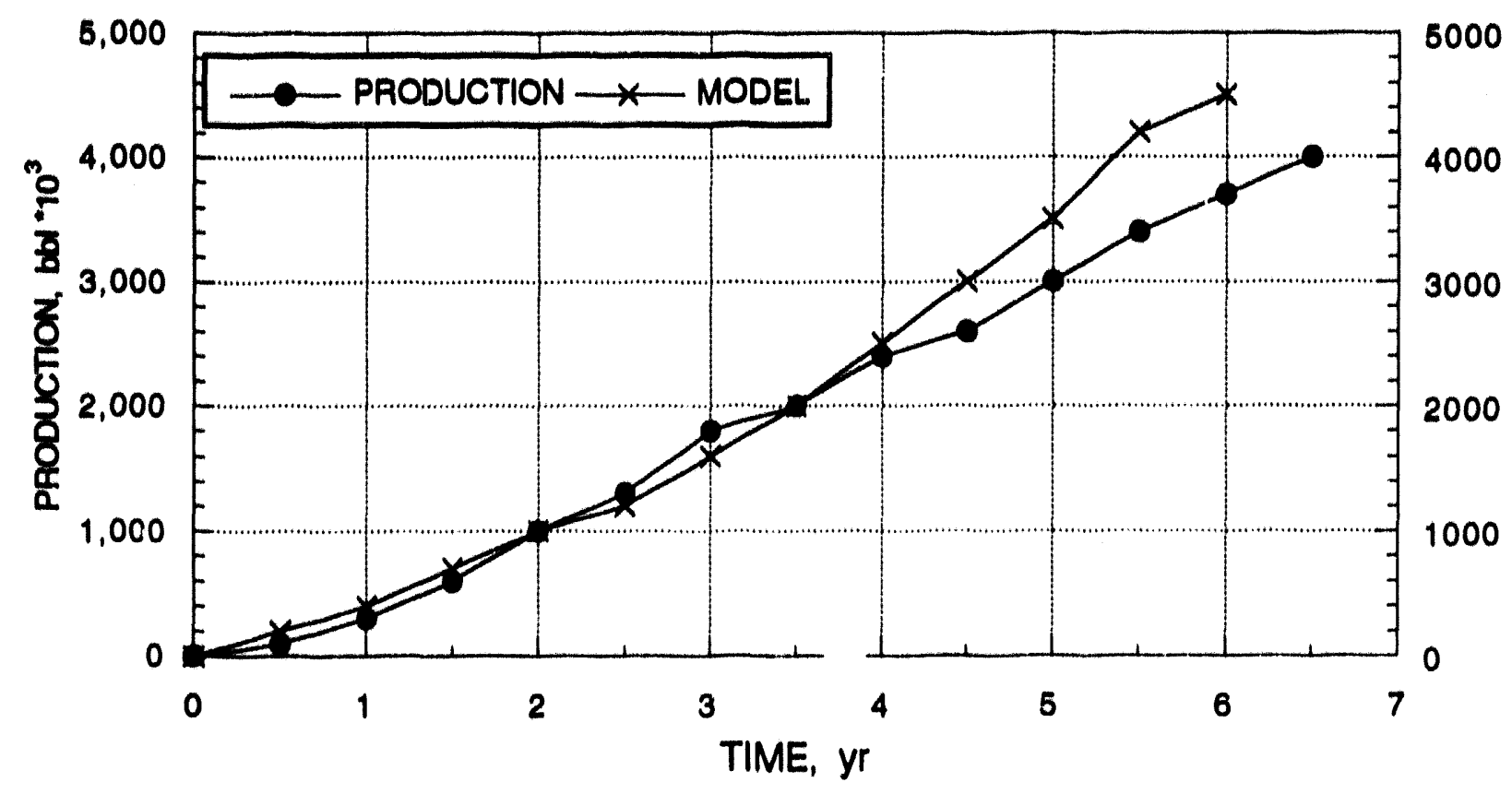

FIGURE 6.5 - Comparison of predicted and observed cumulative oil production-Georgsdorf Field, Germany.

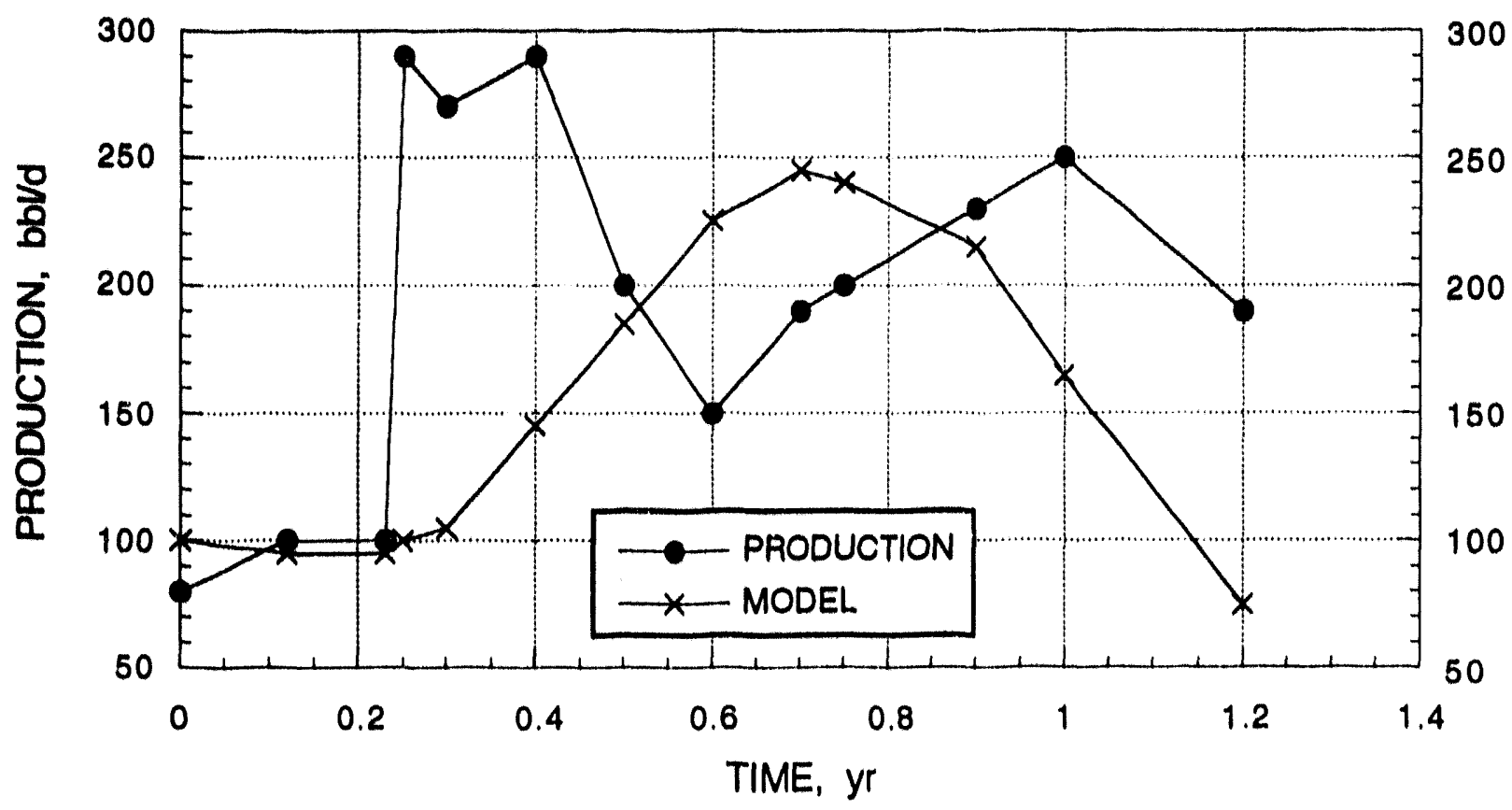

FIGURE 6.6 - Comparison of predicted and observed daily oil production rates-Inglewood Field, CA. 


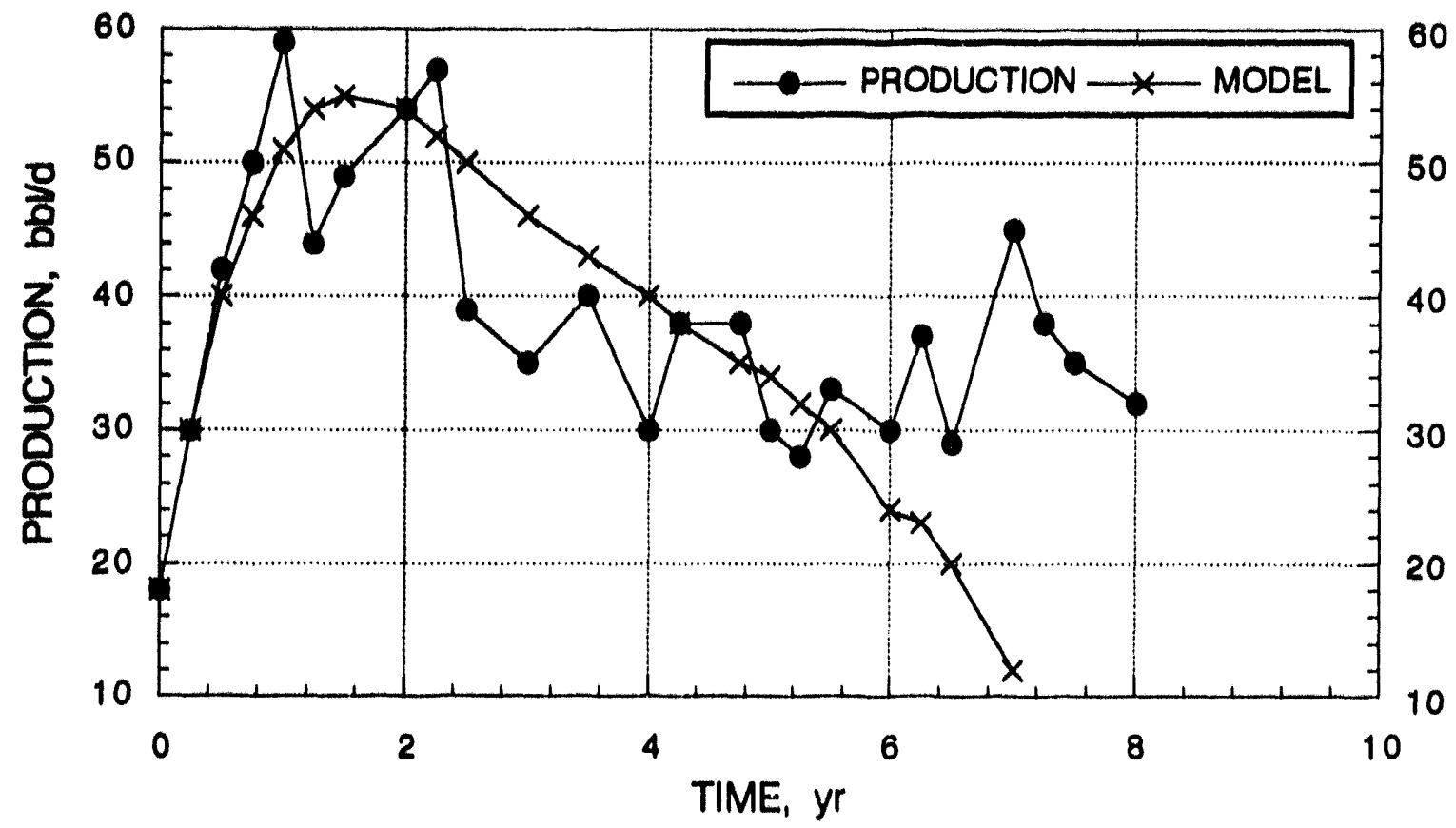

FIGURE 6.7 - Comparison of predicted and observed daily oil production rates-Kern (Green and Whitter Data) Field, CA.

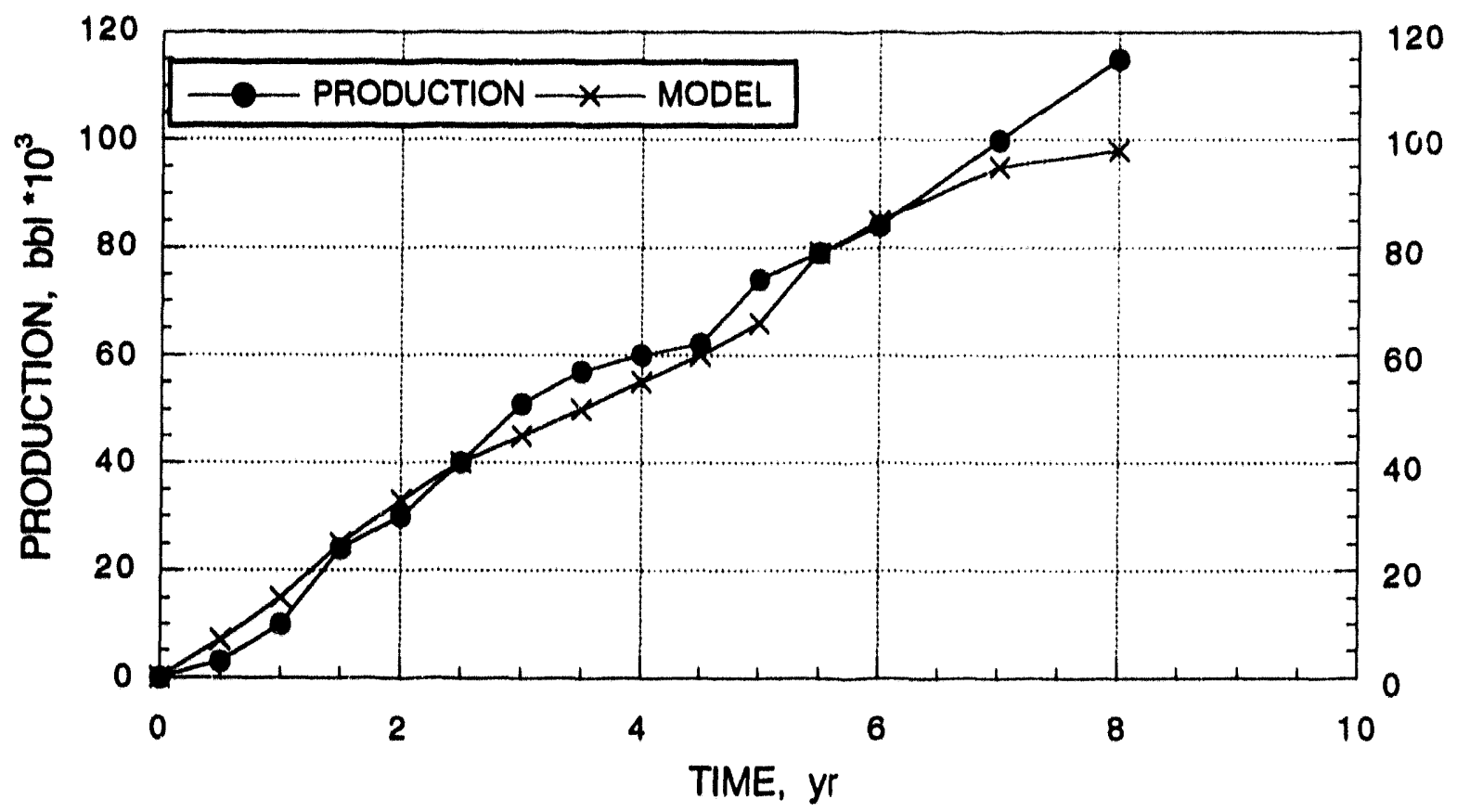

FIGURE 6.8 - Comparison of predicted and observed cumulative oil production-Kern Field, CA (Green and Whitter Data). 


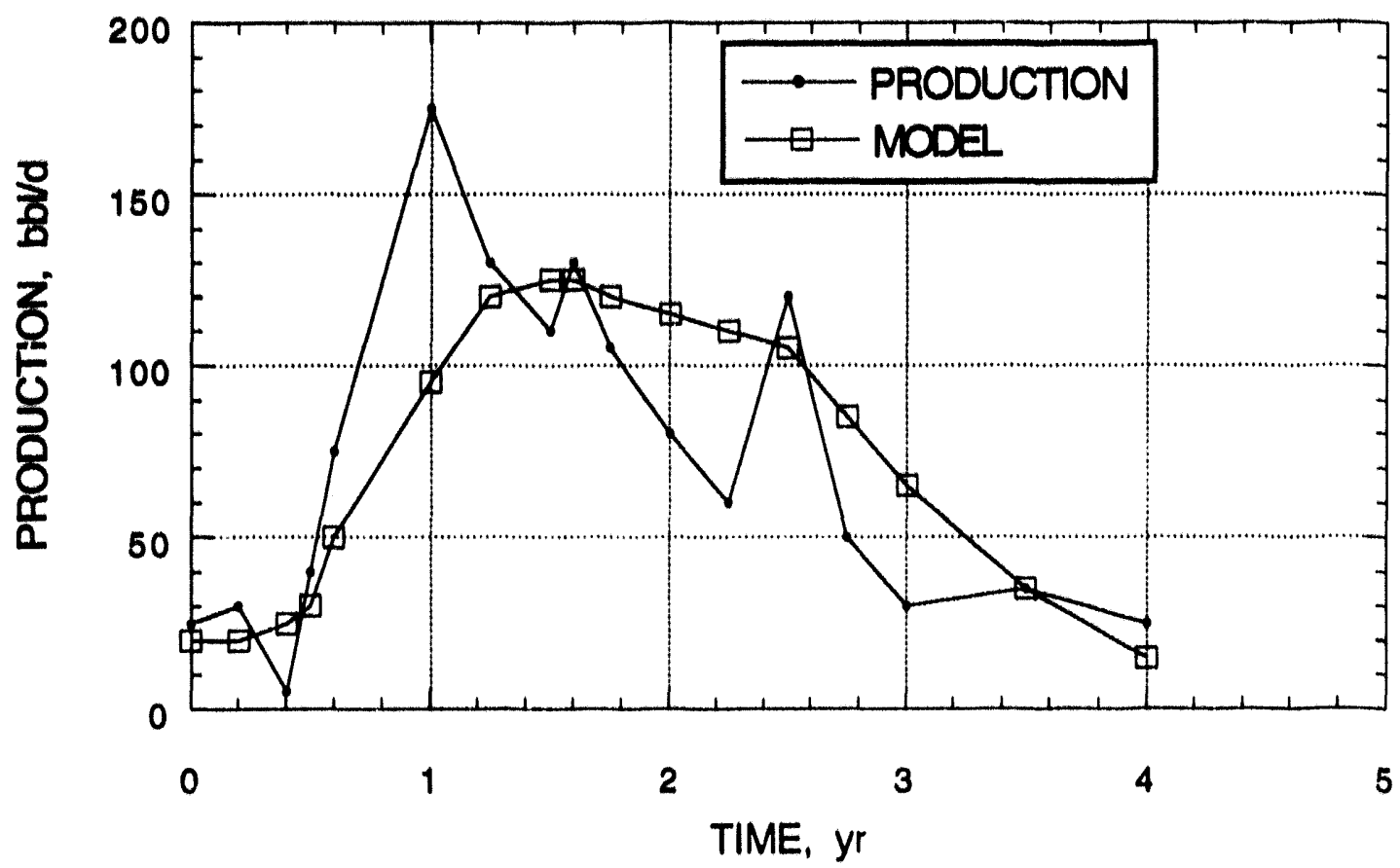

FIGURE 6.9 - Comparison of predicted and observed daily oil production rateKern 'A' Field, CA.

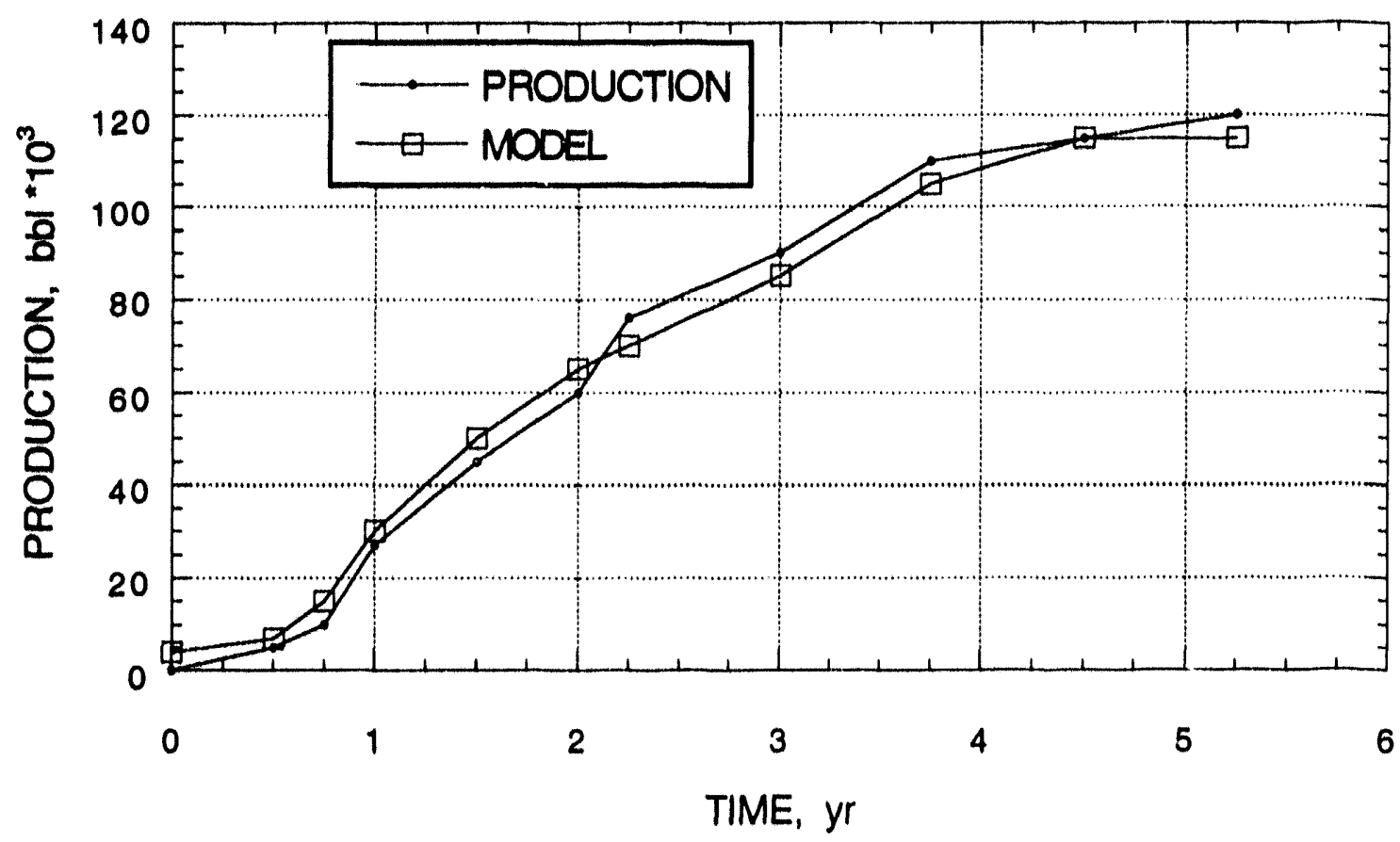

FIGURE 6.10 - Comparison of predicted and observed cumulative oil proauctionKern 'A' Field, CA. 


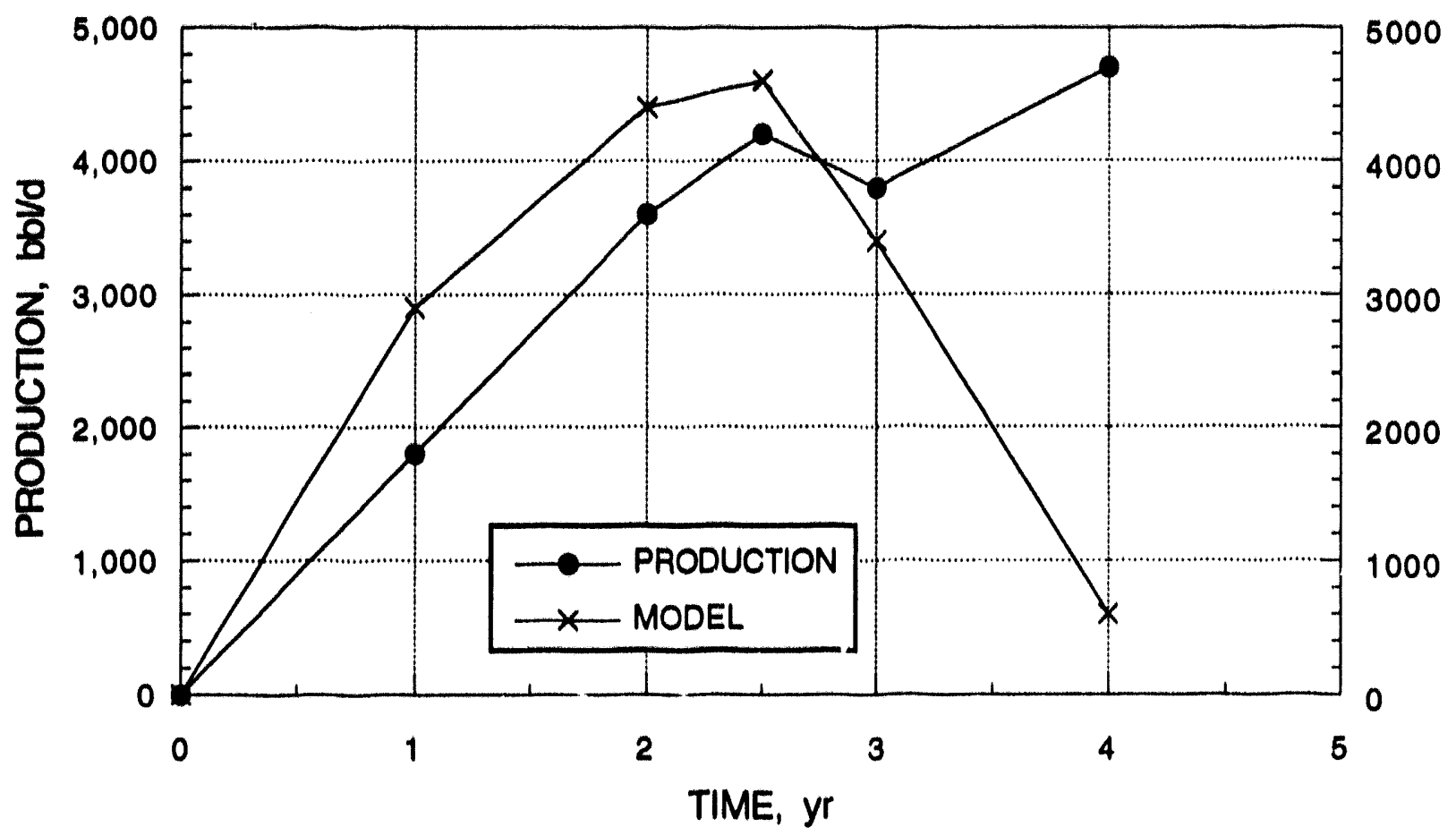

FIGURE 6.11 - Comparison of predicted and observed daily oil production rates-Mount Poso Field, CA.

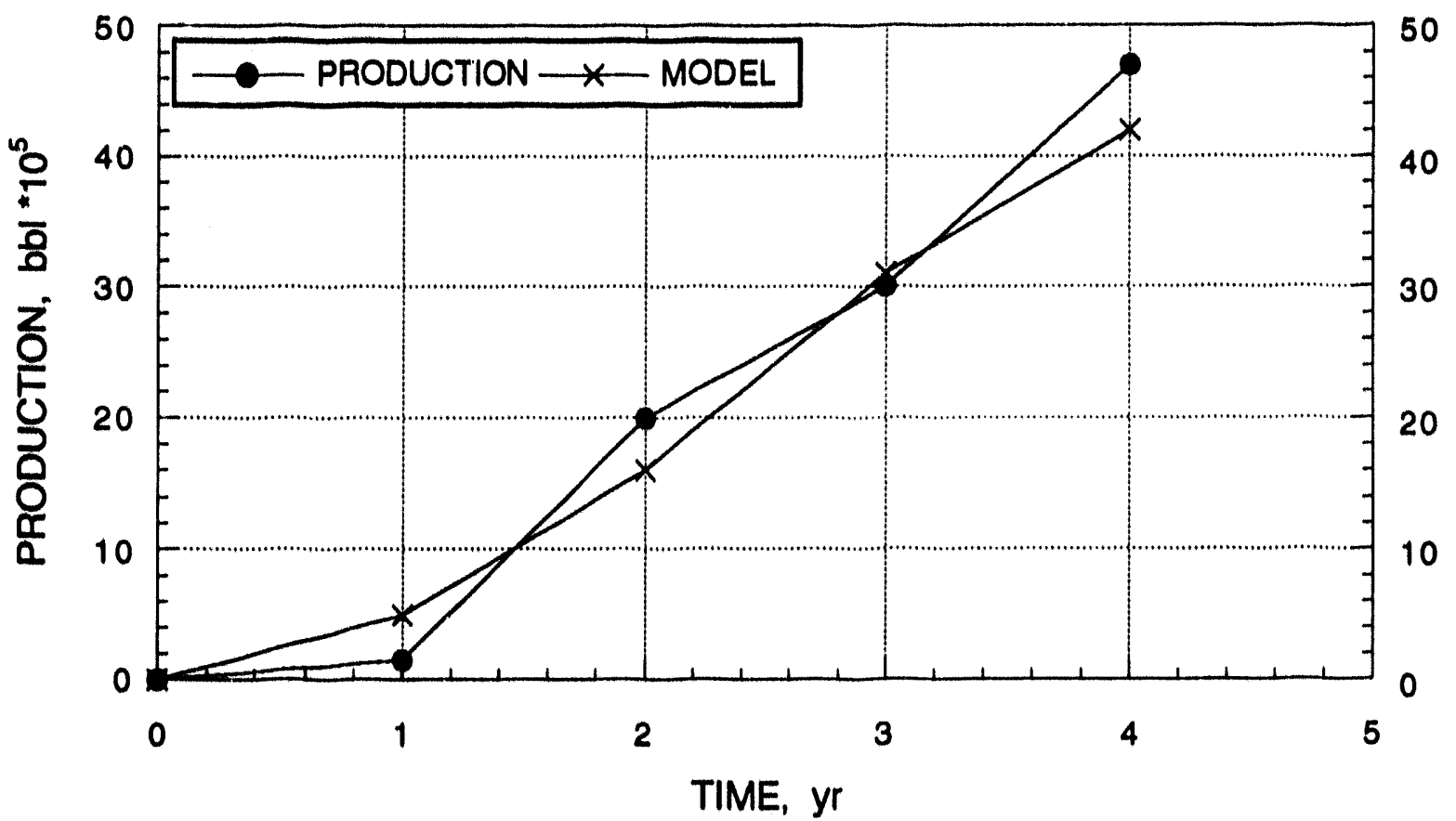

FIGURE 6.12 - Comparison of predicted and observed cumulative oil productionMount Poso Field, CA. 


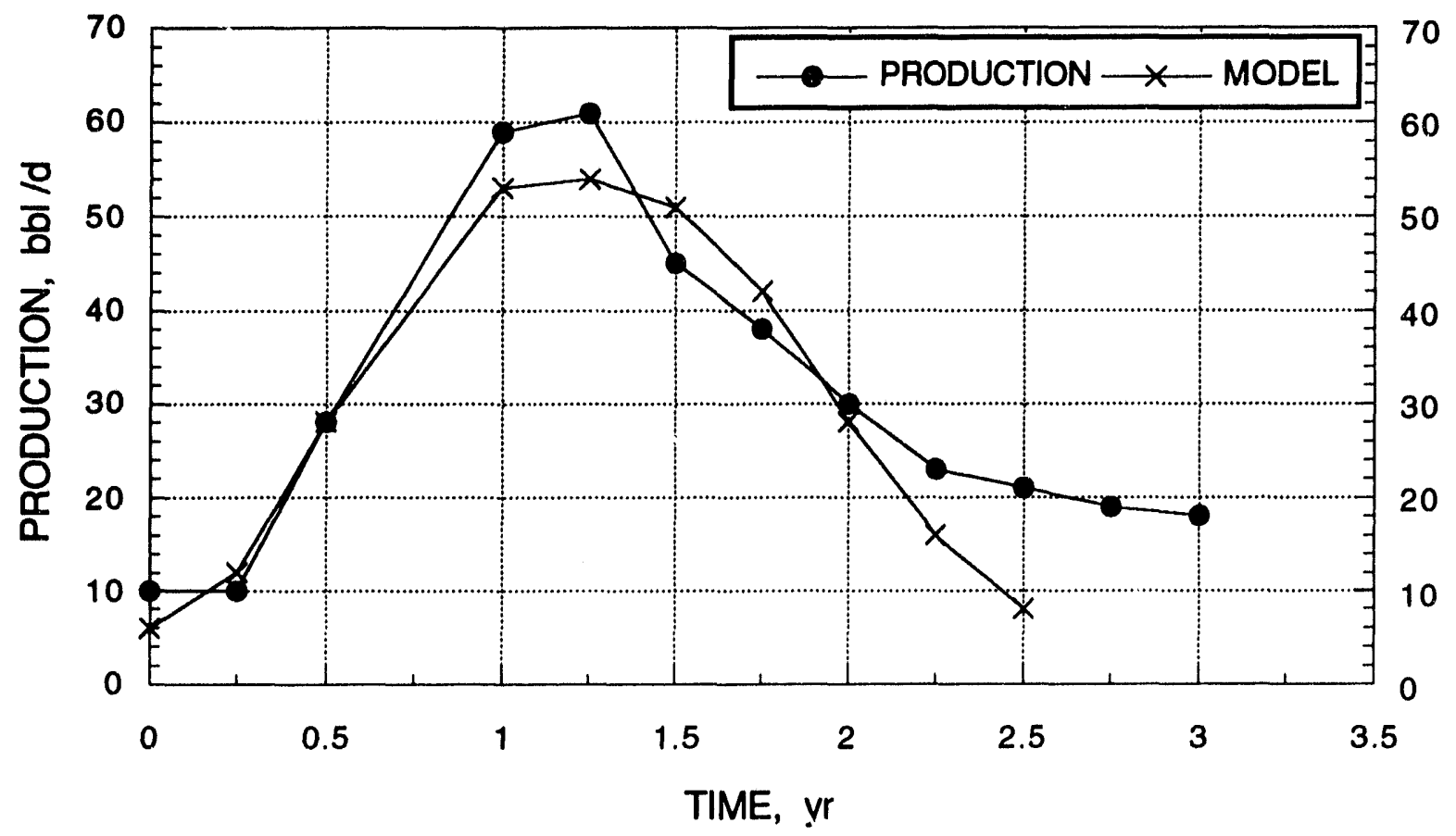

FIGURE 6.13 - Comparison of predicted and observed daily oil production rates-San Joaquin (Kern River) Field, CA.

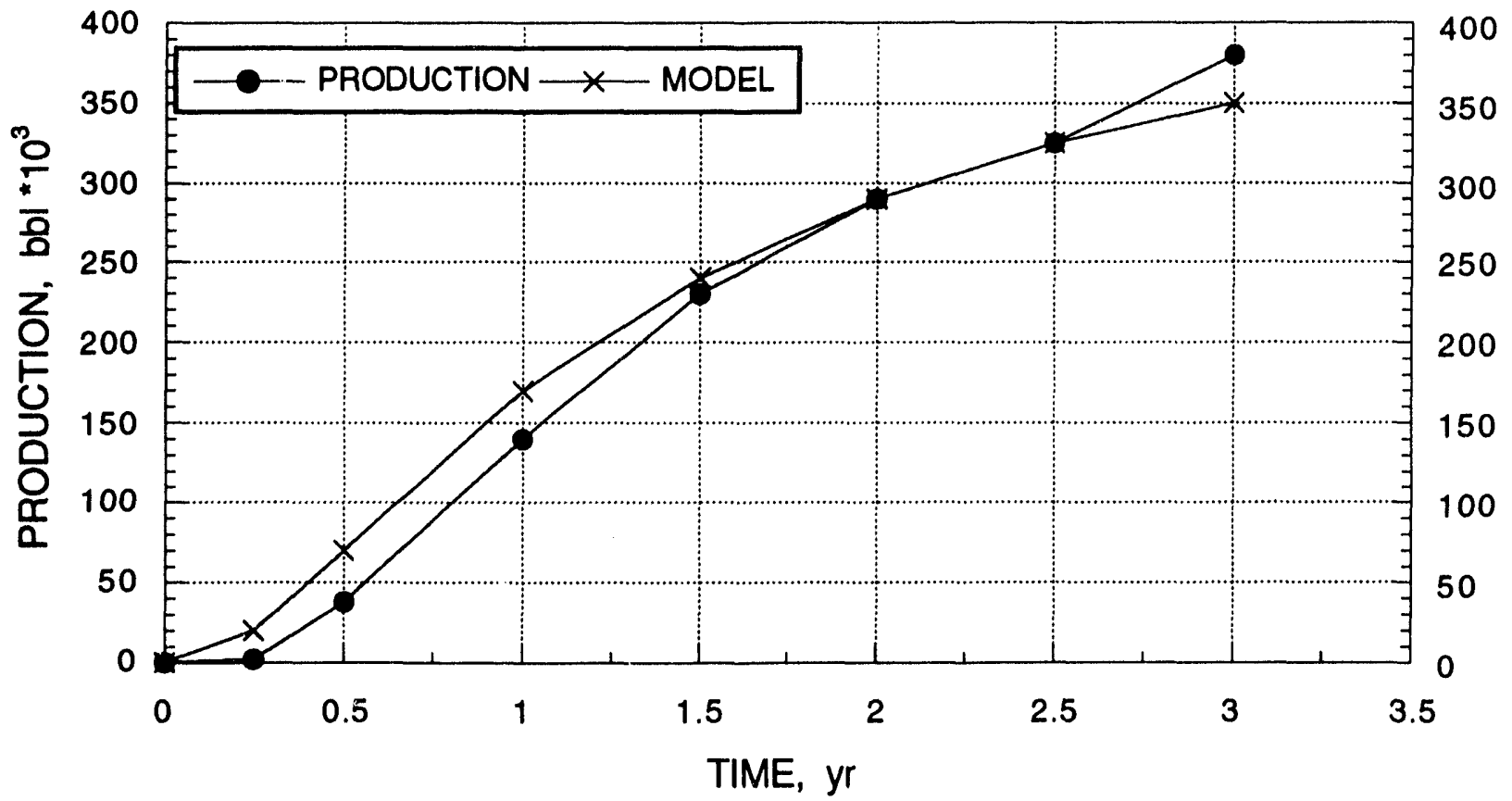

FIGURE 6.14 - Comparison of predicted and observed cumulative oil production-San Joaquin (Kern River) Field, CA. 


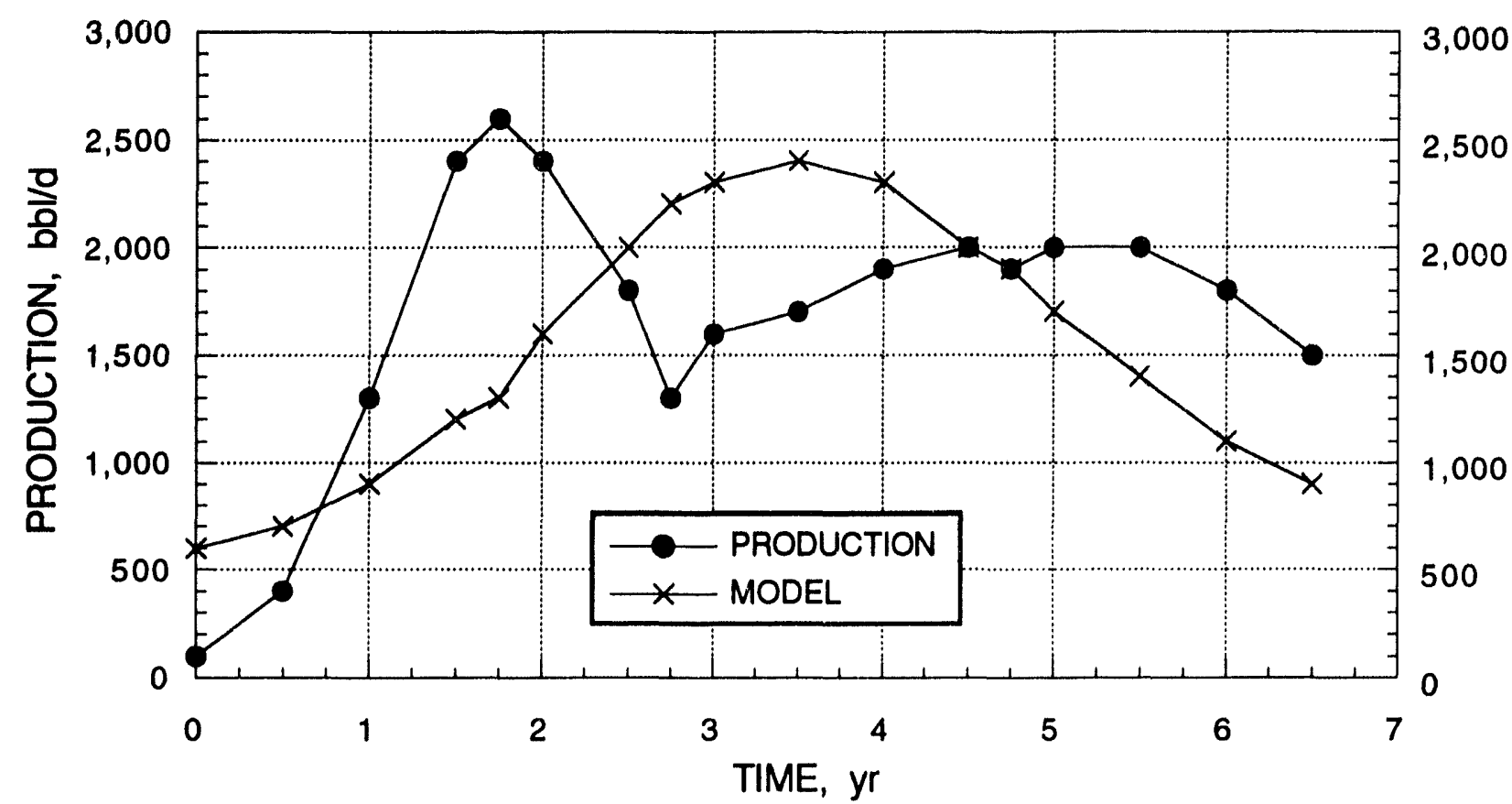

FIGURE 6.15 - Comparison of predicted and observed daily oil production ratesSchoonebeek Field, The Netherlands.

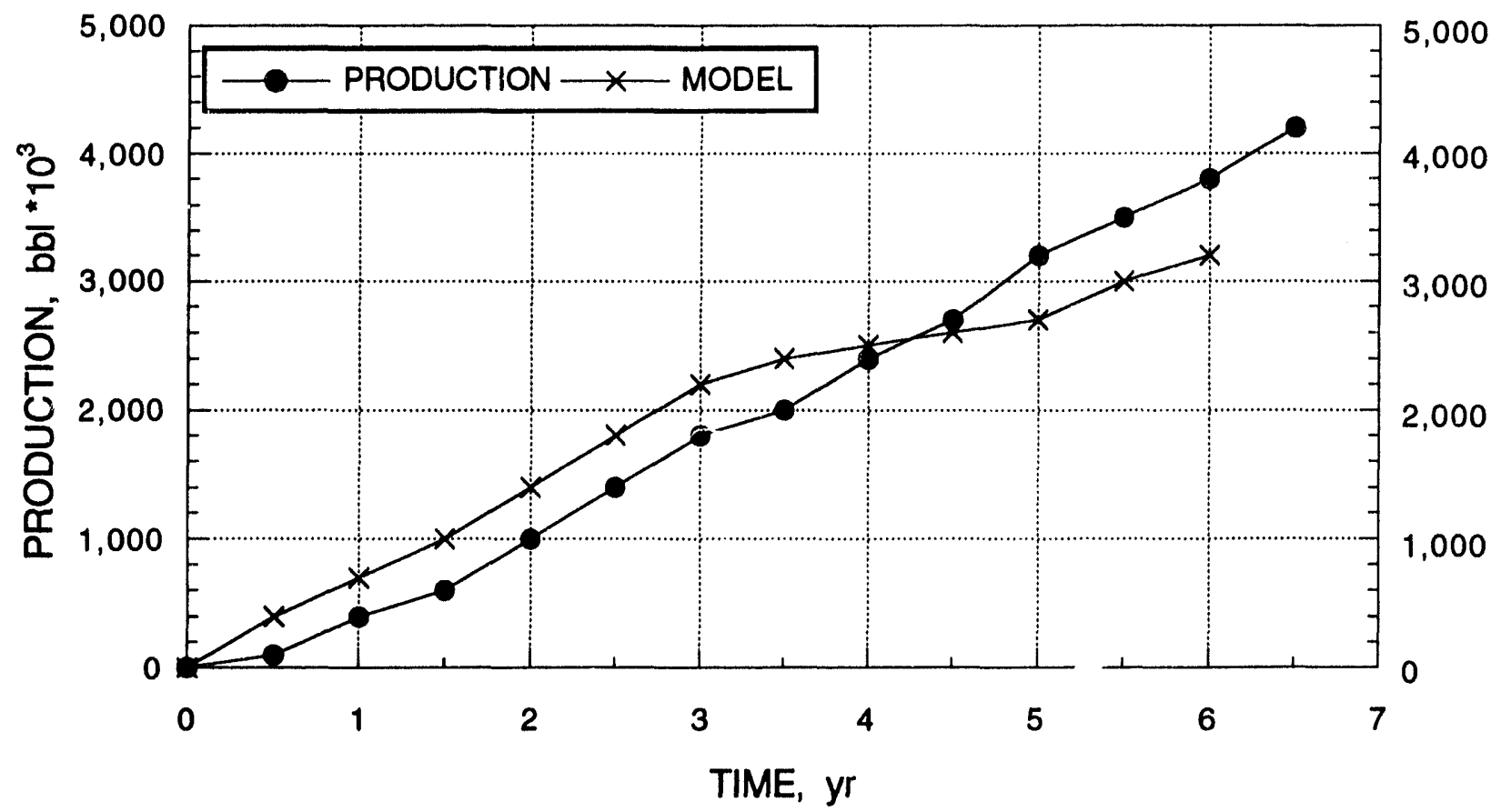

FIGURE 6.16 - Comparison of predicted and observed cumulative oil production-Schoonebeek Field, The Netherlands. 


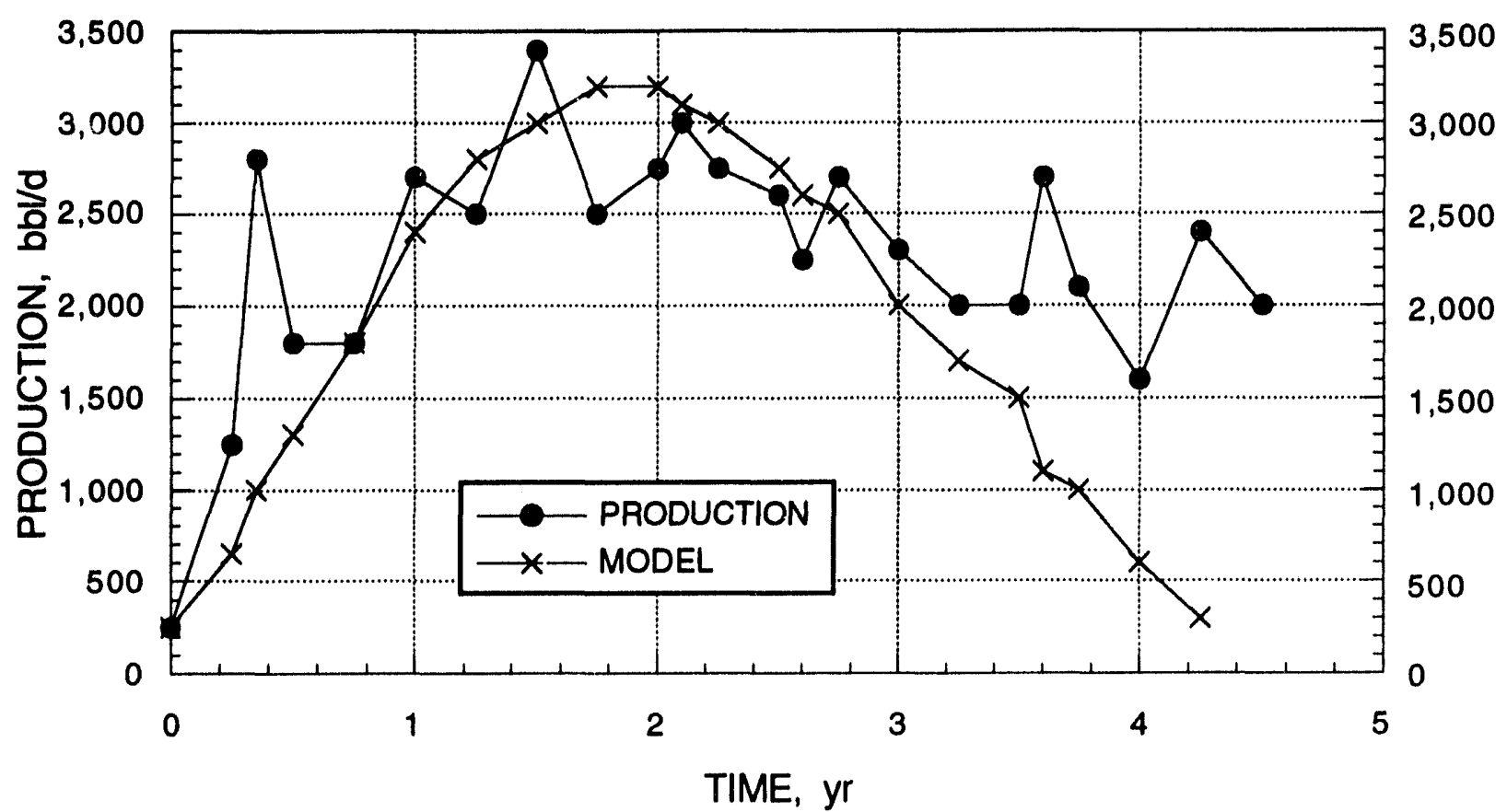

FIGURE 6.17 - Comparison of predicted and observed daily oil production rates-South Belridge Field, CA.

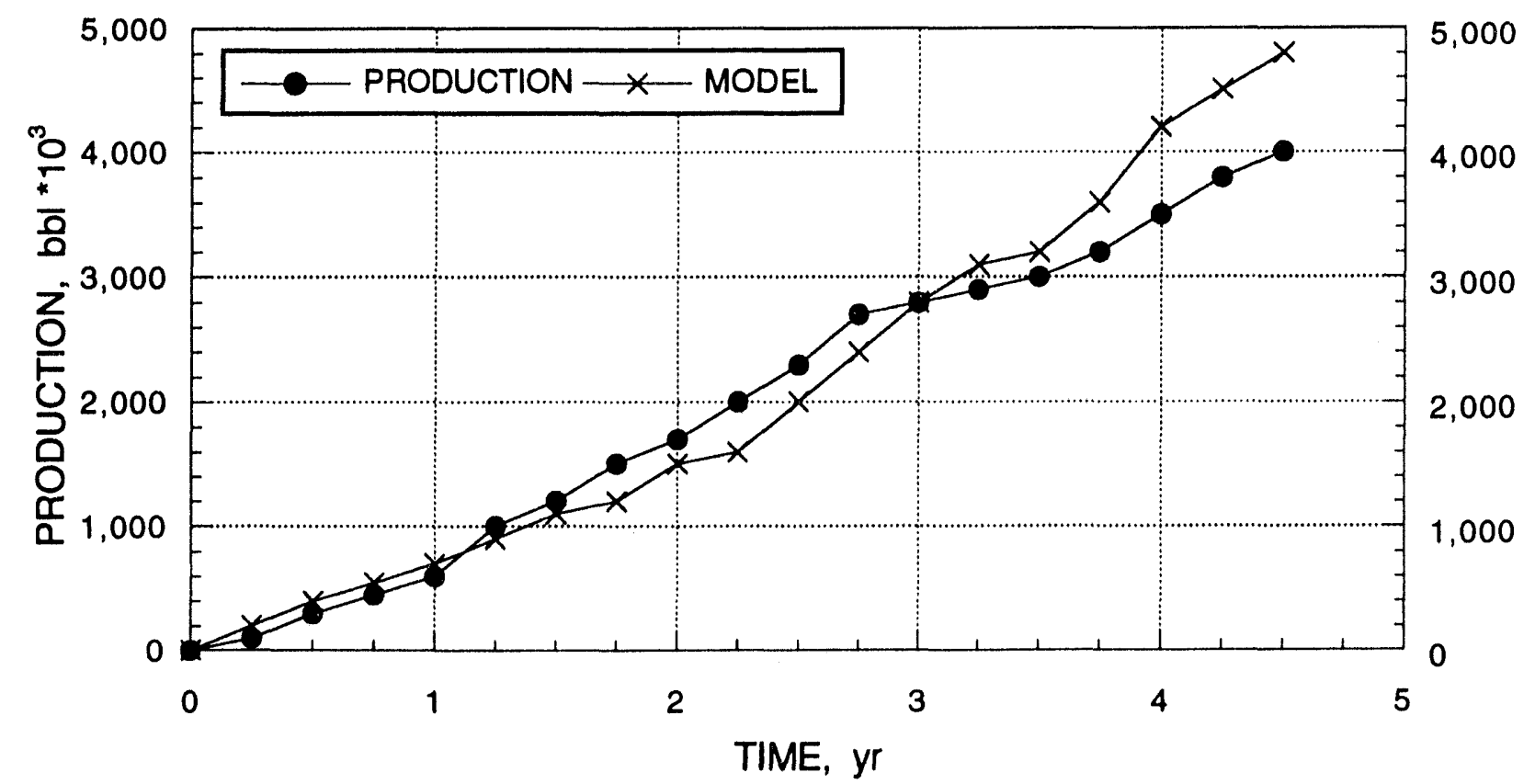

FIGURE 6.18 - Comparison of predicted and observed cumulative production-South Belridge Field, CA. 


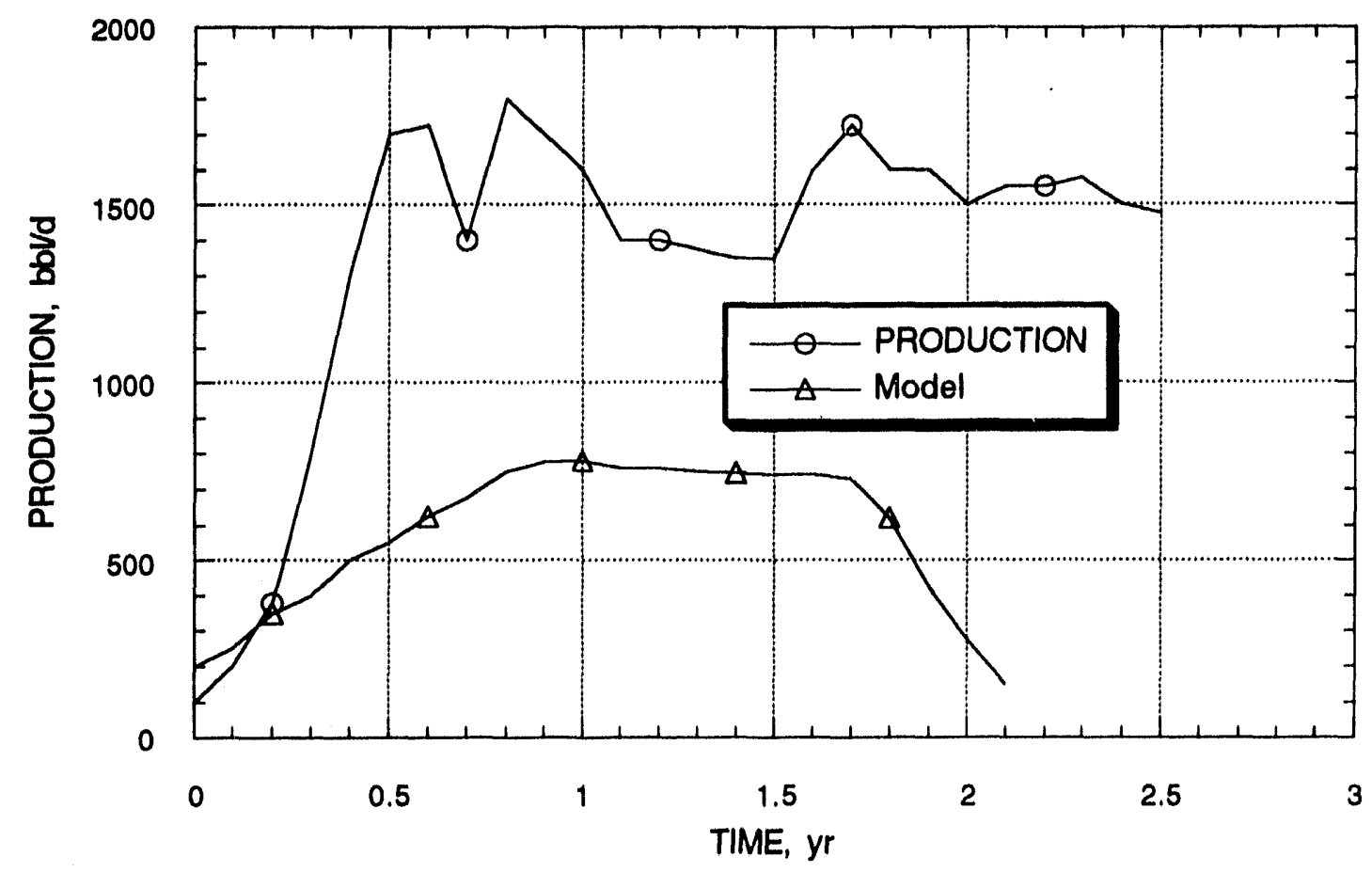

FIGURE 6.19 - Comparison of predicted and observed daily production rates-Slocum Field, TX.

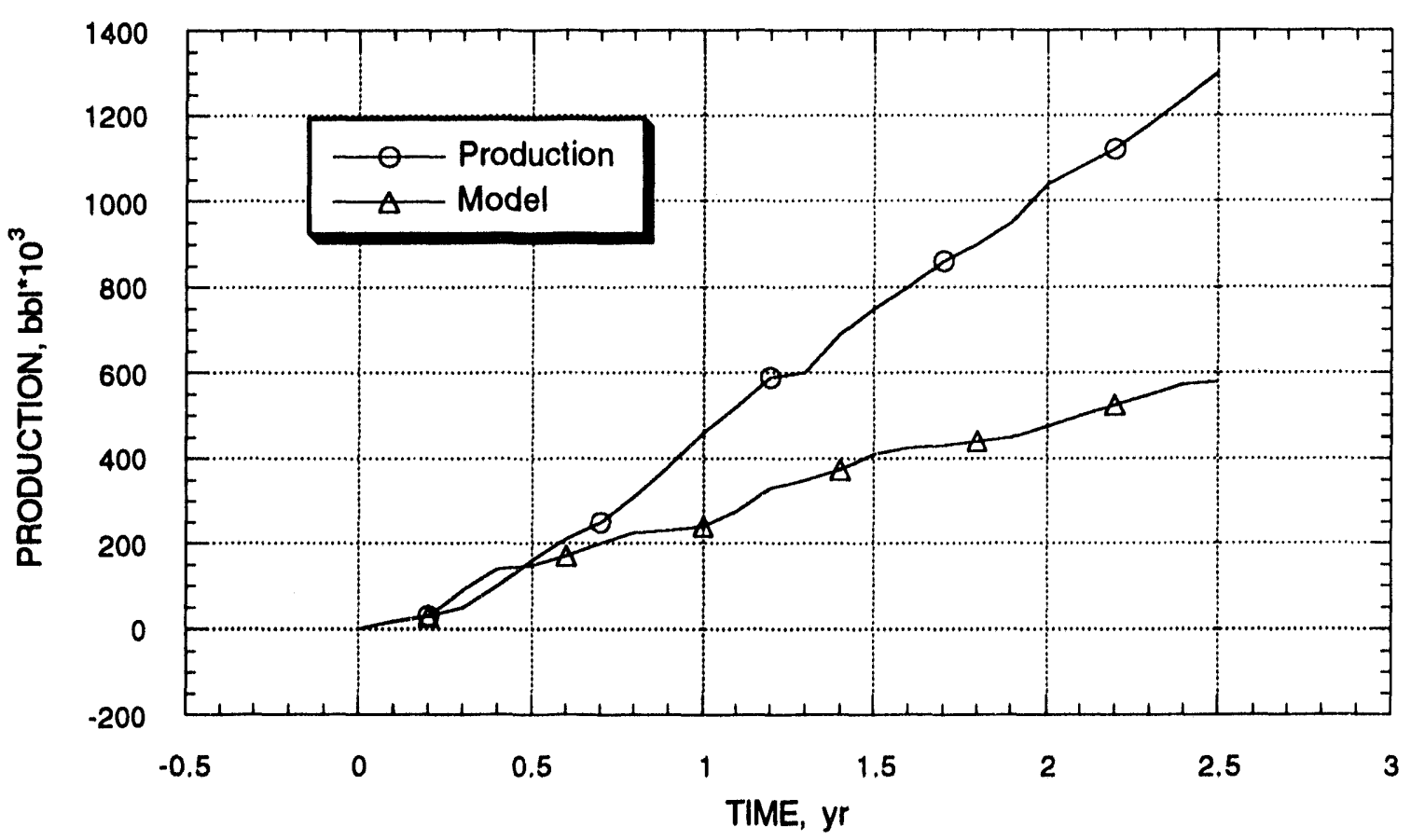

FIGURE 6.20 - Comparison of predicted and observed cumulative oil production-Slocum Field, TX. 


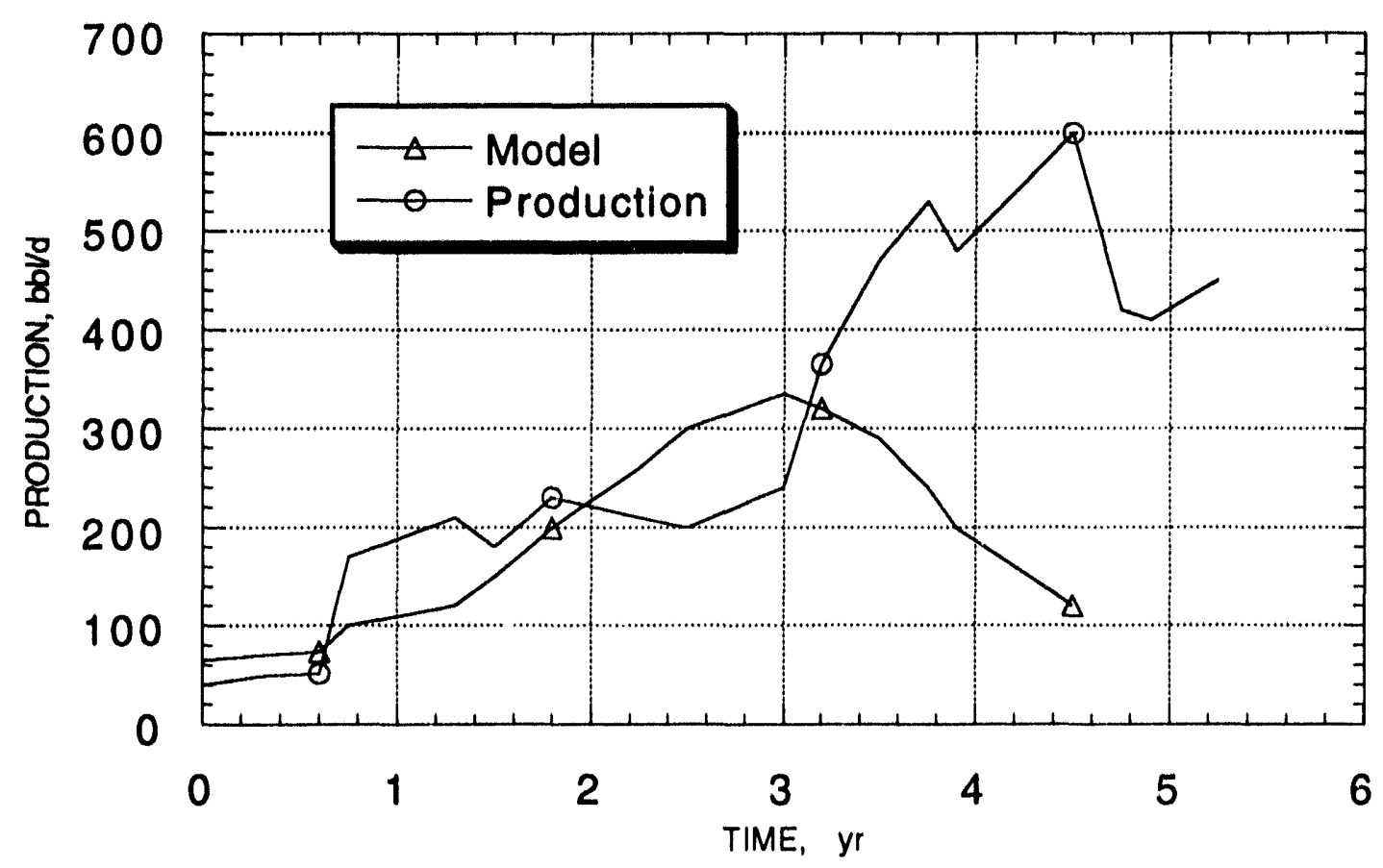

FIGURE 6.21 - Comparison of predicted and observed daily production ratesWinkleman Dome Field, WY.

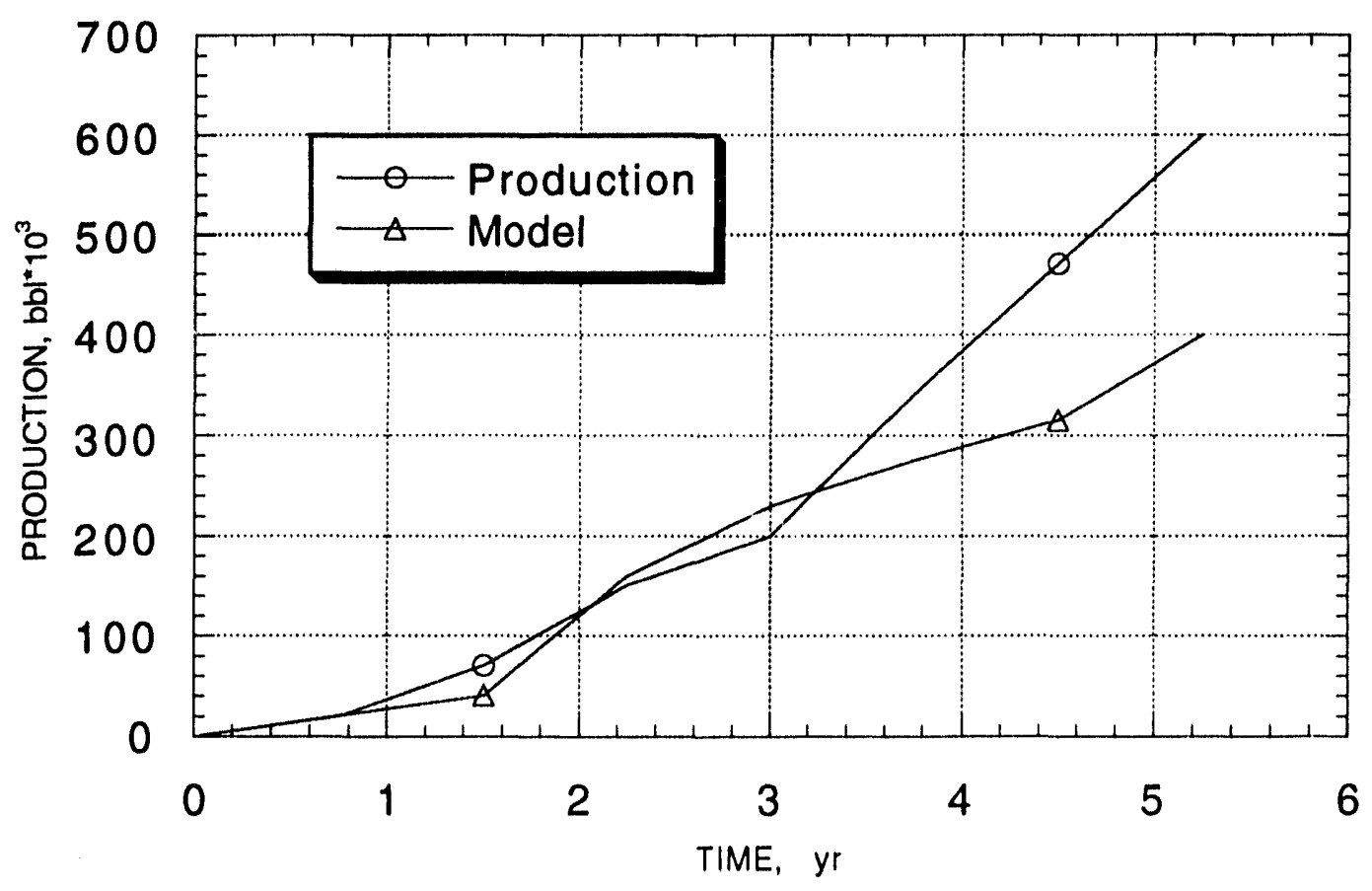

FIGURE 6.22 - Comparison of predicted and observed cumulative productionWinkleman Dome Field, WY. 

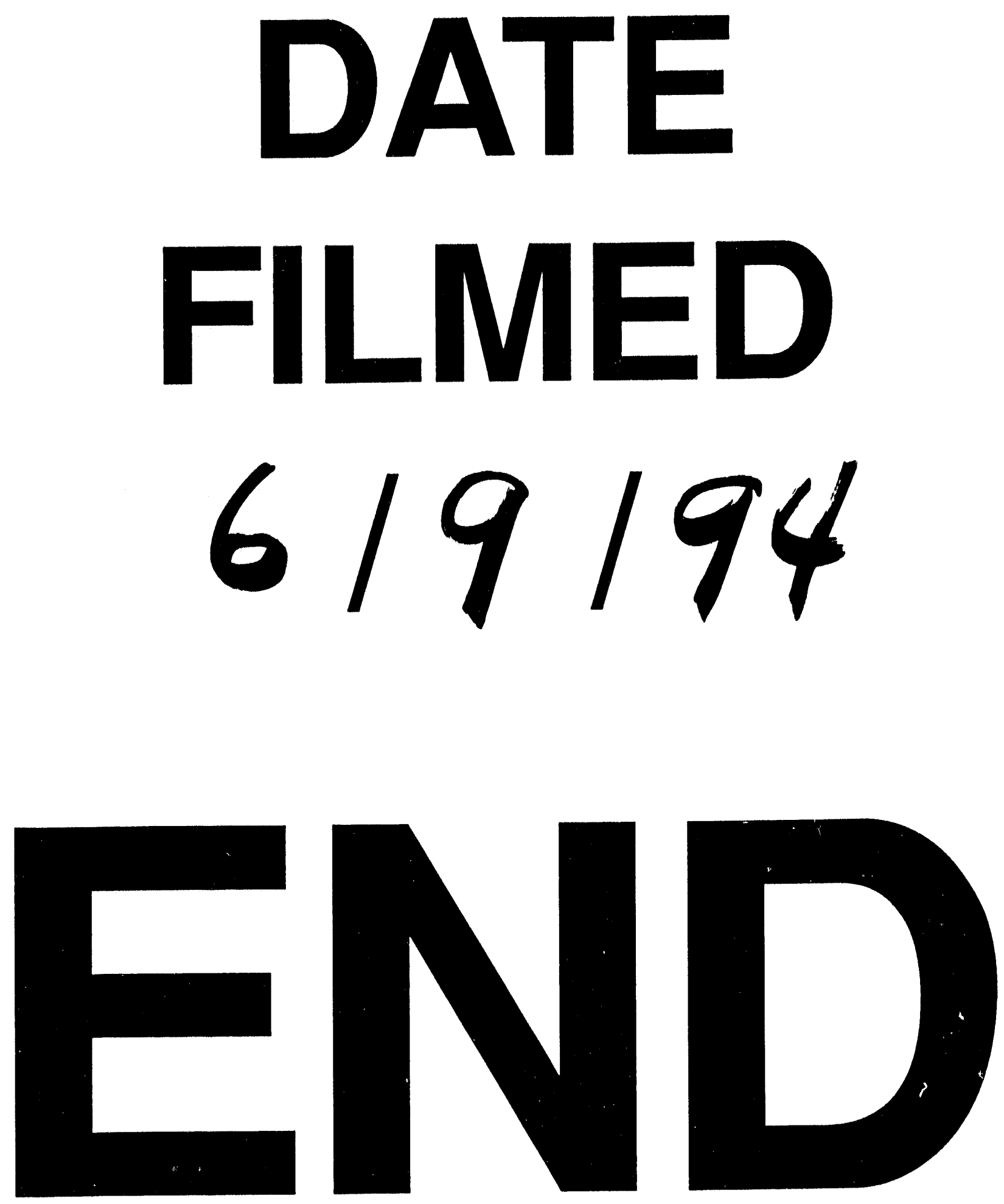


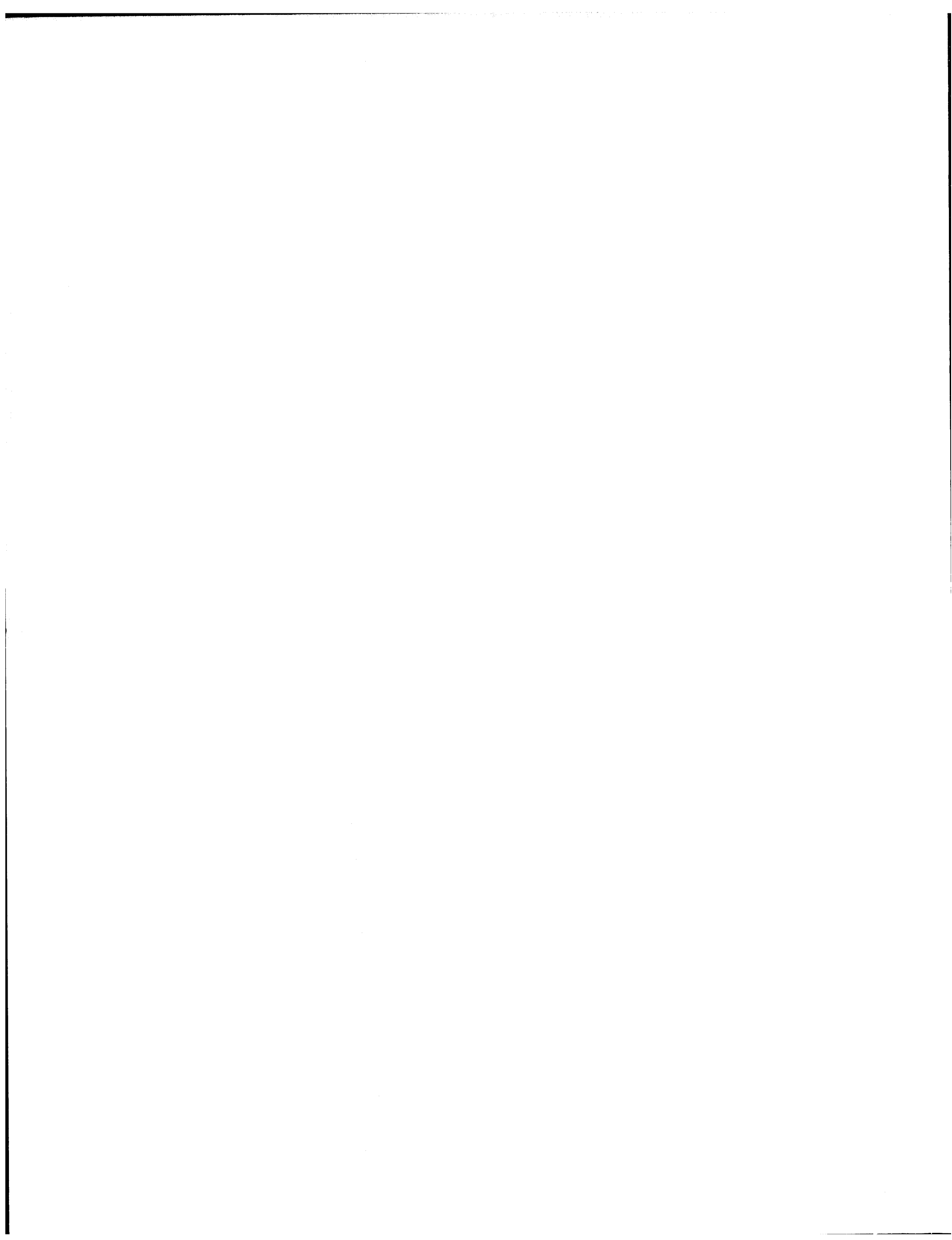

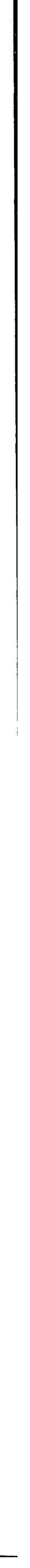

